Greenbelt Homes Pilot Program: Summary of Building Envelope Retrofits, Planned HVAC Equipment Upgrades, and Energy Savings

J. Wiehagen, M. Del Bianco, and D. Mallay Partnership for Home Innovation

May 2015 


\section{NOTICE}

This report was prepared as an account of work sponsored by an agency of the United States government. Neither the United States government nor any agency thereof, nor any of their employees, subcontractors, or affiliated partners makes any warranty, express or implied, or assumes any legal liability or responsibility for the accuracy, completeness, or usefulness of any information, apparatus, product, or process disclosed, or represents that its use would not infringe privately owned rights. Reference herein to any specific commercial product, process, or service by trade name, trademark, manufacturer, or otherwise does not necessarily constitute or imply its endorsement, recommendation, or favoring by the United States government or any agency thereof. The views and opinions of authors expressed herein do not necessarily state or reflect those of the United States government or any agency thereof.

Available electronically at http://www.osti.gov/bridge

Available for a processing fee to U.S. Department of Energy and its contractors, in paper, from:

U.S. Department of Energy

Office of Scientific and Technical Information

P.O. Box 62

Oak Ridge, TN 37831-0062

phone: 865.576 .8401

fax: 865.576 .5728

email: mailto:reports@adonis.osti.gov

Available for sale to the public, in paper, from:

U.S. Department of Commerce

National Technical Information Service

5285 Port Royal Road

Springfield, VA 22161

phone: 800.553 .6847

fax: 703.605.6900

email: orders@ntis.fedworld.gov

online ordering: http://www.ntis.gov/ordering.htm 


\title{
Greenbelt Homes Pilot Program: Summary of Building Envelope Retrofits, Planned HVAC Equipment Upgrades, and Energy Savings
}

\author{
Prepared for: \\ The National Renewable Energy Laboratory \\ On behalf of the U.S. Department of Energy's Building America Program \\ Office of Energy Efficiency and Renewable Energy \\ 15013 Denver West Parkway \\ Golden, CO 80401 \\ NREL Contract No. DE-AC36-08GO28308 \\ Prepared by: \\ Home Innovation Research Labs \\ Partnership for Home Innovation \\ 400 Prince George's Boulevard \\ Upper Marlboro, MD 20774 \\ NREL Technical Monitor: Stacey Rothgeb \\ Prepared under Subcontract No. KNDJ-0-40335-05
}

May 2015 
The work presented in this report does not represent performance of any product relative to regulated minimum efficiency requirements.

The laboratory and/or field sites used for this work are not certified rating test facilities. The conditions and methods under which products were characterized for this work differ from standard rating conditions, as described.

Because the methods and conditions differ, the reported results are not comparable to rated product performance and should only be used to estimate performance under the measured conditions. 


\section{Contents}

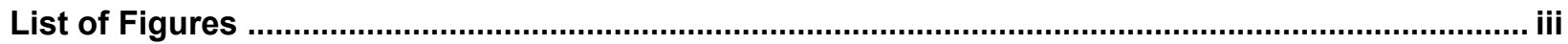

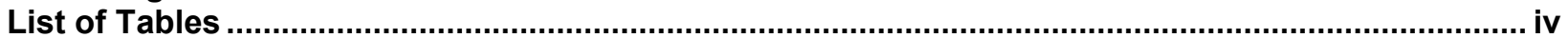

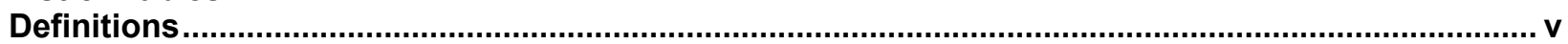

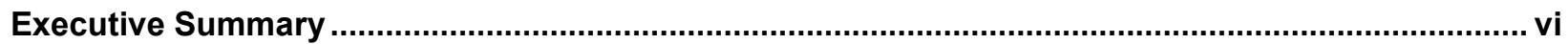

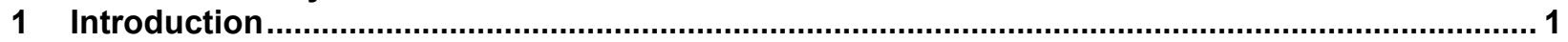

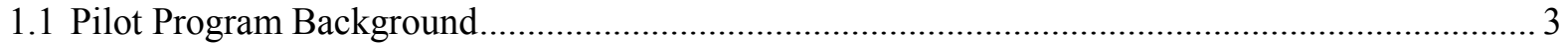

1.2 Phase 2 Pilot Program Building Envelope Upgrades................................................................... 4

2 Greenbelt Homes, Inc. Pilot Program Research Investigation .................................................... 7

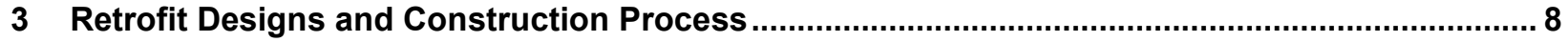

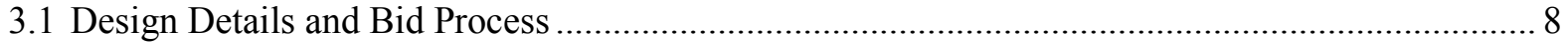

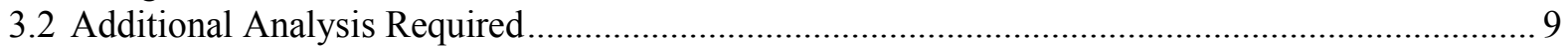

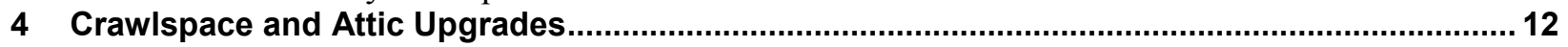

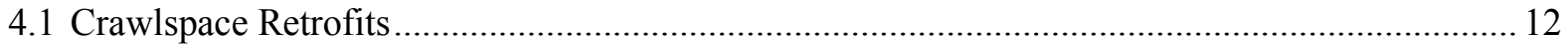

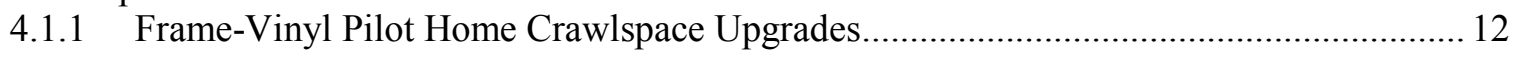

4.1.2 Block and Frame-Brick Crawlspace Upgrades ........................................................... 13

4.1.3 Frame-Brick and Frame-Vinyl Attic Upgrades ...................................................... 14

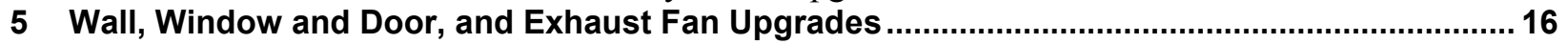

5.1 All Pilot Homes_-Window Replacement .......................................................................... 16

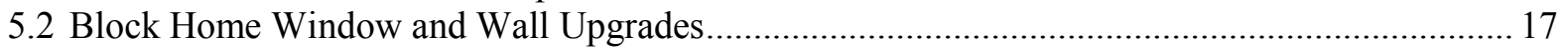

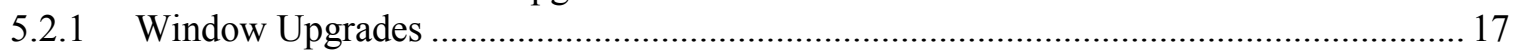

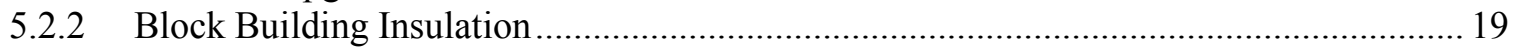

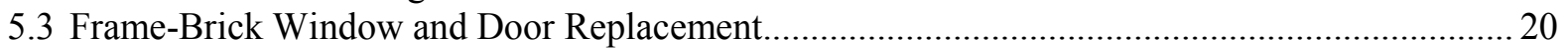

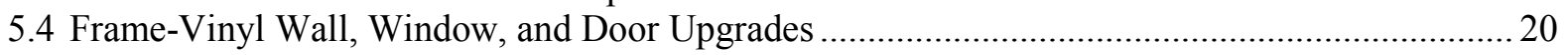

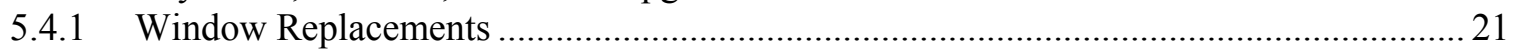

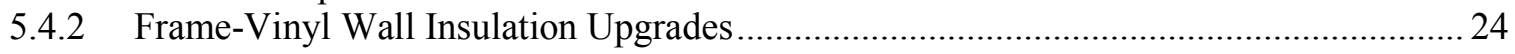

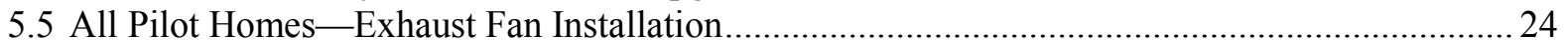

5.6 Energy Upgrade Feature and Monitoring Description............................................................... 26

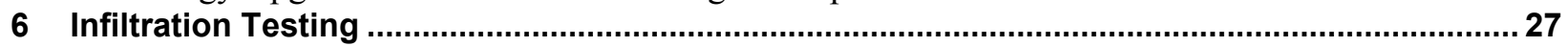

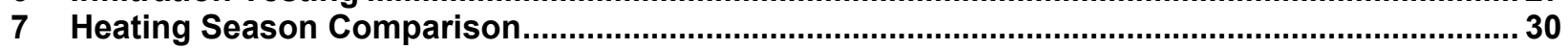

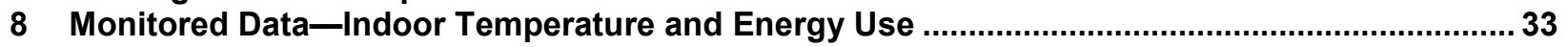

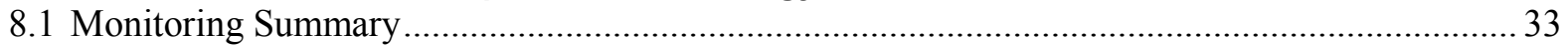

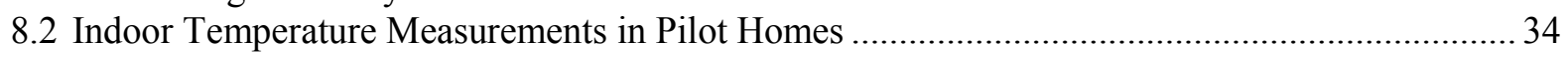

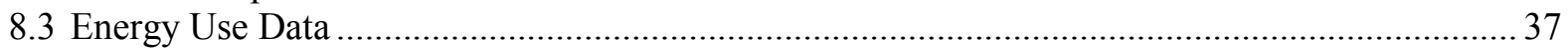

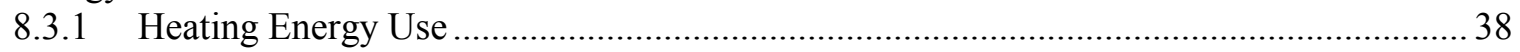

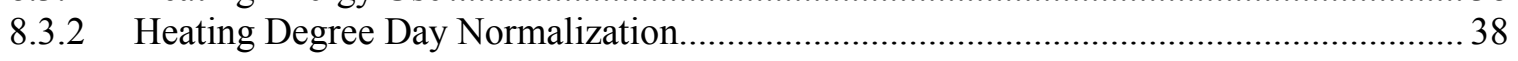

8.3.3 Temperature Difference Normalization and Take-Back Energy Use ............................. 40

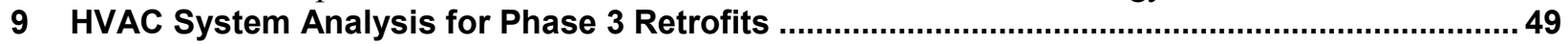

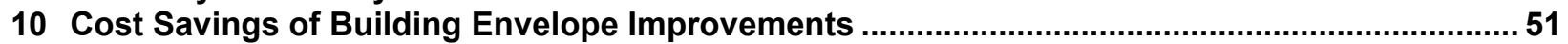

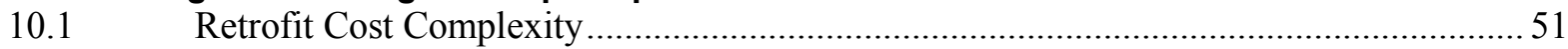

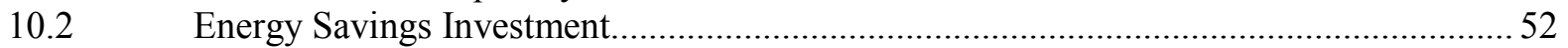

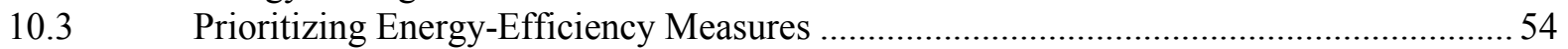

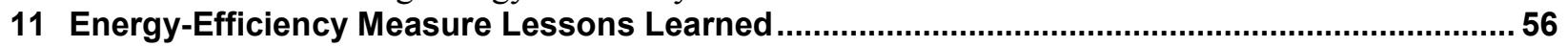

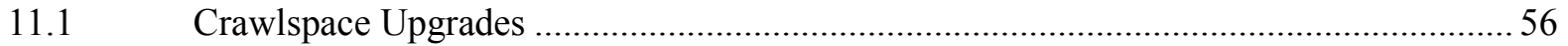

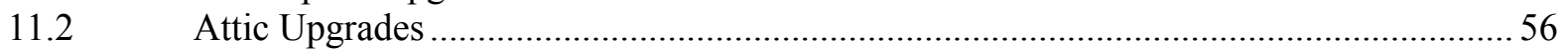

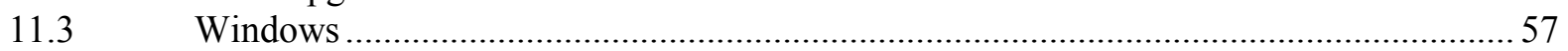

Exterior Insulation and Weather-Resistive Barriers ...................................................... 57

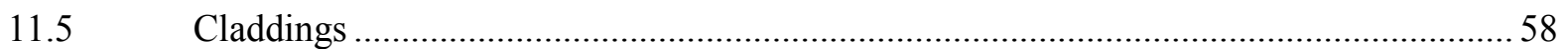

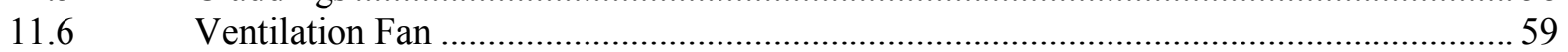

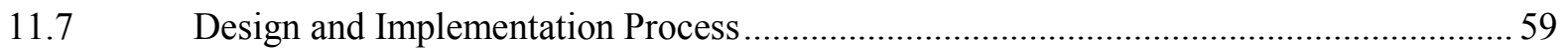




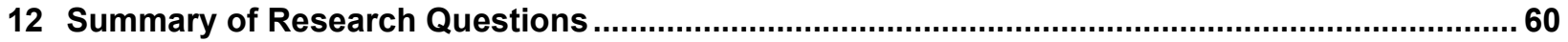

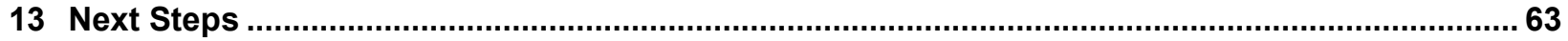

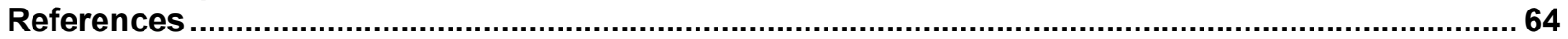

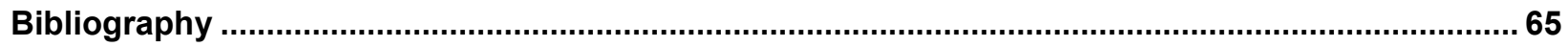

Appendix A: Pilot Program Retrofit Options, Estimated Costs, and Estimated Energy Savings .... 66

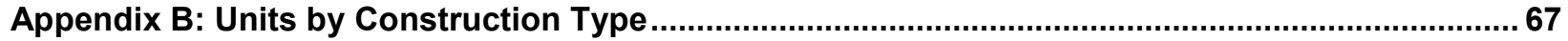

Appendix C: Total Energy Use and Heating Energy Use in Each Pilot Home .................................69

Appendix D: Greenbelt Homes, Inc. Pilot Program Phase 3: Heating Systems Overview ................ 74 


\section{List of Figures}

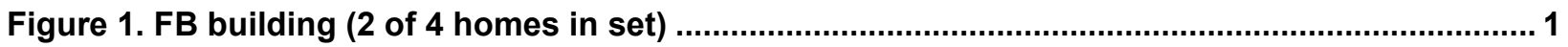

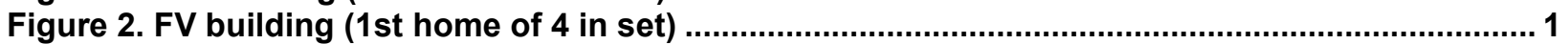

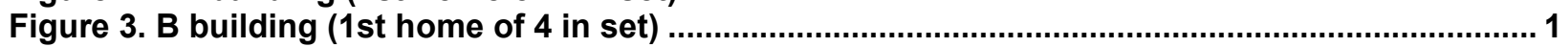

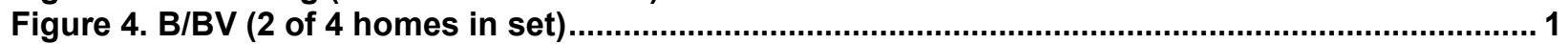

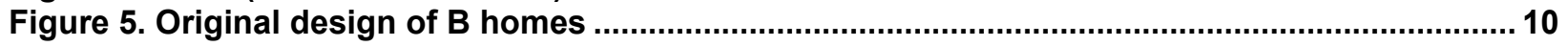

Figure 6. Painted $B$ home with circa 1980 window upgrades..................................................... 10

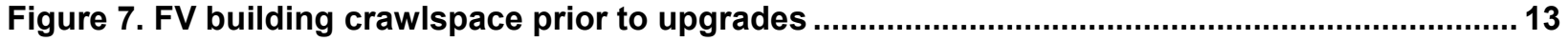

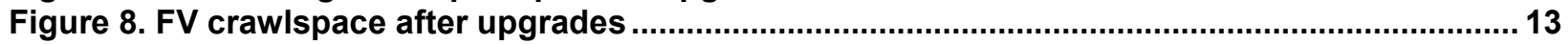

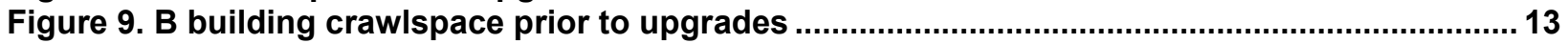

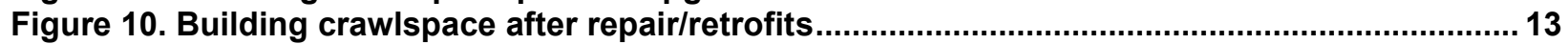

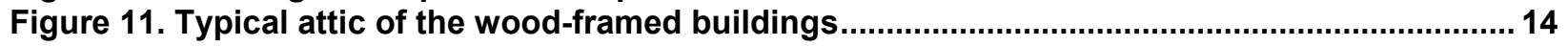

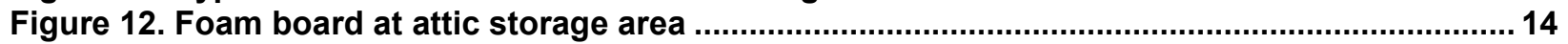

Figure 13. Wood sheathing installed over the foam board to maintain an attic storage area .......... 14

Figure 14. Insulation baffles at edge of new storage area ............................................................. 15

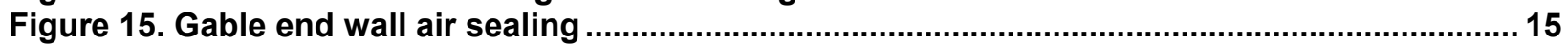

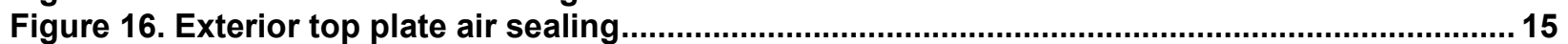

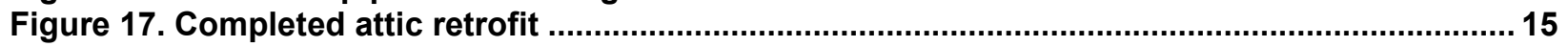

Figure 18. Window rough opening prior to window installation ............................................. 18

Figure 19. New replacement window installed over sill flashing and foamed.................................. 18

Figure 20. Window trim installed to the block rough opening and caulked ...................................... 18

Figure 21. Window flashing integrated with foam insulation ........................................................ 18

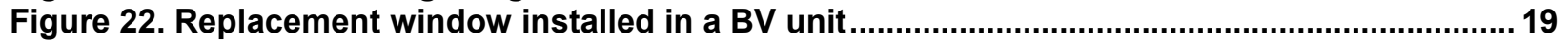

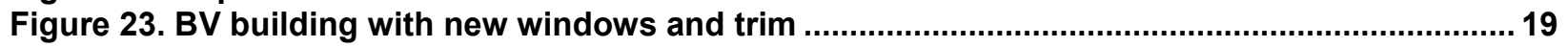

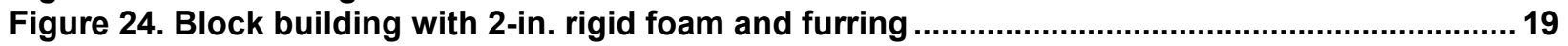

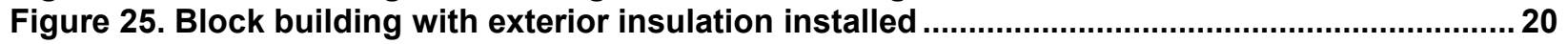

Figure 26. Completed block building with all energy upgrades installed.........................................20

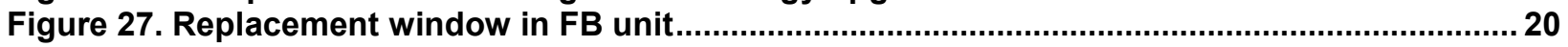

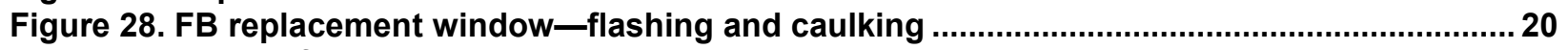

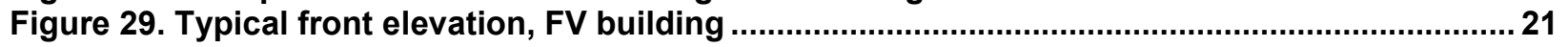

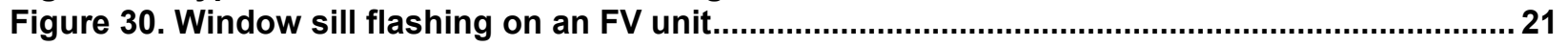

Figure 31. Foam board extends beyond original window trim .................................................... 21

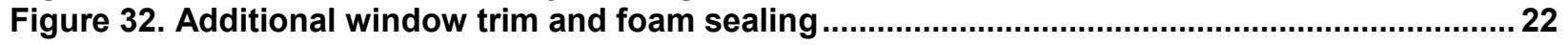

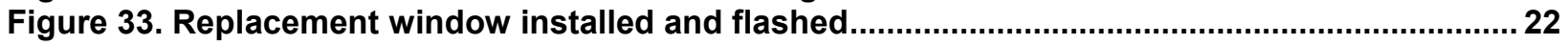

Figure 34. Additional window trim and foam sealing ................................................................... 22

Figure 35. Replacement window installed and flashed................................................................ 22

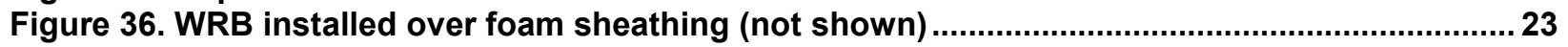

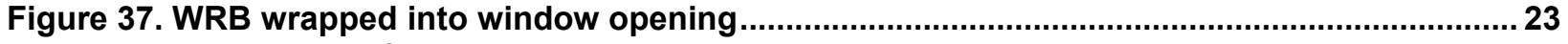

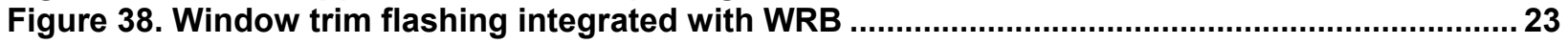

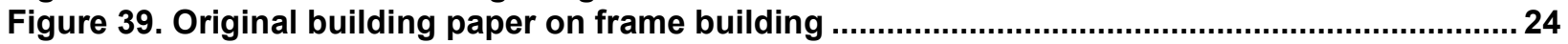

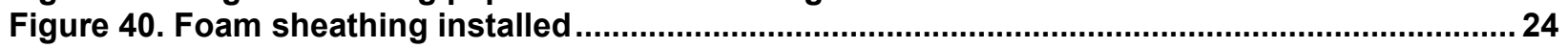

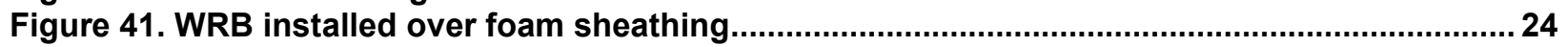

Figure 42. New siding installed following windows, doors, insulation, and WRB ........................... 24

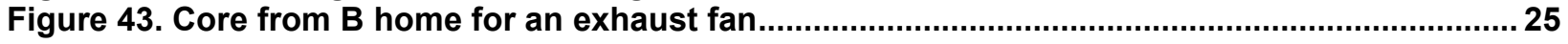

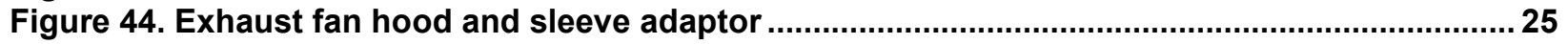

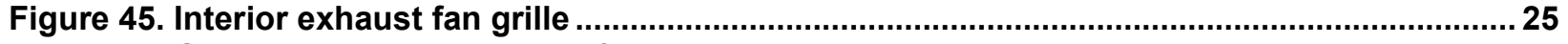

Figure 46. Graphical representation of air leakage in pilot homes............................................... 29

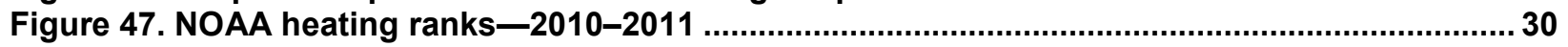

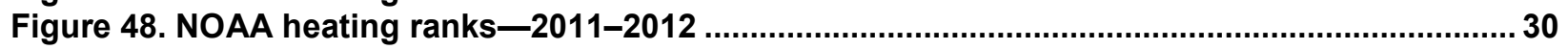

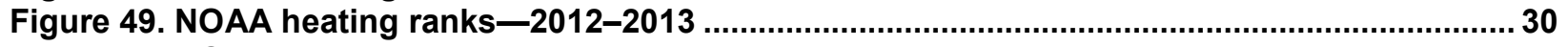

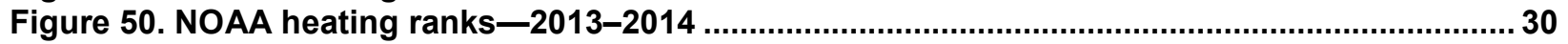

Figure 51. Graphical representation of ambient weather factors .............................................. 32

Figure 52. Average winter period temperature difference from base year ....................................... 48 


\section{List of Tables}

Table 1. Estimated Phase 2 Energy Cost Savings for Envelope Measures by Building Type........... 5

Table 2. Selected Envelope Upgrades by Building Type ............................................................... 6

Table 3. Simulated Energy Savings of Various Insulation Methods for B Units ..............................11

Table 4. Summary of Wall Insulation Upgrades for GHI Pilot Homes ............................................ 16

Table 5. Summary of Energy Features for Each Pilot Home ........................................................... 26

Table 6. Results of Guarded Blower Door Testing-Net Leakage to the Outside............................ 28

Table 7. Monthly Ambient Temperature for Four Heating Seasons................................................ 31

Table 8. Monthly HDDs for Four Heating Seasons ....................................................................... 31

Table 9. Average Seasonal Indoor Temperature and Relative Humidity for Pilot Homes ................. 35

Table 10. Heating Period Average Indoor Temperature and Relative Humidity by Building Type... 37

Table 11. Measured Energy Use in Pilot Homes Over Four Heating Seasons ................................... 37

Table 12. Estimated Heating Energy Use in Pilot Homes Over Four Heating Seasons..................... 38

Table 13. HDD Normalized Heating Energy .................................................................................... 39

Table 14. HDD Normalized Heating Energy Savings Over Base Year (\%) .......................................... 40

Table 15. HDD Normalized Heating Energy Savings Over Base Year (kWh) ..................................... 40

Table 16. TD Normalized Heating Energy .................................................................................. 41

Table 17. TD Normalized Heating Energy Savings Over Base Year (\%) ........................................... 42

Table 18. TD Normalized Heating Energy Savings From Base Year (kWh) .................................... 42

Table 19. Summary Heating Energy Use for Each Season, 23 of 28 Pilot Homes ............................43

Table 20. Summary of Energy Savings Building Type and Upgrade ............................................... 44

Table 21. Heating Energy Savings by Building Using Combined Measured Data ............................. 47

Table 22. Cost Estimates (Installed) for Heating Systems........................................................ 50

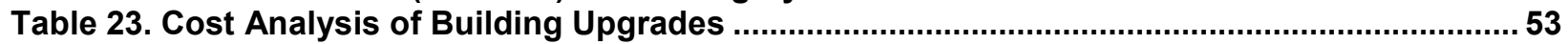

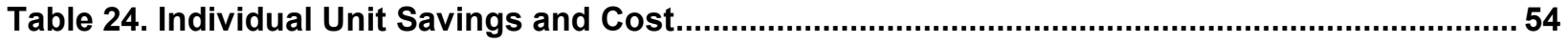

Table 25. Homeowner Reponses to Energy and Comfort Questionnaire ..........................................61

Table 26. Heating Season Total Energy Use in Each Pilot Home ....................................................... 70

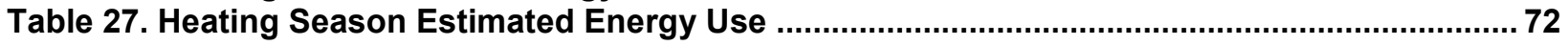

Unless otherwise noted, all figures and tables were created by Home Innovation Research Labs. 


\section{Definitions}

$\mathrm{A} \& \mathrm{E}$

B

BA

BV

CMU

EBB

EEM

EIFS

FB

FV

GHI

HDD

HVAC

$\mathrm{kWh}$

PHI

SPF

TD30

WRB
Architectural \& Engineering Firm

GHI Block buildings constructed of 8-in. CMU with exterior paint

Building America

GHI Block Buildings constructed of 8-in. CMU with exterior vinyl siding over furring strips and up to $3 / 4-$ in. foam board

Concrete Masonry Unit

Electric Baseboard

Energy-Efficiency Measure

Exterior Insulation and Finishing System

GHI Frame-Brick Veneered Buildings

GHI Frame-Vinyl Buildings

Greenbelt Homes, Inc. (A Nonprofit Housing Cooperative)

Heating Degree Day

Heating, Ventilating, and Air Conditioning

Kilowatt Hour (Measure of Electricity Usage)

Partnership for Home Innovation

Spray Polyurethane Foam

Temperature Difference Normalization to a $30^{\circ} \mathrm{f}$ average seasonal temperature difference based on actual measured temperature differences in a given heating period

Weather-Resistive Barrier 


\section{Executive Summary}

In fall 2010, Greenbelt Homes, Inc. (GHI) undertook a multiyear pilot energy-efficiency retrofit project - a 1,566-home cooperative of circa 1930 to 1940 homes in Greenbelt, Maryland. GHI established this pilot project to serve as a basis for decision making for the rollout of a decadelong community-wide upgrade program that will incorporate energy-efficiency improvements to the building envelope and equipment with the modernization of other systems such as plumbing, mechanical equipment, and cladding. The community upgrade was fully funded by the cooperative through its membership without outside subsidies; thus, this project presents a unique opportunity to evaluate and prioritize the wide range of benefits of high-performance retrofits based on the consumers' experience with — and acceptance of - the retrofit measures implemented during the pilot project. The authors address the complex interactions between benefits, tradeoffs, construction methods, project management implications, realistic upfront costs, financing, and other considerations. This approach serves as a case study for energy retrofit projects to include high-performance technologies based on the long-term value to the homeowners.

The three predominant wall construction methods for townhomes in the GHI community are materials common to the area and climate zone, including: (1) 8-in. concrete masonry unit block, (2) wood frame with brick veneer, and (3) wood frame with vinyl siding.

The pilot project has three phases focused on identifying the added costs and energy savings benefits of improvements planned for implementation during a planned community-wide retrofit program commencing in 2015. Phase 1 provided a baseline evaluation of the current operation, use, environmental conditions, and energy costs for a representative set of 28 townhomes sited in seven buildings. Phase 2 included the installation of the building envelope improvements identified in Phase 1, continued monitoring of the energy consumption for the heating season for comparative evaluation of the performance before and after the improvements, and energy simulations supporting recommendations for heating, ventilating, and air conditioning and water heating upgrades to be implemented in Phase 3.

The U.S. Department of Energy Building America team Partnership for Home Innovation wrote a report on Phase 1 of the project that summarized a condition assessment of the homes and evaluated retrofit options within the constraints of the cooperative provided by GHI. Phase 2 was completed following monitoring in the 2013-2014 winter season; the results are summarized in this report. Phase 3 upgrades of heating equipment will be implemented in time for the 2014-2015 heating season and are not part of this report.

This report:

- Summarizes the Phase 2 activities that include crawlspace, attic, and wall upgrades, testing, and an energy use summary.

- Includes an analysis (requested by GHI) of interior insulation options, which have been of interest to some GHI members seeking to maintain the exterior "block" profile of the original buildings. 
- Includes analyses of heating and cooling system options, community impacts, costs, and benefits.

After the Phase 2 crawlspace, attic, and wall upgrades were completed and the bath ventilation fans were installed, tests showed the frame-vinyl pilot homes had reduced air infiltration by an average of $36 \%\left(12-7.7 \mathrm{ACH}_{50}\right)$, the frame-brick pilot homes by an average of $10 \%(8.1-7.3$ $\left.\mathrm{ACH}_{50}\right)$, and the block homes by an average of 31\% (4.9-3.4 $\left.\mathrm{ACH}_{50}\right)$.

Following is a list of GHI building types and corresponding pilot home upgrades with resultant reductions in energy use as measured in the tests.

- GHI uninsulated block buildings that had only crawlspace and window/door upgrades. This yielded a 10\% heating energy reduction, primarily from the window/door upgrades and reduced infiltration.

- One uninsulated block unit, which included a new ductless heat pump with the upgrade package. This achieved a $43 \%$ heating energy reduction. This savings was attributed primarily to the operation of the ductless heat pump rather than the baseboard resistance heaters, and secondarily to the envelope improvements.

- GHI block homes with vinyl siding and $1 / 2$-in. exterior insulation board between the furring. The homes had only crawlspace/basement and window/door upgrades. These yielded a $29 \%$ heating energy reduction that was attributed primarily to the window upgrades and reduced infiltration.

- GHI block homes (both end units), which originally had vinyl siding and $1 / 2$-in. exterior insulation board between furring. The homes had crawlspace and window/door upgrades and all existing siding and insulation removed and upgraded with $2-1 / 2-$ in. exterior rigid insulation. New siding was also installed. These measures achieved a $46 \%$ heating energy reduction that was attributed primarily to the wall insulation, window upgrades, and reduced infiltration.

- GHI block home (one interior unit), uninsulated, which had crawlspace and window/door upgrades and $2-1 / 2-i n$. rigid insulation added to the exterior and new siding installed. These yielded a $61 \%$ heating energy reduction that was attributed primarily to the wall insulation, window upgrades, and reduced infiltration.

- GHI frame-brick (end units in two buildings) that had crawlspace, attic, and window/door upgrades. These improvements achieved a 34\% heating energy reduction that was attributed to attic insulation, and window upgrades, and reduced infiltration.

- GHI frame-brick (interior units in two buildings) that had crawlspace, attic, and window/door upgrades. These improvements yielded a $40 \%$ heating energy reduction that was attributed to attic insulation, window upgrades, and reduced infiltration.

- GHI frame-vinyl (end units in two buildings) that had crawlspace floor insulation and air sealing, attic, window/door, and 1-in. exterior insulating sheathing upgrades. This achieved a $42 \%$ heating energy reduction that was attributed to attic and wall insulation, window upgrades, and reduced infiltration. 
- GHI frame-vinyl (interior units in two buildings) that had crawlspace floor insulation and air sealing, attic, window/door, and 1-in. exterior insulating sheathing upgrades. These improvements yielded a $46 \%$ heating energy reduction that was attributed to attic and wall insulation, window upgrades, and reduced infiltration.

When looking at the overall cost of the upgrades implemented during the pilot program and evaluating these costs solely on the basis of energy savings, the simple paybacks are long - 2970 years. However, with the costs of the upgrades, including new crawlspace vapor barriers, windows, and siding (which are replaced on a regular schedule and financed separately), the payback periods are reduced by 11-34 years. Based on the type of upgrades - and given the more than 30-year periods between major improvements - payback periods of 30 years or longer are acceptable.

The analysis of the measured data also highlights the complexity of comparative evaluation of the energy use (energy savings) before and after the home retrofits, especially because the occupants' preferences for thermostat setting levels changed after the retrofit. The high energy costs prior to the retrofit may have led to lower thermostat settings during the winter in an effort to conserve energy; however, envelope improvements helped lower heating energy consumption, which led to a higher thermostat setting for improved comfort. This was the case in most of the GHI pilot homes. During the latest winter season after the upgrades, the highest average indoor temperatures were recorded even though the average outdoor temperature was lower than in any of the previous three monitored winter periods. 


\section{Introduction}

A multiyear energy-efficiency retrofit pilot project has been undertaken by Greenbelt Homes, Inc. (GHI), a 1,600-unit housing cooperative of circa 1930 to 1940 homes located in Greenbelt, Maryland. The three dominant materials of construction of the approximately $800-$ to $1,200-\mathrm{ft}^{2}$ townhome units in the community are:

- Frame $(2 \times 4)$ with brick veneer (frame-brick or FB, Figure 1)

- Frame $(2 \times 4)$ with vinyl siding (frame-vinyl or FV, Figure 2)

- Eight-inch concrete masonry unit block; painted (block or B, Figure 3) or clad with vinyl siding (block-vinyl or BV, Figure 4).

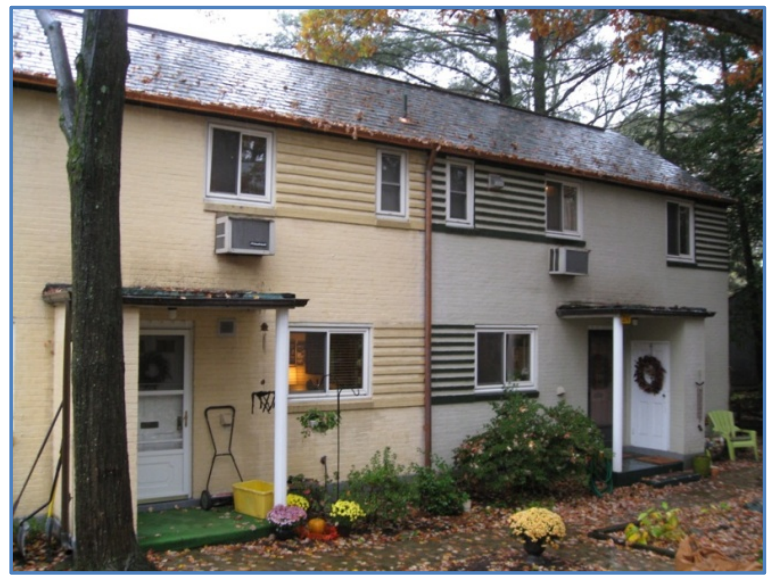

Figure 1. FB building (2 of 4 homes in set)

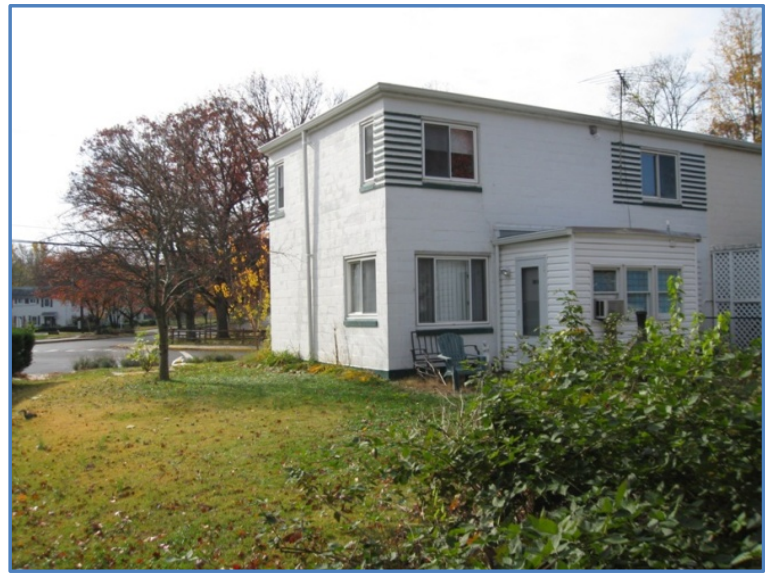

Figure 3. B building (1st home of 4 in set)

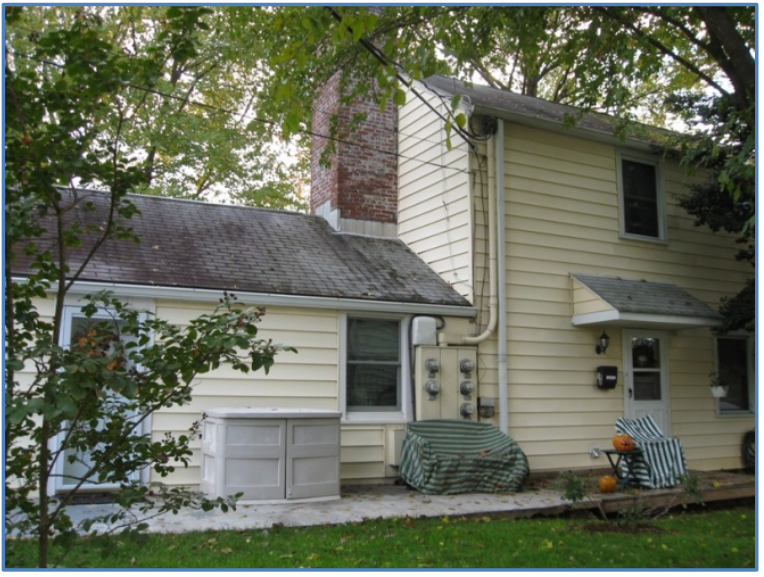

Figure 2. FV building (1st home of 4 in set)

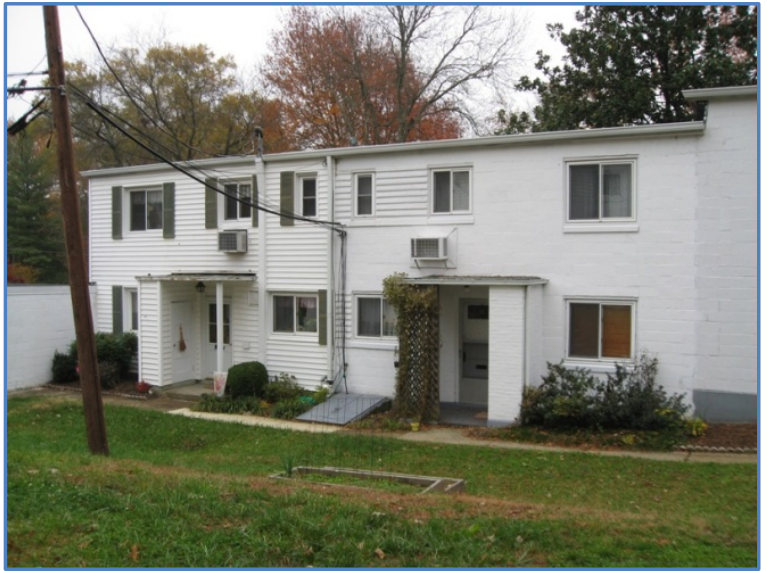

Figure 4. B/BV (2 of 4 homes in set) 
A detailed summary of the community and of the pilot homes is provided in an initial baseline performance report (Wiehagen et al. 2013). The GHI pilot project was envisioned with three phases focused on identifying the added costs and energy savings benefits of energy-efficient features for a set of representative pilot homes. Based on the outcome of the pilot project, select energy-efficiency upgrades are to be installed in all units outside of the pilot program during a planned community-wide replacement program commencing in 2015. Phase 1 of the pilot project consisted of a baseline evaluation of the current operation, use, environmental conditions, and energy costs for a representative set of 28 townhomes (units) sited in seven buildings: six block units (designated B1 through B6), six block-vinyl units (BV1 through BV6), eight frame-vinyl units (FV1 through FV8), and eight frame-brick units (FB1 through FB8). Phase 2 consisted of installing the building envelope improvements identified in Phase 1, continuing to monitor the energy consumption for the heating season both before and after installation, and performing energy simulations supporting recommendations for heating, ventilating, and air conditioning (HVAC) and water heating upgrades to be implemented in Phase 3. Monitoring will continue through the 2014-2015 heating season.

The U.S. Department of Energy's Building America (BA) team Partnership for Home Innovation (PHI) wrote a report on Phase 1 that summarized a condition assessment of the homes and evaluated retrofit options for the homes within the constraints of the cooperative provided by GHI (Wiehagen et al. 2013). Retrofit options, estimated costs, and estimated energy savings for the pilot homes are summarized in Appendix A.

With the support of National Renewable Energy Laboratory staff, the homes were monitored for energy use and indoor temperature and humidity. The recorded data from the energy meters and utility meter readings and the monitored energy usage were compared with the computer simulation. The results showed that the predictive capability of the software was within $11 \%$ of actual for the subject set of buildings after three outliers were removed (Wiehagen et al. 2013).

Phase 1 of the GHI pilot program efforts conducted during 2010-2011 included a field assessment (which included existing conditions), energy simulations of select options for projected savings, building envelope energy improvements, cost estimates, recommendations for upgrades, installation and maintenance of monitoring equipment, and maintenance of the data produced. Results were published in a report to the GHI community (NAHBRC 2011).

Phase 2 consisted of installing the building envelope improvements identified in Phase 1 and was implemented over 3 years. Crawlspace improvements were completed in 2011; attic improvements were completed in 2012; and wall, window, door, and exhaust fan upgrades were completed in 2013. Energy consumption and indoor temperature and humidity were monitored throughout the staged envelope upgrades. Bath exhaust fans with timed controls were added to the work in Phase 2 to provide some mechanical air exchange and to vent the largest source of moisture in the homes. An analysis of heating and cooling system upgrades, including simulation results and example system installation, was completed in 2013 in preparation for system installation and testing in 2014. One aspect of the Phase 2 effort was to evaluate different types of heating - and in some cases cooling - equipment for estimated savings and costs. 
The phases were organized in this sequence to encompass a systems approach to building retrofit that evaluated the benefits of envelope improvements independently of any equipment improvements. The goal of the GHI buildings committee was to identify envelope improvements that would reduce energy consumption, provide a higher level of comfort to members, and demonstrate actual costs and payback periods. Based on this investigation, GHI members would have much better information to guide their decisions about the large investment necessary for a community-wide upgrade.

GHI has created a reserve fund that is used for replacing the windows, doors, siding, and roofs at obsolescence. However, the reserve funds were not intended to cover energy upgrades such as air sealing, insulation, or HVAC improvements other than replacing the electric baseboard (EBB) heaters as required. This combination of the reserve funds and the opportunity for long-term investment in energy upgrades is the primary impetus for the pilot project. The energy-efficiency improvements that were not budgeted in reserve funds yielded energy savings that will be analyzed; this analysis will provide the estimate of the costs and payback periods for the members to make reasonable and informed decisions.

\subsection{Pilot Program Background}

GHI is a nonprofit entity that was organized to purchase or otherwise acquire, operate, and manage housing projects in Greenbelt in the interest of and for the housing of its members (GHI 2012). A nine-member board of directors hears the five standing committees, makes decisions for the corporation, and hires the general manager. The board of directors and management recognized the impending need to replace numerous components nearing the end of their useful lives. In the interest of good governance, the directors and managers polled the community members for their input on features that they would like to see incorporated into the scheduled renovations. Increased comfort and decreased energy costs achieved with limited lifestyle disruption were the overwhelming responses from members who voted to support the pilot program - a 28-unit demonstration project of energy-efficient features that could be incorporated with the façade and systems updates planned for 2015-2025.

The GHI pilot program was established in 2010 to form the basis for decision making for the rollout of a 10-year community upgrade program incorporating energy-efficient buildings and equipment with the modernization of other systems and building components such as plumbing pipes, windows, and siding replacement. The goals for such capital improvements are to:

- Improve member comfort and "livability."

- Emphasize the use of sustainable, environmentally friendly energy sources, technologies, and products where economically feasible.

- Reduce overall life cycle costs, including preventive and corrective maintenance, for heating, cooling, and domestic hot water systems.

- Minimize disruption to households as improvements are being made.

- Implement the program while maintaining the unique and historic character of the GHI homes. 
The pilot program was developed by the buildings committee to have three phases focused on identifying the added costs and benefits of energy-efficient features that would be installed during the planned replacement timetable commencing in 2015.

Because building envelope energy retrofits necessarily include some surface finish tasks after the insulation and air sealing are installed, it is prudent to schedule these tasks with other retrofit work, such as siding replacement or interior gut/rehab. Thus, the cost of the energy-efficient component can be separated from the cost of the façade upgrade, which was going to be undertaken regardless.

\subsection{Phase 2 Pilot Program Building Envelope Upgrades}

Improvement to the walls' thermal resistance from the exterior was identified as a primary pathway to long-term energy efficiency and member comfort. The FV units are constructed of $2 \times 4$ walls with R-13 wall cavity insulation, horizontal board sheathing, tar paper, and vinyl siding. The FB units are constructed of $2 \times 4$ walls with R-13 wall cavity insulation, horizontal board sheathing, tar paper, a capillary break/drainage cavity, and brick veneer. The block units (B) are constructed of 8-in. concrete masonry units (CMUs) that have been painted or vinyl-sided (BV). Some B units have interior furring, air space, and foil backed plaster board beneath a plaster finished wall. Others have no insulation with plaster directly applied to the masonry. The pre-retrofit summary of energy features, most of which were installed during the 1980s upgrades following the oil crisis, is included in Appendix B.

In keeping with the owners' desire to minimize lifestyle interruption and maximize benefits from scheduled façade replacement work, externally

Q2. Why did we need a pilot program? Couldn't we get reliable information from prior industry studies and from modeling?

A2. To decide whether we want to make specific improvements to the energy efficiency and comfort of our units, we need to know what the actual costs and energy savings are for alternative improvements used in our particular types of homes. The pilot program is providing us with: (a) reliable cost and benefit information on the energy used in the pilot homes; (b) actual installation costs and energy saving data; and (c) life cycle costs and payback periods. In addition, it is revealing challenges for installing and maintaining new, alternative energy-efficiency improvements to our homes; helping us learn about logistics of such improvements (such as how to handle storage in attics during and after attic insulation is installed); and teaching us how to minimize disruption and inconvenience to members during construction.

Response of the Buildings Committee to FAQ by the GHI membership. applied insulation measures were explored. Computer-generated Building Energy Optimization software v1.2 (NREL 2015) simulations were used to identify the energy-efficiency measures (EEMs) that would provide the optimal benefits at the least cost. Simulated building savings indicated that these homes could benefit from energy cost savings ranging from $9 \%$ to $28 \%$ - depending on building construction typewith the implementation of Phase 2 upgrades only (see Table 1). These initial estimates were evaluated to provide the largest energy savings with the lowest investment cost before the heating (and cooling) systems were analyzed. The cost analysis contains the residential electricity cost scheduled by PEPCO, the owner of the local transmission service, at an average cost per kilowatt-hour of $\$ 0.15$ (Pepco). Because the homes are all electric, the energy conversions to source energy reflect similar savings percentages. 
Table 1. Estimated Phase 2 Energy Cost Savings for Envelope Measures by Building Type

\begin{tabular}{c|c|c|c}
\hline \multirow{2}{*}{ Building Type } & $\begin{array}{c}\text { Block } \\
\text { 8-in. CMU (B) }\end{array}$ & FB & FV \\
\cline { 2 - 4 } & \multicolumn{2}{|c|}{ Per Building Average Estimates (4 units) } \\
\hline $\begin{array}{c}\text { Pre-Retrofit Use, Whole House } \\
\text { (4 homes in building) }\end{array}$ & $\$ 9,734$ & $\$ 7,508$ & $\$ 7,730$ \\
\hline $\begin{array}{c}\text { Post-Retrofit Savings, Whole House } \\
\text { (4 homes in building) Envelope Only } \\
\text { Average Savings, Whole House } \\
\text { (4 homes in building) }\end{array}$ & $\$ 2,680$ & $\$ 702$ & $\$ 1,331$ \\
\hline
\end{tabular}

Appendix A contains the cost and feature matrix that was developed for the GHI building committee's consideration in providing pilot study recommendations to the membership. EEMs presented for consideration included overall foundation/floor insulation values between R-5 (B, $\mathrm{BV}$, and $\mathrm{FB}$, foundation walls) and R-19 (FV, floors); wall insulation values of R-13 to R-18; and an attic insulation value of R-38 (FB and FV). The flat concrete roofs of the $\mathrm{B}$ and $\mathrm{BV}$ units were updated between 1996 and 2004 with R-26 rigid insulation and ethylene propylene diene methylene membranes. Improved crawlspace ground vapor barriers and mechanical ventilation via timed bath fan exhaust were included with the Phase 2 upgrades to maintain or improve indoor air quality after the retrofit.

Overall, the goal of the U.S. Department of Energy's BA program is to "reduce [existing] home energy use by 30\%-50\% compared to the pre-retrofit energy use" and "develop market-ready energy solutions that improve efficiency of new and existing homes in each U.S. climate zone, while increasing comfort, safety, and durability (DOE undated)." The GHI pilot program facilitates the integration of specific data on the energy reduction, cost, and constructability of the installed envelope energy retrofit measures. These data will inform the GHI board of directors and members about solutions that serve the needs and budgets of the community members. Further savings attributed to any heating (or cooling) system upgrades will be evaluated following Phase 3 of the pilot program.

A summary list of the upgrades that were suggested and approved by GHI for implementation in the pilot program is contained in Table 2. The pilot program consists of seven four-unit buildings - one B painted, two buildings with mixed units of B painted and BV, two FV, and two FB buildings. Selected energy-efficiency upgrades by building type are noted in Table 2. In addition, siding, windows, and doors were scheduled for replacement with the launch of the community-wide upgrade.

Because unanticipated complications arose during the bidding process, the crawlspace improvements were implemented in fall 2011, the attic improvements in fall 2012, and the wall upgrades (except for the EIFS, which has not been implemented) in fall 2013. 
Table 2. Selected Envelope Upgrades by Building Type

\begin{tabular}{|c|c|c|c|}
\hline & B or BV Buildings & FB Buildings & FV Buildings \\
\hline \multirow[t]{2}{*}{ Crawlspace $^{\mathrm{a}}$} & $\begin{array}{l}\text { Repair side wall and slab } \\
\text { ceiling rigid insulation }\end{array}$ & $\begin{array}{l}\text { Repair side wall and } \\
\text { slab ceiling rigid } \\
\text { insulation }\end{array}$ & $\begin{array}{l}\text { Remove } \mathrm{FG}^{\mathrm{b}} \text { batts and } \\
\text { install R-19 SPF }\end{array}$ \\
\hline & Repair and seal GVB ${ }^{\mathrm{d}}$ & Repair and seal GVB & $\begin{array}{l}\text { Re-grade and repair } \\
\text { and seal GVB }\end{array}$ \\
\hline \multirow[t]{4}{*}{ Attic } & $\mathrm{n} / \mathrm{a}$ & $\begin{array}{l}\text { Install 2-in. } \\
\text { XPS } / \text { oriented strand } \\
\text { board for storage }\end{array}$ & $\begin{array}{l}\text { Install 2-in. } \\
\text { XPS/oriented strand } \\
\text { board for storage }\end{array}$ \\
\hline & & $\begin{array}{l}\text { Air-seal exterior wall } \\
\text { top plates }\end{array}$ & $\begin{array}{l}\text { Air-seal exterior wall } \\
\text { top plates }\end{array}$ \\
\hline & & $\begin{array}{l}\text { Install an additional } \\
\text { 8- to12-in. (R-38) blown } \\
\text { cellulose around storage } \\
\text { area }\end{array}$ & $\begin{array}{c}\text { Install an additional } \\
\text { 8- to } 12 \text {-in. (R-38) } \\
\text { blown cellulose around } \\
\text { storage area }\end{array}$ \\
\hline & & $\begin{array}{c}\text { Weather strip and } \\
\text { insulate attic access } \\
\text { panel }\end{array}$ & $\begin{array}{l}\text { Weather strip and } \\
\text { insulate attic access } \\
\text { panel }\end{array}$ \\
\hline Walls & $\begin{array}{l}\text { Add 2-in. polyisocyanurate } \\
\text { (R-12) and new vinyl siding, } \\
\text { or, add 3.5-in. expanded } \\
\text { polystyrene and EIFS }{ }^{\mathrm{f}} \text {, or } \\
\text { leave as is (control building) }\end{array}$ & $\mathrm{n} / \mathrm{a}$ & $\begin{array}{l}\text { Remove vinyl siding, } \\
\text { install 1-in. XPS (R-5), } \\
\text { WRB }^{\text {g }} \text {, and new vinyl } \\
\text { siding }\end{array}$ \\
\hline Windows & $\begin{array}{l}\text { Remove and reinstall new } \\
\text { vinyl sliding windows } U= \\
0.30, \text { solar heat gain } \\
\text { coefficient }=0.30 \text { with } \\
\text { flashing and trim included }\end{array}$ & $\begin{array}{l}\text { Remove and reinstall } \\
\text { new vinyl sliding } \\
\text { windows } U=0.30 \text {, solar } \\
\text { heat gain coefficient }= \\
0.30 \text { with flashing and } \\
\text { trim included }\end{array}$ & $\begin{array}{l}\text { Remove and reinstall } \\
\text { new vinyl sliding } \\
\text { windows } U=0.30, \\
\text { solar heat gain } \\
\text { coefficient }=0.30 \text { with } \\
\text { flashing and trim } \\
\text { included }\end{array}$ \\
\hline Doors $^{h}$ & $\begin{array}{l}\text { Remove existing, install } \\
\text { new prehung insulated door, } \\
\text { flash, and trim. }\end{array}$ & $\begin{array}{l}\text { Remove existing, install } \\
\text { new prehung insulated } \\
\text { door, flash, and trim. }\end{array}$ & $\begin{array}{l}\text { Remove existing, } \\
\text { install new prehung } \\
\text { insulated door, flash, } \\
\text { and trim. }\end{array}$ \\
\hline
\end{tabular}

\footnotetext{
${ }^{a}$ Crawlspace of the B, BV, and FB units are monolithic poured concrete from stem walls through first floor slab.

${ }^{\mathrm{b}}$ Fiberglass

${ }^{\mathrm{c}} \mathrm{SPF}$ is spray polyurethane foam

${ }^{\mathrm{d}} \mathrm{GVB}$ is ground vapor barrier

${ }^{\mathrm{e}} \mathrm{XPS}$ is extruded polystyrene

${ }^{\mathrm{f}}$ EIFS is exterior insulating finishing system, a wall finishing system that combines typically expanded polystyrene foam attached to the wall and covered with a synthetic stucco. The insulation can be installed at various thicknesses depending on the level of insulation desired.

${ }^{\mathrm{g}} \mathrm{WRB}$ is weather-resistive barrier

${ }^{\mathrm{h}}$ Some members elected to keep the existing doors.
} 


\section{Greenbelt Homes, Inc. Pilot Program Research Investigation}

With support from the BA program through the PHI BA team, the GHI pilot program was crafted to investigate the potential for energy upgrades to be cost-effective and improve the livability of the homes. The phased approach described previously facilitates the research investigation. This report focuses on the Phase 2 effort and links the Phase 1 simulation estimates and baseline energy measurements with the improvements implemented in Phase 2, the planning for specific HVAC modifications, and the resultant energy use measurements. The following specific research questions serve as the basis for the investigation:

- How does the energy use for the homes with energy retrofits compare with the preretrofit energy use for space heating and total consumption?

- Can either enhanced energy savings or "take-back" energy consumption be identified from the pre- and post-retrofit measurements?

- What is the difference between the average indoor air temperatures for the homes with energy retrofit and the pre-retrofit home (and occupants) measurements?

- How does the realized energy savings for the efficiency retrofits compare with the realized installation cost of the retrofits?

- What is the homeowner perspective on the home comfort following the energy retrofits?

- How does the relative humidity within the home change from the pre- to the post-retrofit conditions?

- What is the change in the crawlspace environmental conditions from the pre- to postretrofit conditions?

- What is the comparison between the metered energy use data (electric utility meter) and the measured daily energy use and can this relationship be standardized for similar analysis in homes in heating climates to avoid costly instrumentation? 


\section{Retrofit Designs and Construction Process}

A primary goal of the pilot project is to develop the process to implement energy retrofit upgrades throughout the GHI cooperative. This process, typically handled by a remodeler or trades contractor in an individual home, is much broader and more complicated when it is implemented community wide.

\subsection{Design Details and Bid Process}

Using pilot homes and members as willing participants in the process, the perceived path to completion of the pilot retrofits consisted of GHI's engagement of the services of an architectural and engineering firm $(\mathrm{A} \& \mathrm{E})$ to define the existing conditions and recommended upgrades to each building type. Once the details were developed, these were formatted into a scope of work and placed out for bid. But because of the uniqueness of the construction and details of the GHI buildings, the reliance of the A\&E industry on generic details that were not applicable to the actual conditions, and boilerplate requirements for contractors working in the GHI cooperative, the details did not provide the intended design and instructional framework for the energy upgrades. Several rounds of GHI requesting proposals resulted in bids that were considerably higher than estimated, which stalled progress. The process was originally envisioned as:

1. A\&E submits design, including details of existing conditions and integration details for the proposed thicker walls and window and door components.

2. GHI requests bids of contractors based on A\&E-produced plans.

3. Build from plans and specifications after GHI accepts the bid.

GHI found that the process wasn't as straightforward as desired. Causes ranged from unfamiliarity with unique or uncommon building construction types to a delayed selection of window and door style/type decisions that are dependent on individual homeowners and GHI's insurance and unique working hours specifications. Because of the bidding process, the window supplier and installation subcontractor and installation methodology were selected by GHI independently of consultation with the general contractor or with the PHI team. This caused the prime contractor to be delayed in installing windows or doors and in resolving the discontinuity in the drainage plane caused by the selected window installation method - a block frame (retrofit) window that might have been more efficiently installed as a flanged window.

Adding to the complexity of the bid process was the selection of an EIFS as one of the exterior finishes intended for the B buildings. This system was originally considered as a solution that might be more flexible in providing details that would more closely resemble the look of the original block construction. The EIFS installation was postponed indefinitely because of the cost and complexity of integrating it with the windows and door components in a retrofit situation, but the concept may be revisited once the other wall upgrades have been completed.

The shortcomings of the design-bid-build process flow are often obvious in many retrofit projects where construction modifications are made after the work has been initiated. In this case, the variation in building types and the wide range of the scope of work created a significant challenge to define all details of the upgrades before the bid process was initiated. 
Fortunately, the oversight of the GHI project manager, the dedication of the GHI buildings committee, the attention to detail by the general contractor, and the continued support of the BA program allowed for ongoing and timely decisions that accommodated the many questions that arose during the upgrades. Without these partners and their level of commitment to the project success, project costs would likely have increased significantly and durability concerns may have arisen. Cost increases would have been incurred from added materials and labor for window installation, siding trim details over thick foam, and other issues. Durability concerns might have arisen, such as from the location of the drainage plane, window flashing, flashing of thicker foam integrated with existing roof flashing, attachment of furring strips through thick foam, and siding attachment to furring strips. The partners helped to resolve many of these issues and achieve outcomes that can be repeated in other community-wide upgrades.

The team continued to communicate during the retrofit process for each building, working through details as they arose and reviewing the solutions after the installation to document opportunities for changes and improvements in preparation for the community-wide upgrade. This approach will enable future work to be estimated more precisely and installed with more defined steps and sequencing — all aspects that enhance affordability.

By a similar approach, after the completion of the crawlspaces, PHI translated a new construction scope of work for the construction of crawlspaces to one that could serve as an inspection, design, build, and quality management system report to aid in the retrofit of existing building foundations. GHI will use this report (Del Bianco et al. 2013) to guide the improvement program in assessing crawlspace retrofit needs and solutions as the community-wide upgrade is initiated after the pilot program's results are reviewed.

\subsection{Additional Analysis Required}

Another development that arose after the start of the pilot project was a renewed interest in maintaining the original exterior façade and look of the buildings, especially the B buildings. The pilot homes (B1 to B4), which had been anticipated at the outset of the pilot program to be retrofitted with EIFS, emerged at the center of an inquiry supported by the Maryland Historical Trust to investigate opportunities to leave the exterior of the B buildings unchanged and insulate their interiors. The issue raised with the Maryland Historical Trust suggested that the historical significance of the B buildings might be lost by covering the painted CMU of one B building in the pilot program. Figure 5 shows the original drawings of the B buildings, including the casement style windows. The block is shown unpainted. Figure 6 shows a B building after the 1980 upgrades, which included the change to a slider type window. 


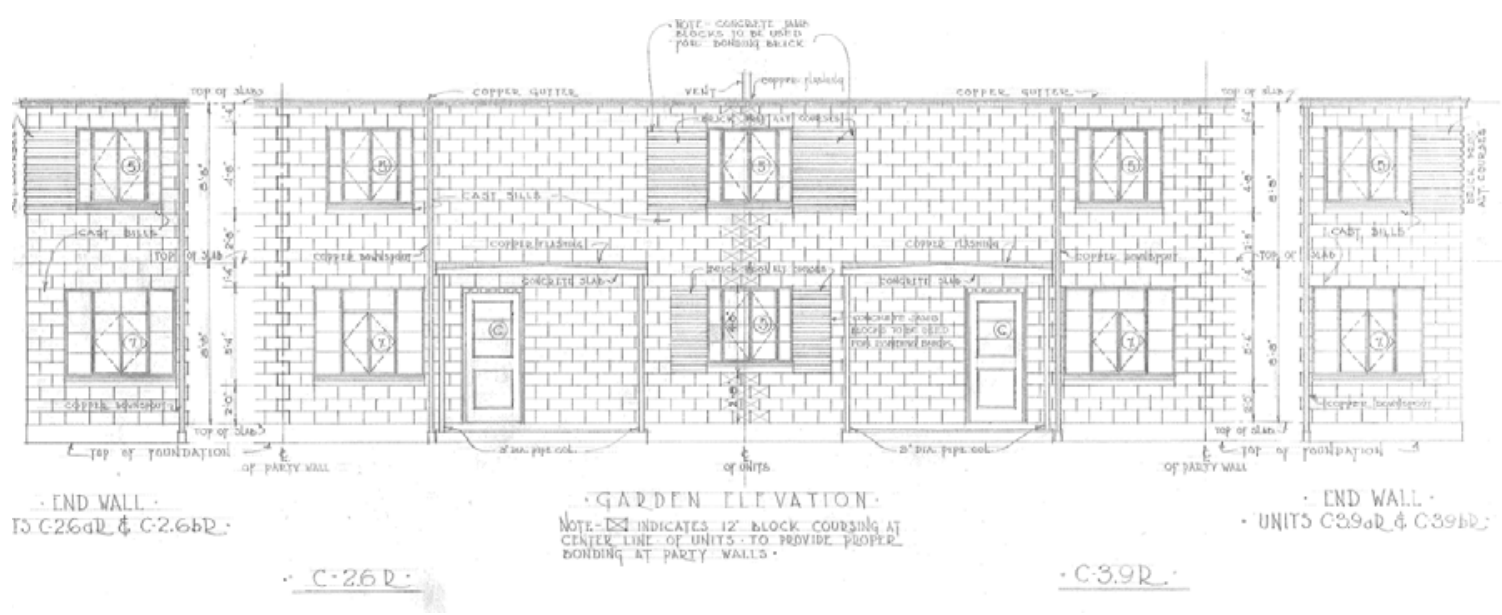

Figure 5. Original design of B homes

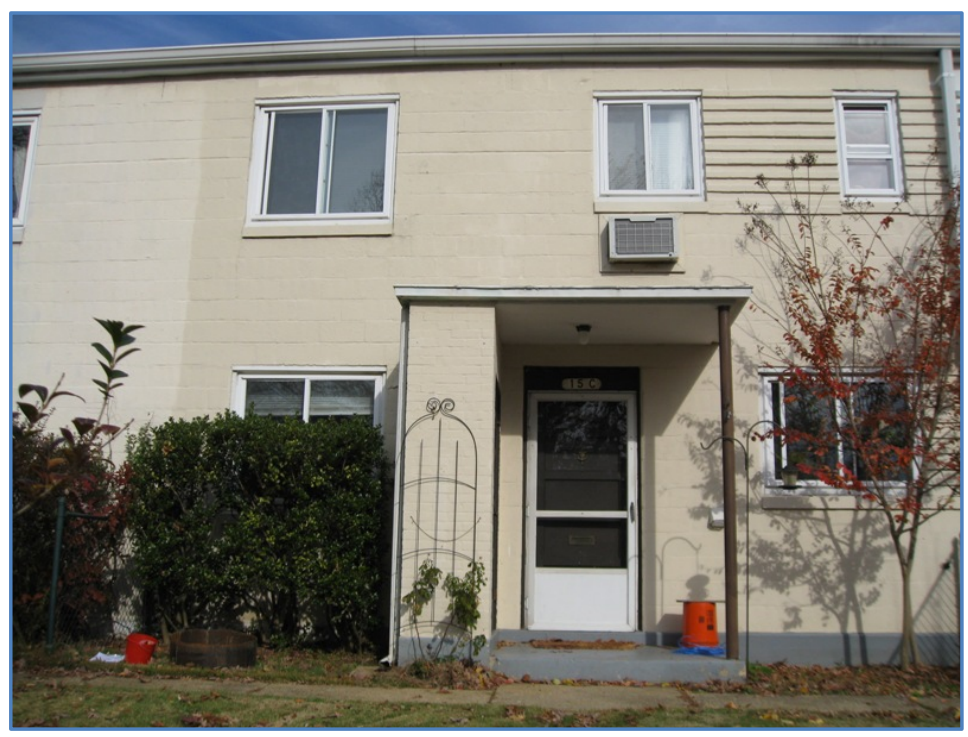

Figure 6. Painted B home with circa 1980 window upgrades

Although the specifics of building cladding types, including the use of EIFS on the exterior of the B buildings, had been vetted by the community nearly 2 years earlier, the interior insulation options were raised as alternatives to exterior claddings. The Maryland Historical Trust recognizes part of the community as a "Greenbelt Historic District," the originally developed inner core of GHI, which was known for "the predominant building type of multistoried apartment houses." The National Historic Trust comments that, "Settled in 1937 as a cooperative New Deal era community, Greenbelt is now nationally recognized for its unique design and strong sense of place," inferring that the historical recognition is designated by the community and its infrastructure and orientation rather the architecture per se (Maryland Historic Trust).

The Maryland Historical Trust provided a grant to an architectural firm (through GHI) to study alternative cladding methods. The PHI BA team was asked to provide a follow-up analysis of 
interior insulation options consistent with the study that was originally performed using exterior insulation options. Results are covered in Table 3.

Table 3. Simulated Energy Savings of Various Insulation Methods for B Units

\begin{tabular}{|c|c|c|c|c|}
\hline \multirow[b]{2}{*}{ Type of Usage } & \multirow[b]{2}{*}{$\begin{array}{c}\text { Existing } \\
\text { Usage } \\
\text { (kWh) }\end{array}$} & \multicolumn{3}{|c|}{ Insulation System Upgrade Option } \\
\hline & & $\begin{array}{c}\text { Exterior } \\
\text { EIFS/Glass Fiber- } \\
\text { Reinforced } \\
\text { Concrete } \\
\text { R-12 } \text { Added }^{\text {b }}\end{array}$ & $\begin{array}{l}\text { Interior }^{\mathrm{a}} \\
\text { R-5 Added }\end{array}$ & $\begin{array}{c}\text { Interior }^{\mathrm{a}} \\
\text { R-7.5 } \\
\text { Added }\end{array}$ \\
\hline $\begin{array}{c}\text { End Unit, Heating Energy, } \\
\text { kWh }\end{array}$ & 8,001 & 3,016 & 4,756 & 4,074 \\
\hline $\begin{array}{c}\text { End Unit, Heating Energy } \\
\text { Savings }\end{array}$ & & $62 \%$ & $41 \%$ & $49 \%$ \\
\hline $\begin{array}{l}\text { Interior Unit, Heating } \\
\text { Energy, kWh }\end{array}$ & 4,481 & 1,628 & 2,824 & 2,407 \\
\hline $\begin{array}{c}\text { Interior Unit, Heating } \\
\text { Energy Savings }\end{array}$ & & $64 \%$ & $37 \%$ & $46 \%$ \\
\hline $\begin{array}{l}\text { Whole Building, Heating } \\
\text { Energy, kWh }\end{array}$ & 24,964 & 9,288 & 15,160 & 12,962 \\
\hline $\begin{array}{c}\text { Whole Building, Heating } \\
\text { Energy Savings }\end{array}$ & & $63 \%$ & $39 \%$ & $48 \%$ \\
\hline
\end{tabular}

${ }^{a}$ Assume $8 \%$ of end unit and $12 \%$ of an interior unit wall area are left uninsulated because of kitchen and bath features.

${ }^{b}$ EIFS/glass fiber reinforced concrete upgrades are exterior-applied insulation systems of equal R-value.

If an internal wall insulation upgrade option were selected, the small interior area of the B homes $\left(844-1,596 \mathrm{ft}^{2}\right)$ would require that members and their possessions be moved out of the homes for the 7- to 14-day period that would be required to complete the interior retrofit of insulation and gypsum with a painted finish. Cabinetry and appliances in the kitchens and baths that span exterior wall surfaces would preclude those areas from being retrofitted from the inside, because removing and reinstalling these are neither affordable nor practical. GHI required that temporary storage and relocation be included in the project's estimated cost; thus, retrofitting from the inside was more expensive than the cost estimates attached to the exterior applications in the $\mathrm{B}$ and BV CMU units.

Because the interior insulation options had higher costs and lower energy savings, these were determined to be less cost-effective than an exterior insulation option. These results provided the GHI administration with additional detailed information to make an informed decision about energy-efficiency upgrades in the community.

This additional analysis provided confirmation of the original direction for the pilot program in terms of cost-effective energy-efficiency upgrades. 


\section{Crawlspace and Attic Upgrades}

The work was undertaken in stages because of the complicated bidding process and the extensive range of the energy upgrade. All activities were originally intended to be performed over a 6month period that would include crawlspace, attic, wall, and window and door upgrades. Even so, the work scope was deemed sufficiently extensive and complicated for such a large pilot program that a staged process was initiated to tackle different building components. The pilot homes are configured in sets of four attached homes.

\subsection{Crawlspace Retrofits}

In fall 2011, crawlspace upgrades were commenced and completed for all pilot homes. The crawlspace retrofits (refer to Table 2) were performed on each of the seven building sets (28 homes) based on its condition. The B and FB buildings have monolithic poured concrete crawlspace foundations from the stem walls through the first-floor slabs. The walls were insulated with 2-in. XPS foam board in the 1980s; it deteriorated over time in some locations. The porch slab extensions on each home also have crawlspaces beneath that communicate with the home crawlspace, but these areas had previously been covered with a sheet of foam board, much of which had deteriorated. The crawlspaces are effectively semiconditioned, but the monolithic concrete construction prevents direct communication with the home.

The FV homes have wood frame floors that sit on concrete blocks and brick stem walls. The floors are insulated, resulting in unconditioned crawlspaces. Automatic vents allow ventilation in the crawlspaces, which close when the temperature falls below freezing.

Each crawlspace foundation has a ground vapor barrier that in all cases that were inspected had deteriorated over the years. Of the 28 pilot homes, two have a basement level that is above grade on the back side to the rear yard. These basement foundations abut the concrete crawlspace of the adjoining two homes in the building.

\subsubsection{Frame-Vinyl Pilot Home Crawlspace Upgrades}

The insulation and the ground vapor barriers in the FV homes' crawlspaces had deteriorated extensively (Figure 7).

Repairs and upgrades consisted of insulation and ground vapor barrier improvements (Figure 8). The fiberglass batt insulation in the floor joists had been disturbed to the point where they had to be removed and replaced. Three to 4 in. of SPF insulation was installed in place of the fiberglass batts at the underside of the first-floor decks. The SPF provided an air seal in addition to a thermal resistance value of approximately R-6 per inch. The value of the new insulation brought the R-value of the floors to R-19 from an inconsistent R-11. The contractor also removed and replaced all ground vapor barriers and sealed the new ones to the walls and columns of the foundations. 


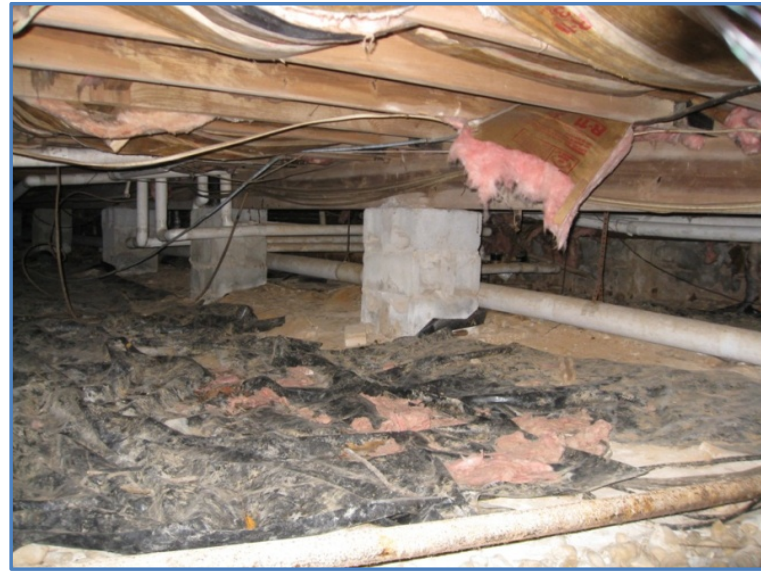

Figure 7. FV building crawlspace prior to upgrades

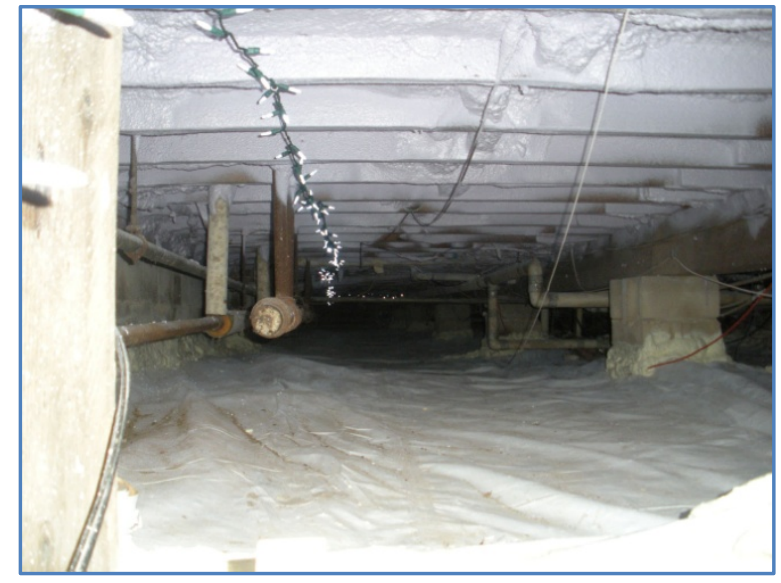

Figure 8. FV crawlspace after upgrades

\subsubsection{Block and Frame-Brick Crawlspace Upgrades}

The B, BV, and FB buildings are constructed of 5 -in. concrete slabs supported by 8 -in. integral poured concrete foundation walls. The crawlspace walls were insulated with rigid XPS in a 1980 renovation to provide a sealed, conditioned crawlspace. Water heaters that service the units are housed in the boiler rooms that allow access to the crawlspaces and are open to the crawlspaces in each building.

Some of the insulating foam boards had fallen off the foundation walls and some of the exterior porch slabs had not been insulated in the earlier retrofit, so these areas were noted for insulation installation. The ground vapor barrier required repair and sealing to the foundation walls to mitigate ground surface moisture entering the crawlspace (Figure 9 and Figure 10).

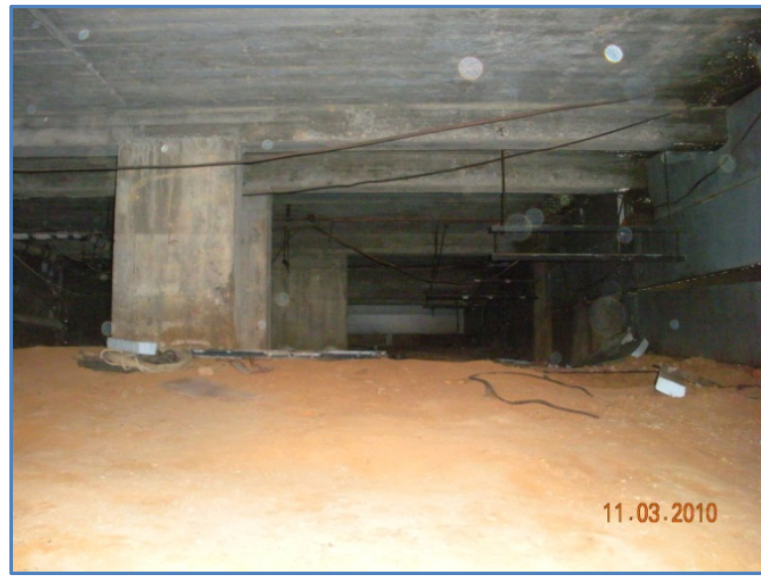

Figure 9. B building crawlspace prior to upgrades

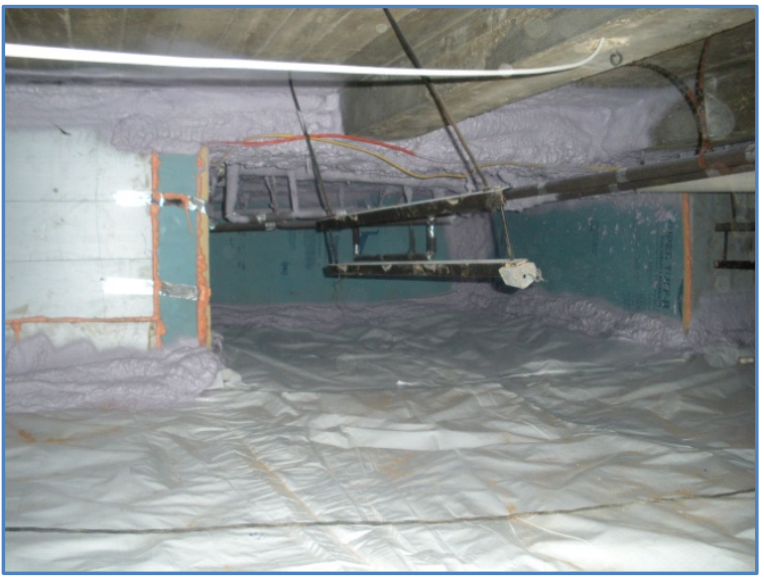

Figure 10. Building crawlspace after repair/retrofits 


\subsubsection{Frame-Brick and Frame-Vinyl Attic Upgrades}

Attics of the wood-framed buildings were constructed with $2 \times 8$ floor and ceiling rafters and originally were insulated with about 6 in. of blown insulation (R-19) at the attic floor. Figure 11 shows typical attic framing and floor.

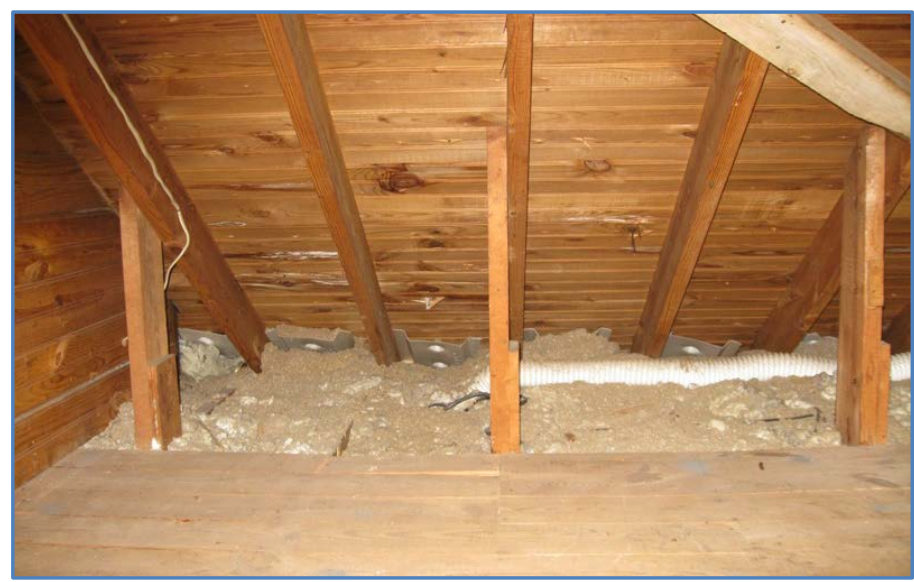

Figure 11. Typical attic of the wood-framed buildings

Most attics were sheathed with boards, which provided a storage area. This feature impeded installation of additional insulation in that area if a storage platform were to be maintained. The solution was to add $2 \mathrm{in}$. of rigid foam and wood sheathing on top of the approximately $192 \mathrm{ft}^{2}$ of surface of the storage area that was to remain. ${ }^{1}$ Figure 12 shows the insulation board at the attic access and Figure 13 shows the protective sheathing over the foam board. The added XPS provided an additional R-10 of thermal resistance at the storage areas.

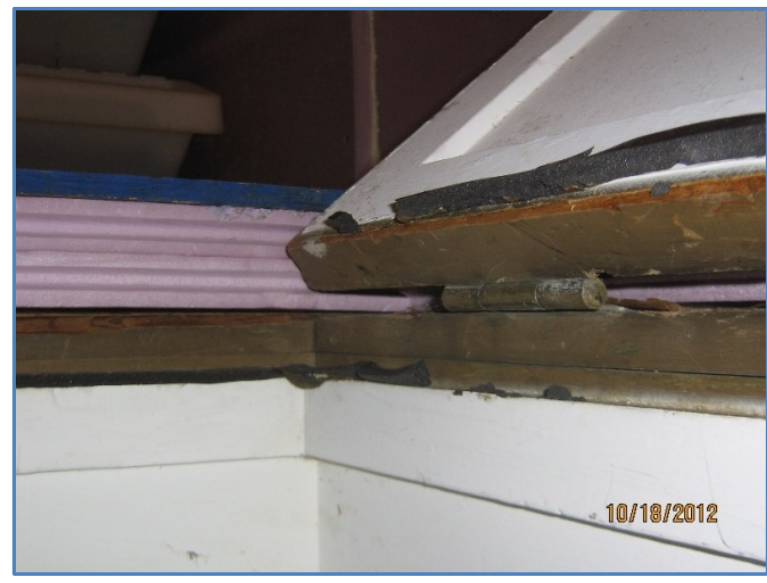

Figure 12. Foam board at attic storage area

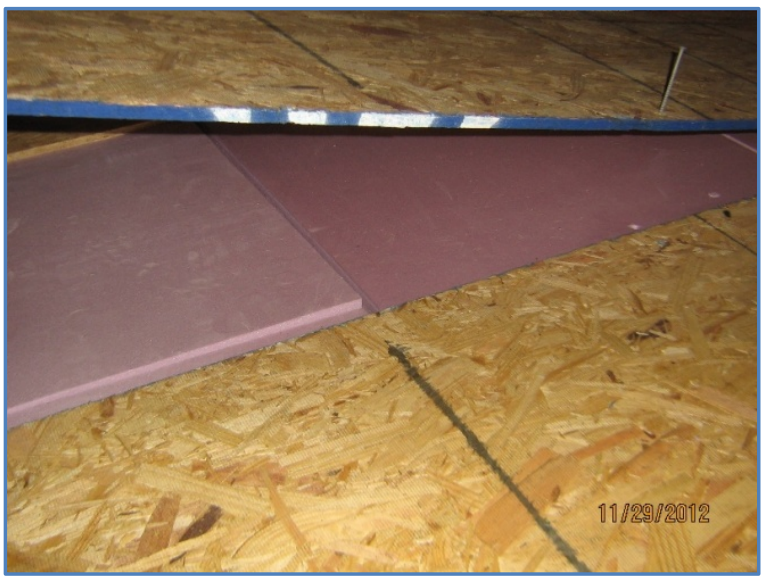

Figure 13. Wood sheathing installed over the foam board to maintain an attic storage area

\footnotetext{
${ }^{1}$ To avoid damage to the ceiling below, the existing flooring was left and insulation board and a durable surface added to keep some area for storage.
} 
Dams made from rigid foam boards were installed around the storage area to hold back the blown insulation that was added to the attics because the depth of the blown-in insulation exceeded the storage deck level by approximately 5 in. (Figure 14).

The attic retrofit included air sealing the exterior gable end top plates (Figure 15) and the exterior eave top plates (Figure 16), repairing eave baffle installation, and weather stripping the attic access hatches. The completed insulated attic storage area and surrounding insulation are shown in Figure 17.

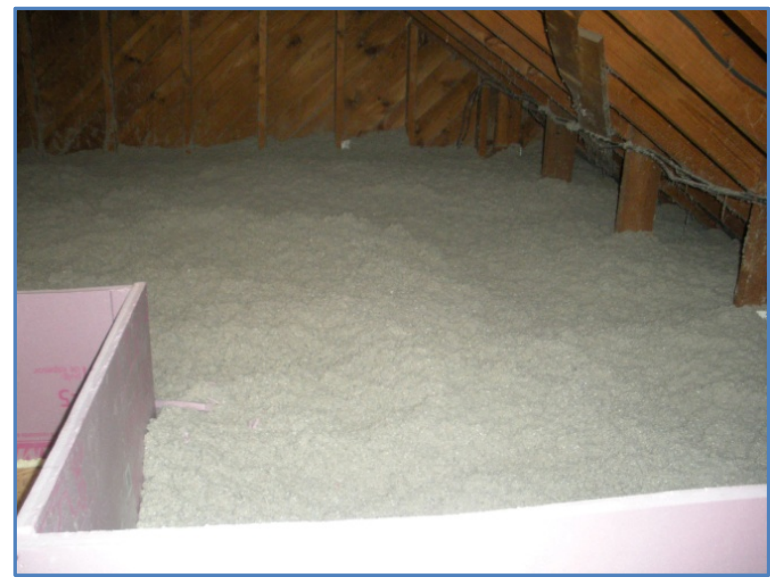

Figure 14. Insulation baffles at edge of new storage area

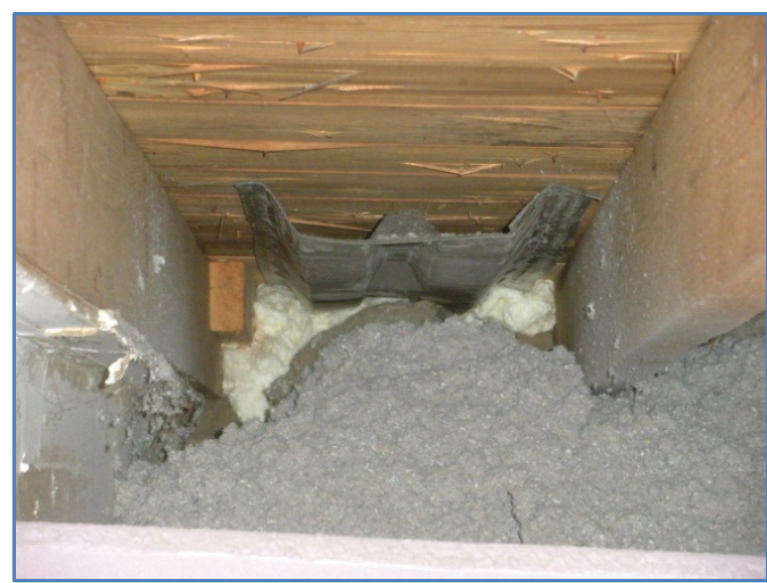

Figure 16. Exterior top plate air sealing

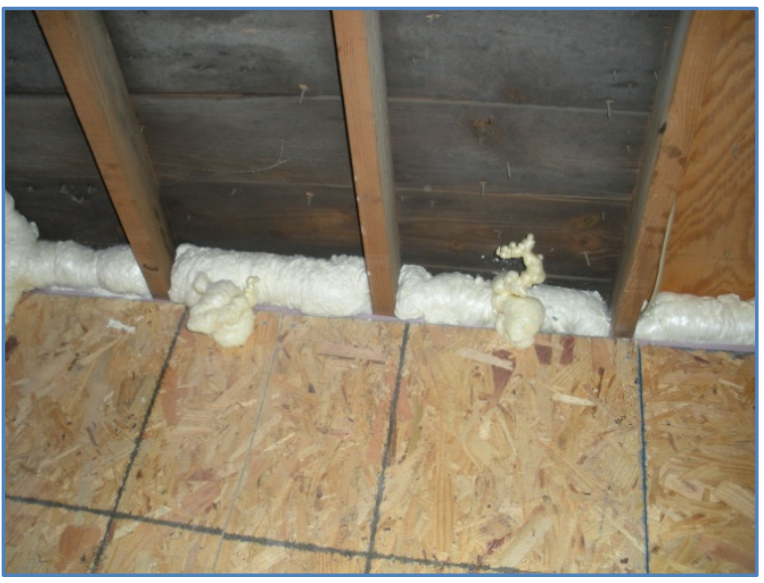

Figure 15. Gable end wall air sealing

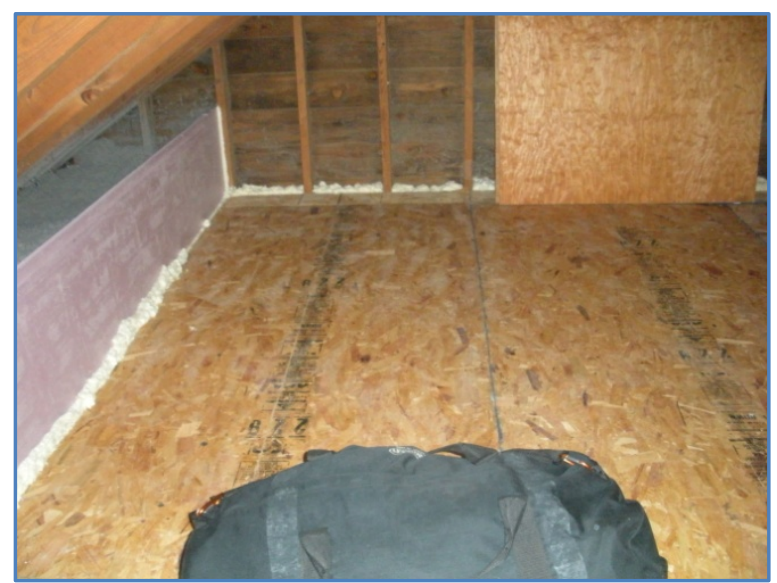

Figure 17. Completed attic retrofit

The attic upgrades included insulation over and air sealing around the access hatch, and in some cases covers for the attic hatch. 


\section{Wall, Window and Door, and Exhaust Fan Upgrades}

GHI staff planned to request a second set of bids for the wall insulation, window and door replacement, and bath exhaust fan installation in the selected pilot homes according to the original pilot home study plan, with one notable exception. The installation of the EIFS system was postponed indefinitely because bids for that project were received that significantly exceeded earlier estimates from contractors and because issues were raised with covering the original block buildings. ${ }^{2}$

An outline of the wall efficiency upgrades for the pilot homes is shown in Table 4.

Table 4. Summary of Wall Insulation Upgrades for GHI Pilot Homes

\begin{tabular}{|c|c|c|}
\hline $\begin{array}{l}\text { Pilot Home } \\
\text { Reference }\end{array}$ & $\begin{array}{c}\text { Building Type } \\
\text { Existing Condition }\end{array}$ & Wall Efficiency Upgrades \\
\hline B1-B4 & Block, uninsulated & $\begin{array}{c}\text { Window and door replacement, exterior insulation } \\
\text { postponed indefinitely, bath exhaust fans }\end{array}$ \\
\hline $\begin{array}{l}\text { BV1 and } \\
\text { BV2 }\end{array}$ & $\begin{array}{l}\text { Block, existing vinyl } \\
\text { siding, } 3 / 4 \text { in. of foam board } \\
\text { between furring }\end{array}$ & $\begin{array}{c}\text { Window and door replacement, remove existing } \\
\text { wall coverings, add } 2 \text { in. of insulation board and } \\
\text { new siding, bath exhaust fans }\end{array}$ \\
\hline B5 and B6 & Block, uninsulated & $\begin{array}{l}\text { Window and door replacement, add } 2 \text { in. of } \\
\text { insulation board and new siding, bath exhaust fans }\end{array}$ \\
\hline BV3-BV6 & $\begin{array}{c}\text { Block, existing vinyl } \\
\text { siding, } 3 / 4 \text { in. of foam board } \\
\text { between furring }\end{array}$ & Window and door replacement, bath exhaust fans \\
\hline FB1-FB8 & $\begin{array}{l}\text { Frame, brick veneer, } \\
\text { existing cavity insulation }\end{array}$ & Window and door replacement, bath exhaust fans \\
\hline FV1-FV8 & $\begin{array}{l}\text { Frame, vinyl siding, } \\
\text { existing cavity insulation }\end{array}$ & $\begin{array}{l}\text { Window and door replacement, remove existing } \\
\text { wall coverings, add } 1 \text { in. of insulation board and } \\
\text { new siding, bath exhaust fans }\end{array}$ \\
\hline
\end{tabular}

The wall upgrades were completed by the end of 2013.

\subsection{All Pilot Homes-Window Replacement}

Windows were replaced on all pilot homes, except in a few cases where the windows had been recently replaced. The procurement process established by GHI resulted in selection of a window manufacturer that installed its own product. The window procurement process functioned in parallel with other wall upgrades; the integration of the window replacement with the new exterior insulation and siding was detailed during the installation process - not an ideal approach and one that will be addressed before the community-wide upgrades begin. When evaluated across all of the pilot homes, the window installation was complicated by:

\footnotetext{
${ }^{2}$ The pilot building (Units B1 through B4) was determined, based on energy simulation estimates, to show the greatest energy savings of any of the pilot homes following the wall insulation upgrades. This building has little insulation and high utility bills showed high energy use (refer to Appendix C for a summary of energy measurements over previous heating periods).
} 
- The different types of buildings into which the windows were installed, i.e., 8-in. thick B, $\mathrm{BF}$, and wood frame with vinyl siding and trim

- The requirement that little or no interior work be required. i.e., all replacement windows were mounted to the interior (because the prime contractor was tasked to perform interior rework)

- The complete window integration, including all flashing and trim details, which had to be completed by the window installer independently of the siding contractor.

These requirements resulted in multiple integration details that required resolution during the wall insulation and siding upgrades. Of these details, the one that appeared most problematic was the use of window flashing material around the rough opening before the window was installed.

The window manufacturer/installer had a well-defined methodology for installing replacement windows:

1. Remove the existing replacement window.

2. Install the new window from the exterior using the interior window trim as the frame's backstop.

3. Apply SPF around the new window from the exterior.

4. Flash the window to meet the existing exterior window trim or wall cladding.

5. Caulk all seams, cuts, and joints in the flashing to protect against water intrusion.

To enhance the long-term durability and provide moisture protection from window leaks and to accommodate the detail of the additional thickness of exterior insulation the window manufacturer/installer was asked to modify its typical installation to include sill pan flashing with flexible, self-adhering flashing to integrate the new window flashing/trim with the wall insulation.

\subsection{Block Home Window and Wall Upgrades}

Wall efficiency upgrades in the block buildings (both uninsulated B and BV with 3/4-in. foam board insulation with vinyl siding) included replacement windows and doors. On one building the upgrade included 2-in. foam board insulation and new vinyl siding.

\subsubsection{Window Upgrades}

The window replacement details included installing the replacement window into the original wood window frames and integrating the window trim flashing with the exterior wall. In the B buildings that do not have exterior insulation, the windows were flashed directly to the block edge and caulked. This method was used for all the replacement window upgrades installed in the 1980s. Figure 18 shows the window framing after the old replacement window was removed. The interior trim, which will provide the interior finish and backstop for the frame of the new replacement window, is visible. Flexible flashing was used over the original window sill and the edges of the window were spray foamed to provide an air seal (Figure 19). 


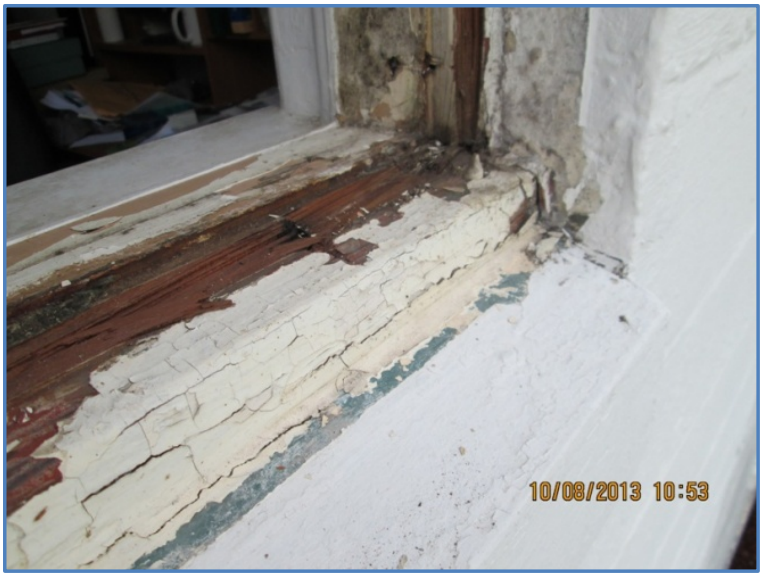

Figure 18. Window rough opening prior to window installation

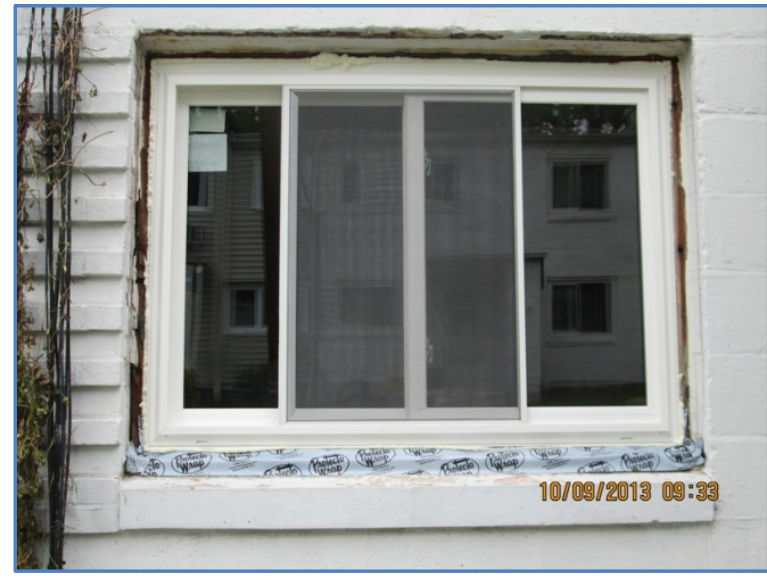

Figure 19. New replacement window installed over sill flashing and foamed

Where the block was to remain uncovered, the window trim was installed to the inside of the window rough opening and caulked at all trim edges and joints (Figure 20).

When insulation was to be added to the exterior of the block buildings, an entirely different detail was developed. In this case, the window flashing was integrated with the foam insulation under the furring strips and taped (Figure 21). In all cases the window trim flashing (and caulking) serves as the primary water barrier.

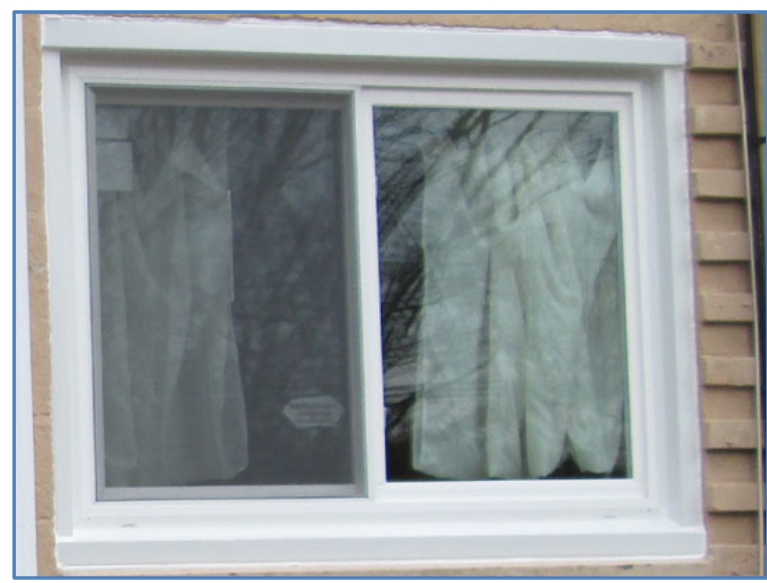

Figure 20. Window trim installed to the block rough opening and caulked

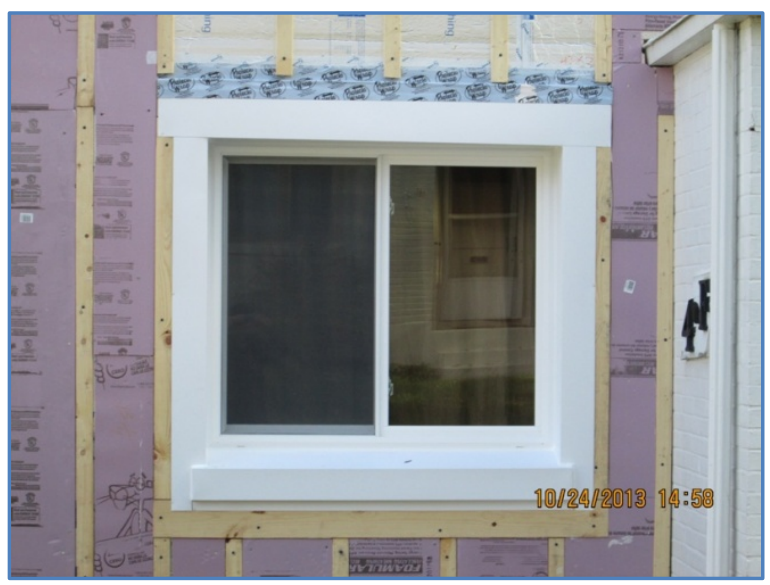

Figure 21. Window flashing integrated with foam insulation

The BV3-BV6 units in the pilot program had window and door upgrades; however, the existing siding was left unaltered. The energy savings and air infiltration results will be evaluated based on the crawlspace improvements and window replacements only. Because each of these units had been clad by different siding contractors and existing window details were not standard at the outset, the windows were installed with counter-flashed window trim that was integrated with the existing siding. Figure 22 shows the replacement window installed before the new flashing; Figure 23 shows a completed window installed with new flashing trim. 


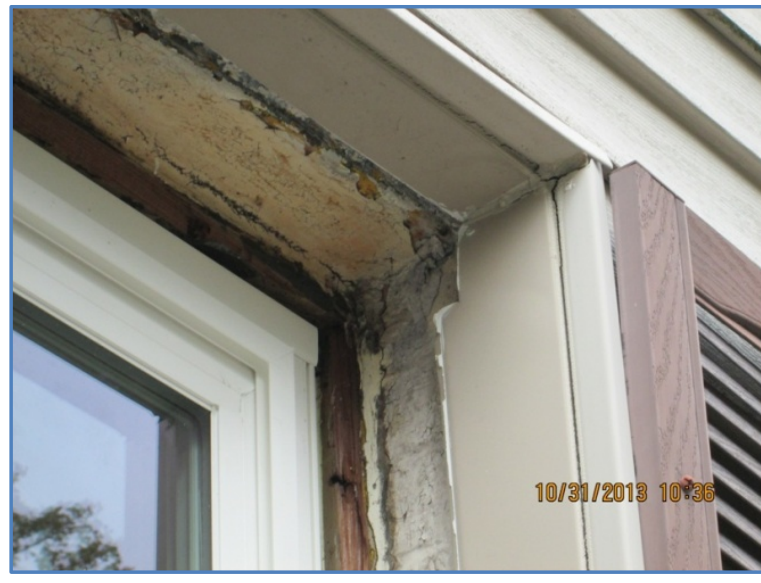

Figure 22. Replacement window installed in a BV unit

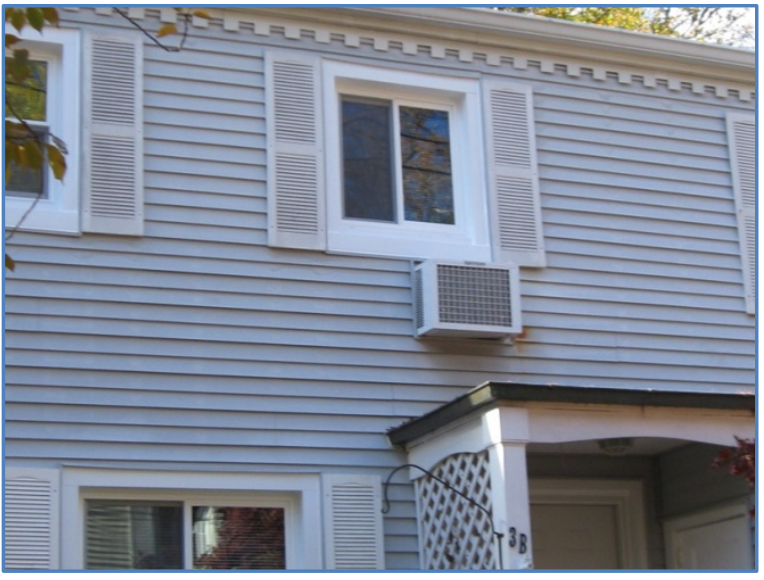

Figure 23. BV building with new windows and trim

\subsubsection{Block Building Insulation}

The $\mathrm{B}$ building upgraded with exterior insulation consisted of $\mathrm{BV}$ units on the end and uninsulated $\mathrm{B}$ units in the middle (Figure 4). The existing siding on the end units, furring, and insulation board were removed and discarded. Two-inch-thick polyisocyanurate rigid foam (polyiso) was specified on all units in the building. The polyiso was tacked in place on the wall using adhesive, taped to serve as a WRB, and then permanently fastened with concrete screws spaced at $24 \mathrm{in}$. along furring strips placed at $16 \mathrm{in}$. along the length of the building (Figure 24). The screw holes were predrilled for the 4 -in. $\times 1 / 4$-in. drill bit fasteners that were to fasten through the furring strip and 2 in. of polyiso into the CMU walls. No anchors were required.

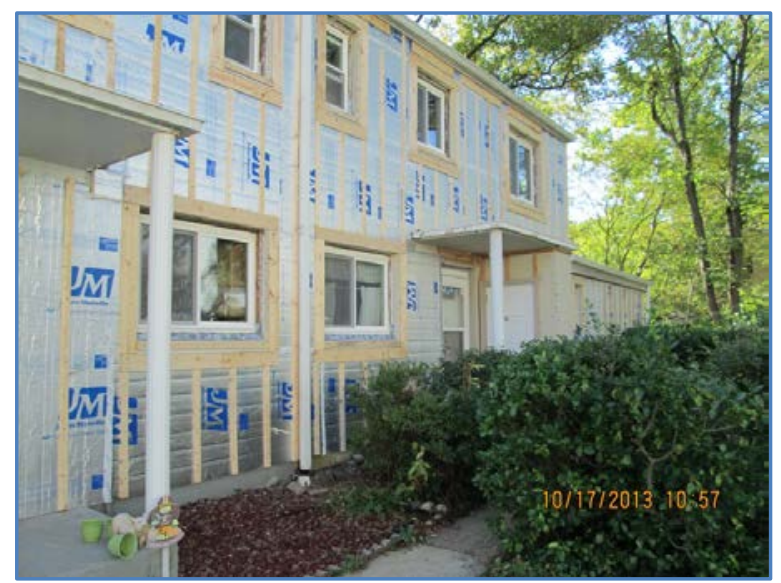

Figure 24. Block building with 2-in. rigid foam and furring

After this assembly was completed, $1 / 2$-in. XPS foam was installed between the furring strips with adhesive to create a smooth, solid surface behind the vinyl siding as recommended by the vinyl siding manufacturer to preserve the warranty. Figure 25 shows the polyiso insulation, furring strips, additional insulation, and window flashing using the flashing trim. The vinyl was installed conventionally - secured to the furring with roofing nails. Figure 26 shows the finished product. 


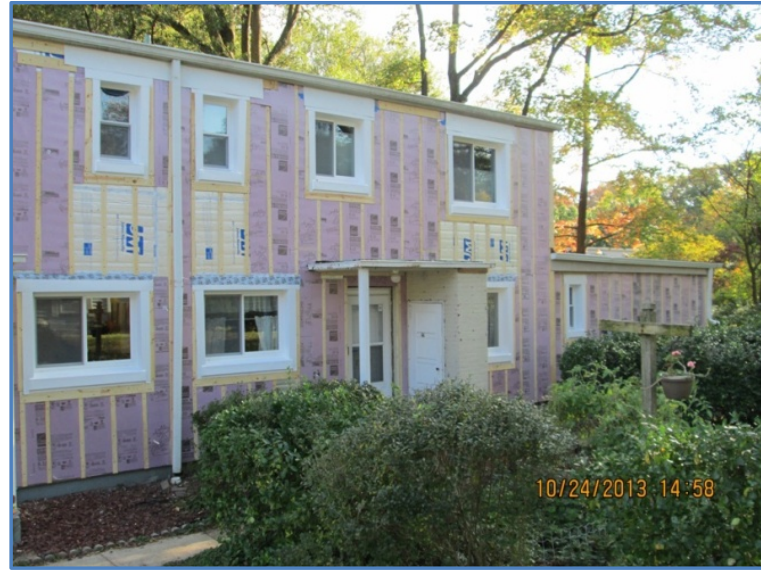

Figure 25. Block building with exterior insulation installed

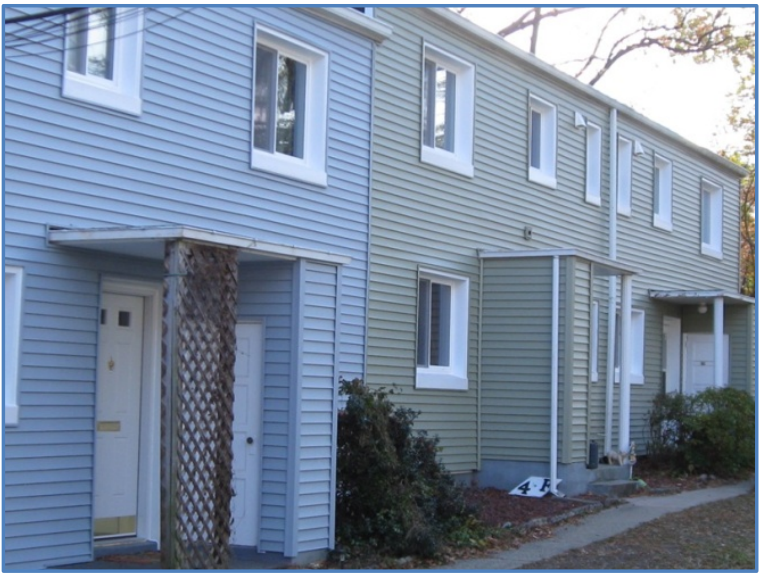

Figure 26. Completed block building with all energy upgrades installed

\subsection{Frame-Brick Window and Door Replacement}

The pilot program includes two FB buildings (eight units). These units were to have window and door replacements as well as the crawlspace improvements (similar to that of the block buildings). The window replacements were integrated with the original window framing, similar to the replacements that were implemented in the 1980s. Figure 27 and Figure 28 show the new window installed in an FB unit.

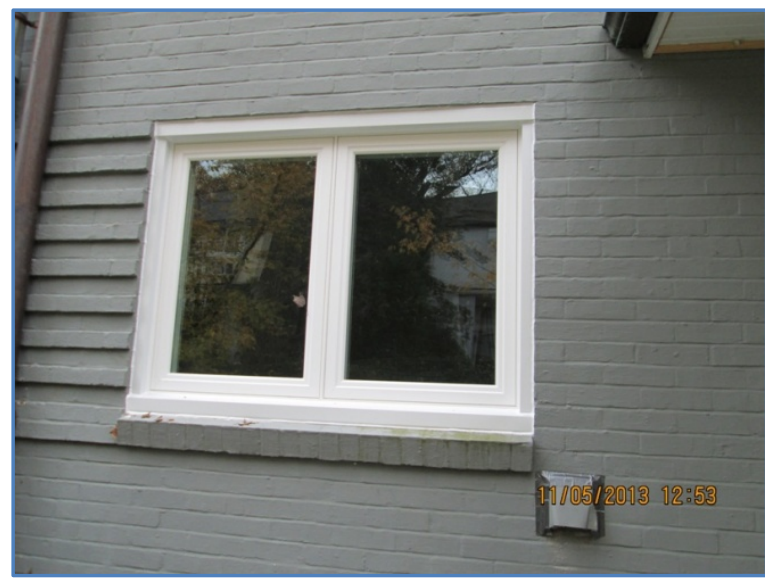

Figure 27. Replacement window in FB unit

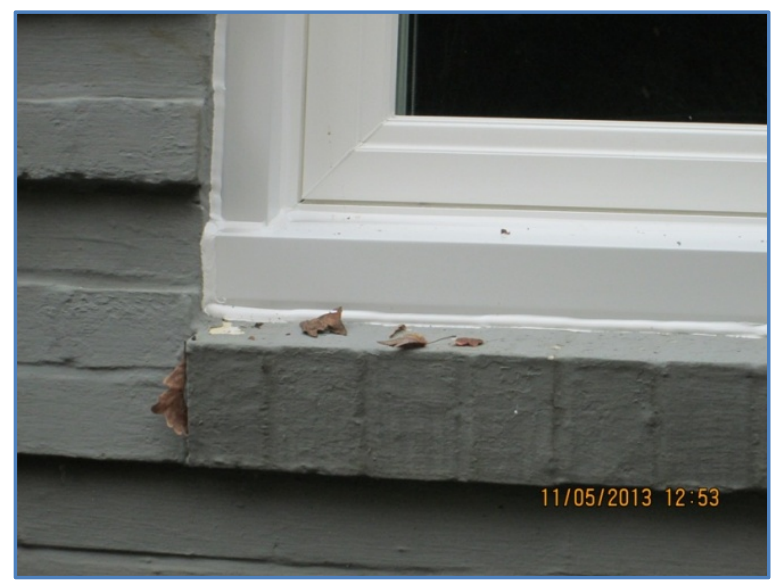

Figure 28. FB replacement window-flashing and caulking

\subsection{Frame-Vinyl Wall, Window, and Door Upgrades}

Energy retrofits to the FV buildings (Figure 29), in addition to the crawlspace and attic improvements outlined earlier, consisted of removing the existing siding and windows, installing replacement windows and doors, and installing 1-in. rigid foam board insulation, a WRB, and new siding. Both FV buildings (eight units) were improved with these same features. As is common with remodeling efforts, the homeowners made some decisions that directly affected the work scope after the work had already commenced. In this case, the decision to cover an inoperable exterior trash door was made while the job was in progress, thus requiring onsite 
changes to the siding installation. Similar changes were necessary for some windows where the interior trim was not the standard installation that had been encountered in previous units.

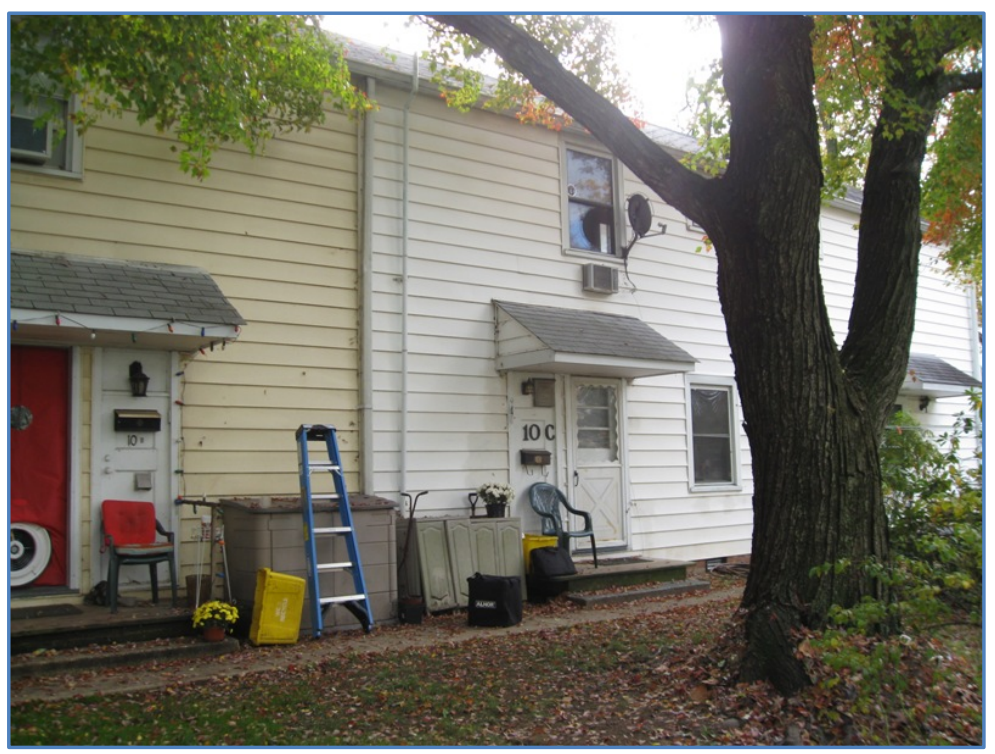

Figure 29. Typical front elevation, FV building

\subsubsection{Window Replacements}

As with the established installation method, the window upgrades were made using replacement windows installed to an interior stop bead so that no interior trim work or painting was required. Sill flashing was installed at PHI's request after the window was removed (Figure 30).

The existing windows were removed and the new windows installed after the siding was removed and 1-in. XPS was installed. This resulted in a wall thicker than that of the original window jamb trim (Figure 31).

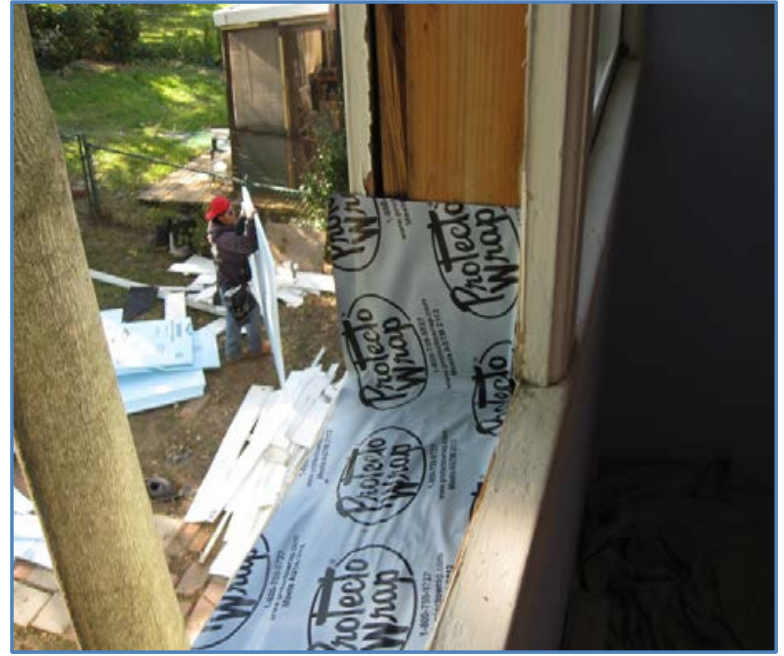

Figure 30. Window sill flashing on an FV unit

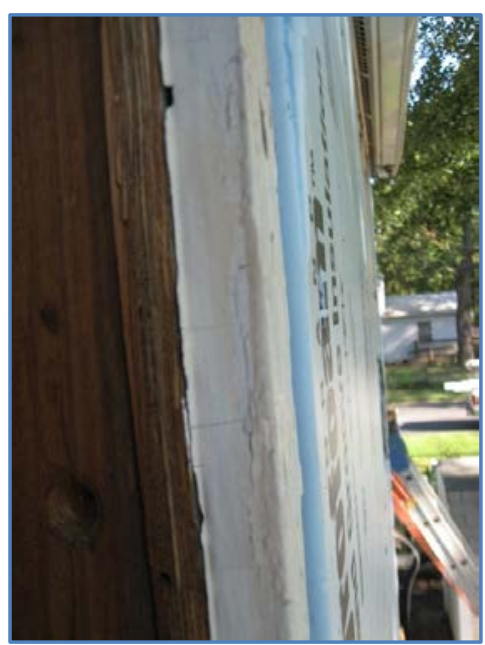

Figure 31. Foam board extends beyond original window trim 
If the existing trim is undamaged, removing it is not preferable for a variety of reasons, including avoidance of disposal and disturbance of old paint layers. For aesthetic purposes, a new 1-1/4-in. thick pine board was installed over the original picture frame trim of the windows and covered with the window counter flashing that was custom made onsite of aluminum coil stock with a vinyl surface coating. SPF was applied as an air seal (Figure 32). An integral flashed edge butted the XPS foam board. Next, a WRB was installed over the foam sheathing and taped to the window trim counter flashing (Figure 33 and Figure 34).

The interior of the window required only caulking to finish (Figure 35).

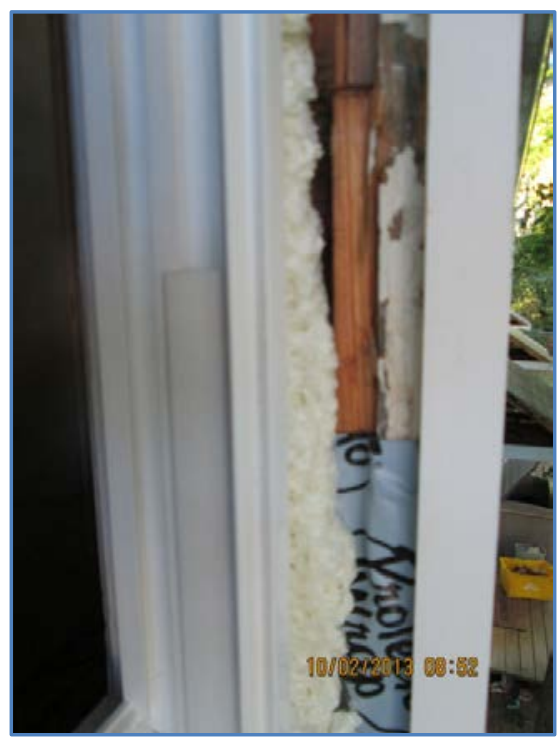

Figure 32. Additional window trim and foam sealing

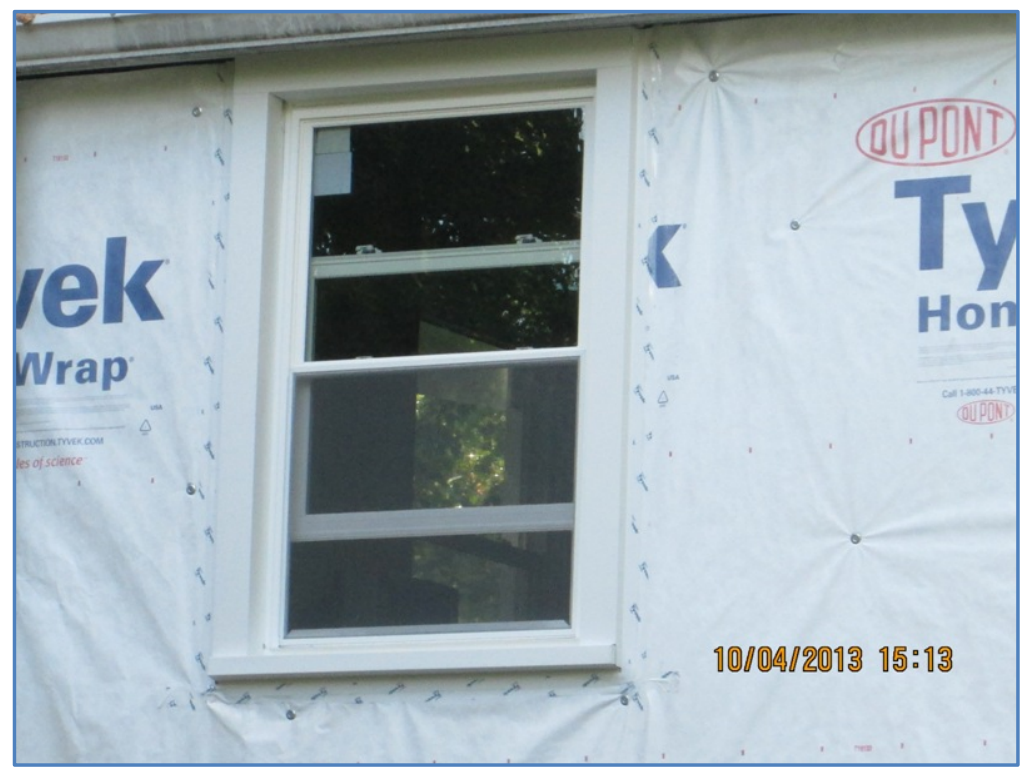

Figure 34. Additional window trim and foam sealing

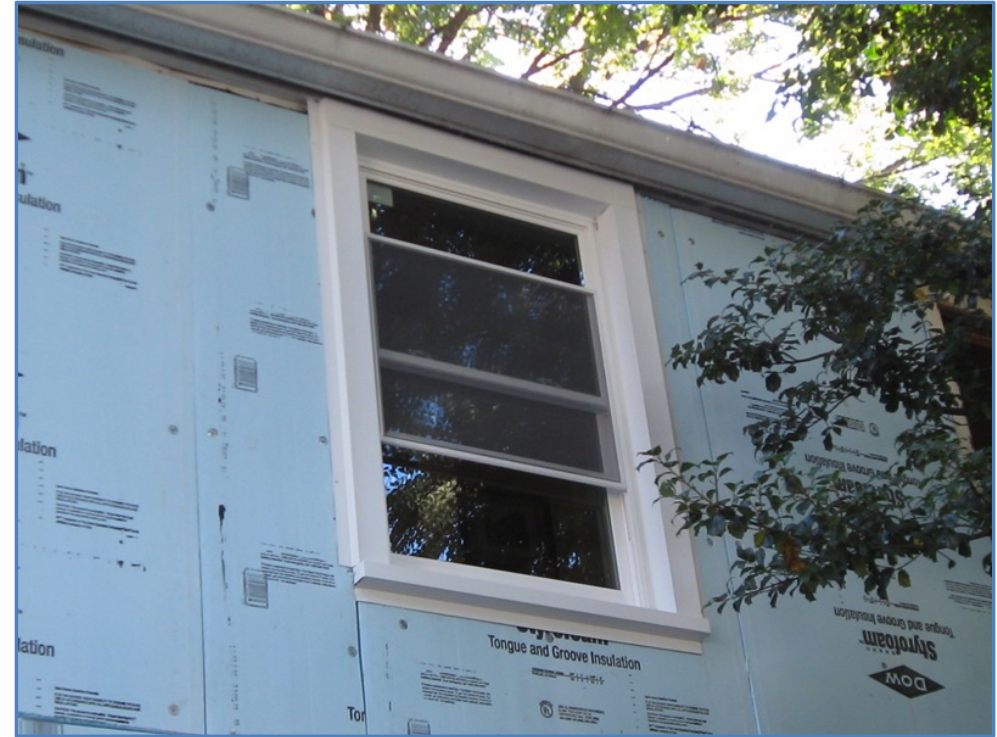

Figure 33. Replacement window installed and flashed

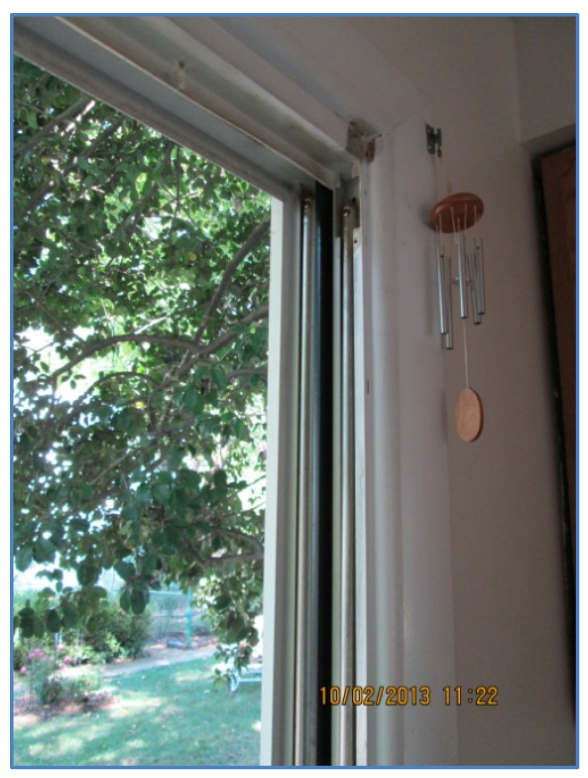

Figure 35. Replacement window installed and flashed 
For the second of the two FV buildings, a slightly different installation method was employed to integrate the window with the new foam board. Once the existing siding was removed, the foam board was installed and covered with a WRB (Figure 36) with overlap that would be folded into the window opening before the replacement window was installed (Figure 37).

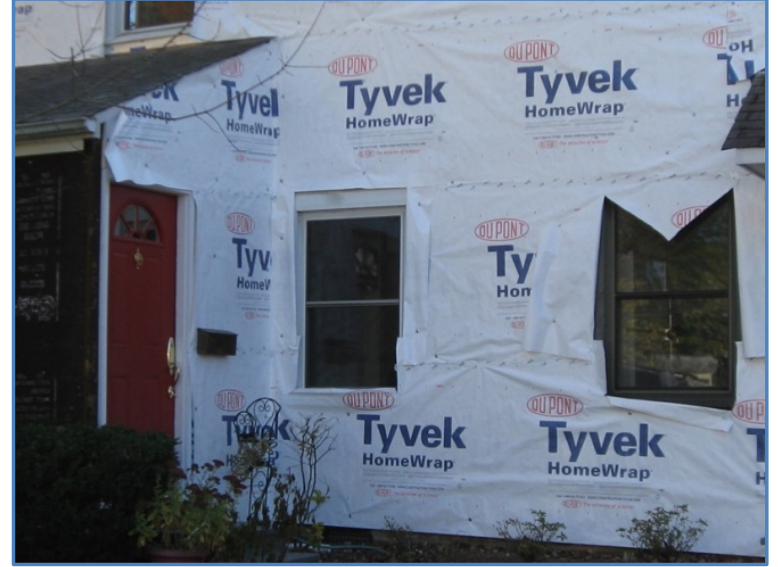

Figure 36. WRB installed over foam sheathing (not shown)

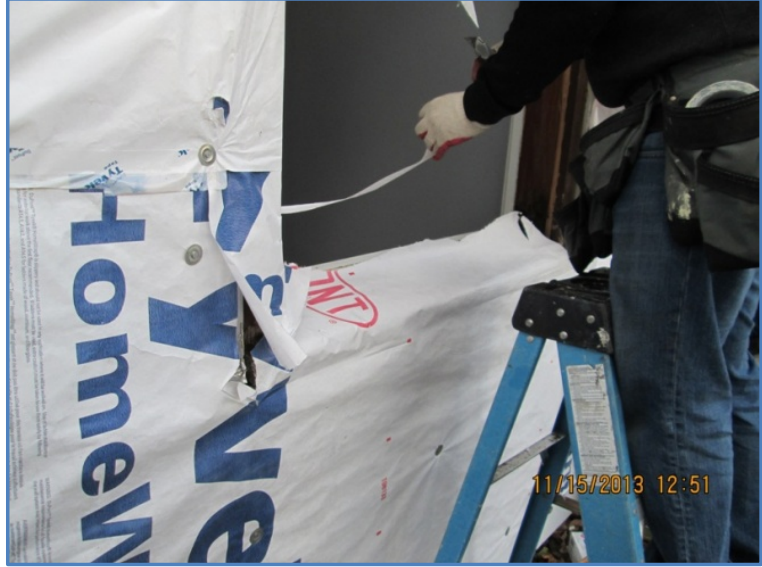

Figure 37. WRB wrapped into window opening

The window was installed with SPF for air sealing and with the trim's counter flashed edge taped to the WRB (Figure 38).

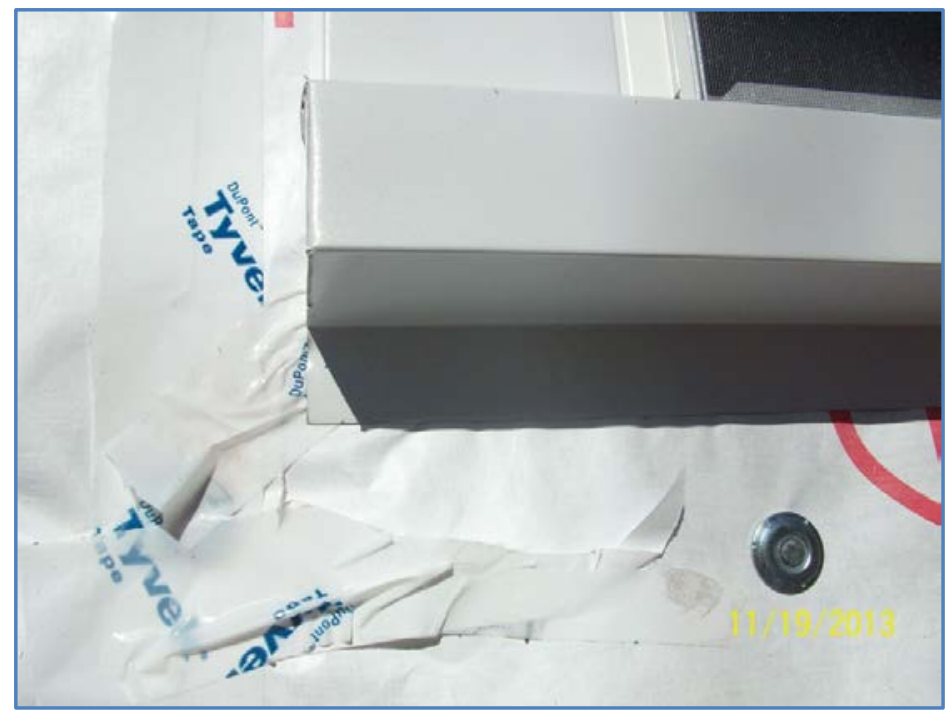

Figure 38. Window trim flashing integrated with WRB

This window installation methodology was somewhat more acceptable to the trade contractors.

The driving force behind the use of the installation details was that the windows had to be installed independently of all other wall upgrades. This was because the contractor's independence was based on the separateness of the contract. This approach is often not ideal but 
is common in residential retrofit projects. The requirement that as little interior work as possible be performed also drove the windows installation method because the windows had to be inset rather than installed as new construction flanged at the face of the added wall thickness, which would have been the ideal installation for ease of detailing.

\subsubsection{Frame-Vinyl Wall Insulation Upgrades}

After the siding was removed, foam board insulation was installed over the existing wall. Figure 39 shows the wall with the siding removed and the building paper installed over the board sheathing. One-inch-thick foam sheathing was installed (Figure 40) over the wall and covered with a WRB (Figure 41). This procedure was used because the foam was often installed in smaller pieces because the irregular openings in the building would have required extensive tape and detailing to completely seal out air and moisture. New siding was installed to complete the exterior (Figure 42).

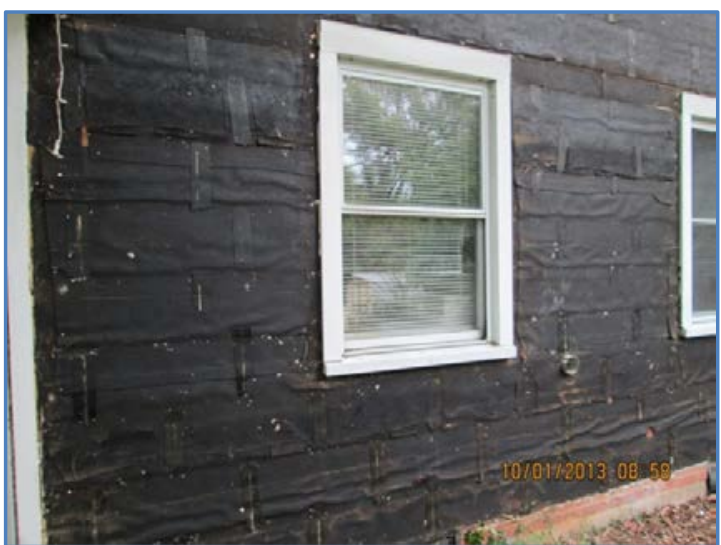

Figure 39. Original building paper on frame building

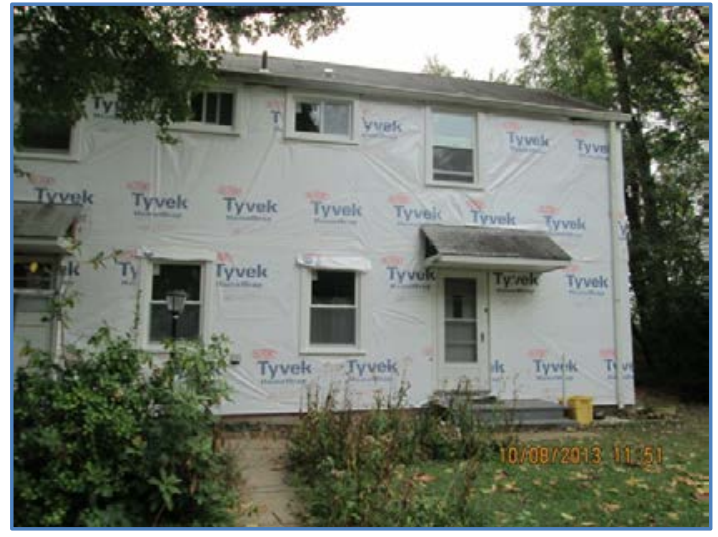

Figure 41. WRB installed over foam sheathing

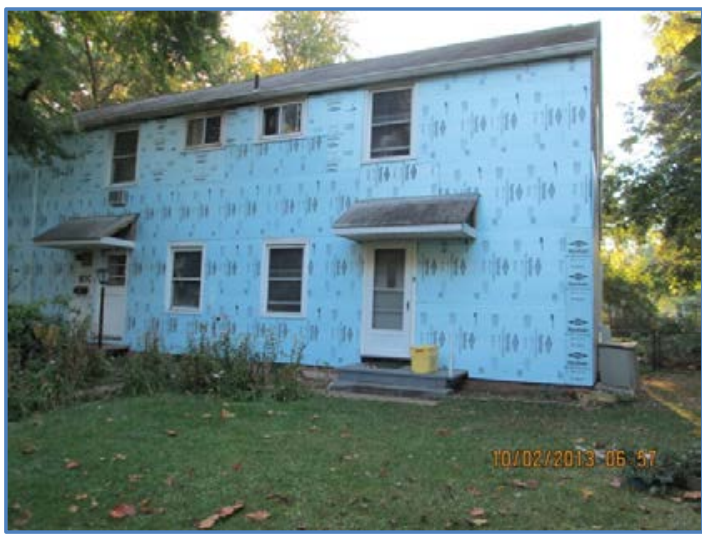

Figure 40. Foam sheathing installed

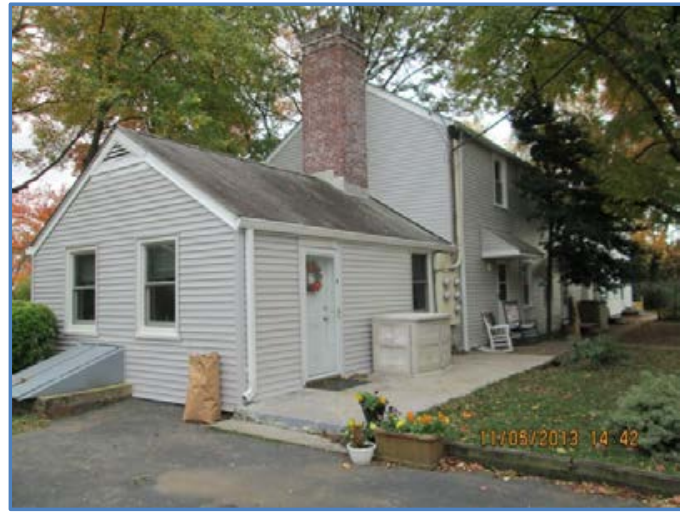

Figure 42. New siding installed following windows, doors, insulation, and WRB

\subsection{All Pilot Homes-Exhaust Fan Installation}

An important aspect to the energy upgrades was the installation of exhaust fans in the bathrooms of the pilot homes. Few fans had been installed and interior humidity could be quite high in winter in some homes, particularly the B homes. The exhaust fans were specified to reduce 
interior relative humidity, which was expected to increase during the heating season as building infiltration decreased after new efficiency features were installed. The fans and a controller allow the occupants to control operation and satisfactorily mitigate excess relative humidity.

Installing the fans was challenging, especially in the B homes where core drilling in the allconcrete envelope was necessary. Because these homes are constructed with block walls and poured concrete floor and roof decks, the least-cost approach was to core drill the bathroom wall. One such core wall bore is shown in Figure 43.



Figure 43. Core from B home for an exhaust fan

The through-the-wall fan selected for installation did not include an exterior hood cover; thus, the fan hood that was used (Figure 44) required an adaptor to match with the fan duct diameter. An air seal at the hood junction and around the fan and grille (Figure 45) was effected using tape and SPF, respectively. The fan was wired to a timer switch via surface wire placed in conduit, as was commonly the wiring detail in the B buildings.

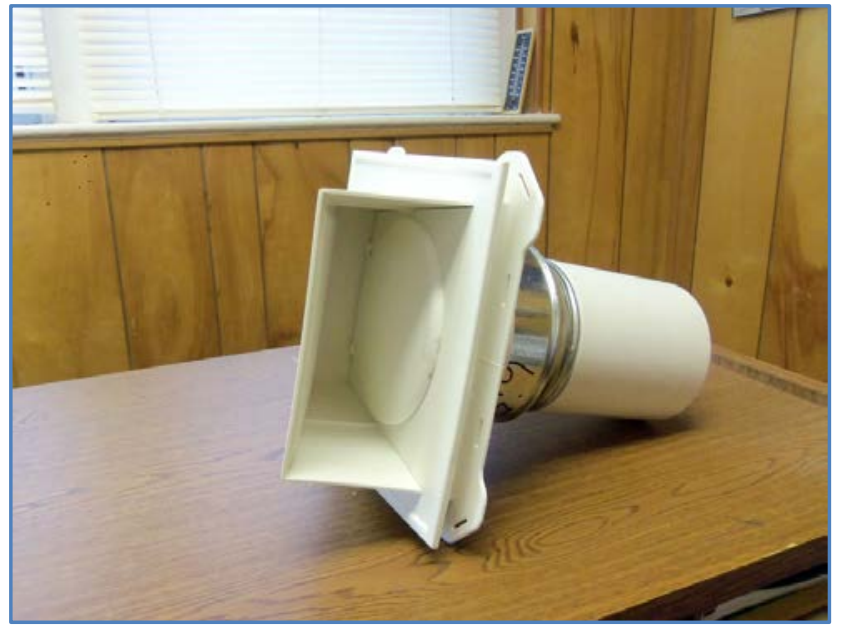

Figure 44. Exhaust fan hood and sleeve adaptor

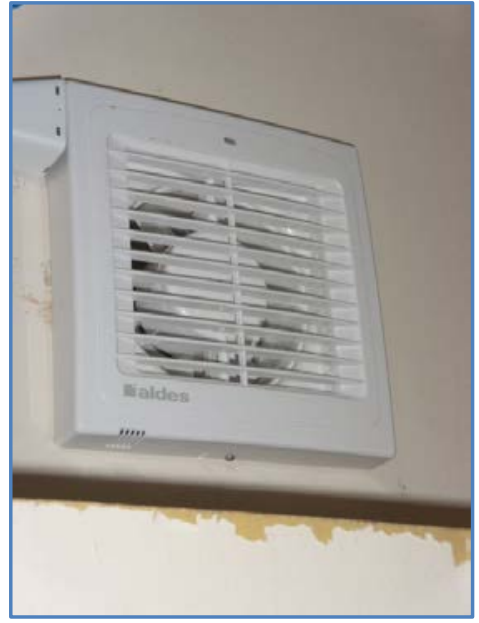

Figure 45. Interior exhaust fan grille 


\subsection{Energy Upgrade Feature and Monitoring Description}

A summary of the upgrades performed on each of the $28 \mathrm{GHI}$ homes in the pilot program is shown in Table 5. The nomenclature for each type of building and unit within the building is used throughout the analysis part of the investigation. Double horizontal lines in Table 5 denote the end of one building and start of another.

Table 5. Summary of Energy Features for Each Pilot Home

\begin{tabular}{|c|c|c|c|c|c|c|}
\hline $\begin{array}{l}\text { GHI Pilot } \\
\text { Home }\end{array}$ & $\begin{array}{c}\text { Crawlspace } \\
\text { Wall } \\
\text { Insulation }\end{array}$ & $\begin{array}{c}\text { Crawlspace } \\
\text { Floor } \\
\text { Insulation }\end{array}$ & $\begin{array}{c}\text { Wall } \\
\text { Insulation }\end{array}$ & $\begin{array}{c}\text { Attic } \\
\text { Insulation, } \\
\text { Air Seal }\end{array}$ & Windows & Bath Fan \\
\hline B-1 & $\checkmark$ & & & & $\checkmark$ & $\checkmark$ \\
\hline B-2 & $\checkmark$ & & & & $\checkmark$ & $\checkmark$ \\
\hline B-3 & $\checkmark$ & & & & $\checkmark$ & $\checkmark$ \\
\hline B-4 & $\checkmark$ & & & & $\checkmark$ & $\checkmark$ \\
\hline BV-1 & $\checkmark$ & & $\checkmark$ & & $\checkmark$ & $\checkmark$ \\
\hline B-5 & $\checkmark$ & & $\checkmark$ & & $\checkmark$ & $\checkmark$ \\
\hline B-6 & $\checkmark$ & & $\checkmark$ & & $\checkmark$ & $\checkmark$ \\
\hline BV-2 & $\checkmark$ & & $\checkmark$ & & $\checkmark$ & $\checkmark$ \\
\hline BV-3 & $\checkmark$ & & & & $\checkmark$ & $\checkmark$ \\
\hline BV-4 & $\checkmark$ & & & & $\checkmark$ & $\checkmark$ \\
\hline BV-5 & $\checkmark$ & & & & $\checkmark$ & $\checkmark$ \\
\hline BV-6 & $\checkmark$ & & & & $\checkmark$ & $\checkmark$ \\
\hline FB-1 & $\checkmark$ & & & $\checkmark$ & 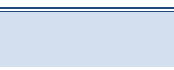 & $\checkmark$ \\
\hline FB-2 & $\checkmark$ & & & $\checkmark$ & $\checkmark$ & $\checkmark$ \\
\hline FB-3 & $\checkmark$ & & & $\checkmark$ & $\checkmark$ & $\checkmark$ \\
\hline FB-4 & $\checkmark$ & & & $\checkmark$ & $\checkmark$ & $\checkmark$ \\
\hline FB-5 & $\bar{\checkmark}$ & & & $\bar{\checkmark}$ & & \\
\hline FB-6 & $\checkmark$ & & & $\checkmark$ & $\checkmark$ & $\checkmark$ \\
\hline FB-7 & $\checkmark$ & & & $\checkmark$ & $\checkmark$ & $\checkmark$ \\
\hline FB-8 & $\checkmark$ & & & $\checkmark$ & $\checkmark$ & $\checkmark$ \\
\hline FV-1 & & $\checkmark$ & $\checkmark$ & $\checkmark$ & $\checkmark$ & * \\
\hline FV-2 & & $\checkmark$ & $\checkmark$ & $\checkmark$ & $\checkmark$ & $\checkmark$ \\
\hline FV-3 & & $\checkmark$ & $\checkmark$ & $\checkmark$ & $\checkmark$ & $\checkmark$ \\
\hline FV-4 & & $\checkmark$ & $\checkmark$ & $\checkmark$ & $\checkmark$ & $\checkmark$ \\
\hline FV-5 & & $\checkmark$ & $\checkmark$ & $\checkmark$ & $\checkmark$ & $\checkmark$ \\
\hline FV-6 & & $\checkmark$ & $\checkmark$ & $\checkmark$ & $\checkmark$ & $\checkmark$ \\
\hline FV-7 & & $\checkmark$ & $\checkmark$ & $\checkmark$ & $\checkmark$ & $\checkmark$ \\
\hline FV-8 & & $\checkmark$ & $\checkmark$ & $\checkmark$ & $\checkmark$ & $\checkmark$ \\
\hline
\end{tabular}

$\mathrm{B}$ is Block building (6 homes), uninsulated; BV is Block building with vinyl siding (6 homes); FB is Frame building with brick veneer ( 8 homes); FV is Frame building with vinyl siding ( 8 homes);

Note: Unit B4 had a ductless heat pump installed in fall 2012. 


\section{Infiltration Testing}

To quantify the convective losses from building leakage, each home was blower-door tested at the time it was originally assessed. Results indicate the volume of air leakage to the outside (or adjacent units) when the home is depressurized with a fan. Air leakage measurements indicate energy losses from unconditioned air leaking into the home or conditioned air leaking out of the home. Air leakage measurements are made at a standard pressure (50 Pascals) to compare buildings. The measurement of air leakage volume is divided by the volume of the house to establish a standard metric for each home - the number of house air changes per hour at the 50 Pascal pressure (ACH50).

An appropriate amount of fresh outdoor air is desirable for good indoor air quality, but excessive air leakage simply wastes energy. Building codes and standards differ on the maximum air leakage rate that is desirable in homes; generally, $7 \mathrm{ACH} 50$ is understood as a maximum target. New residential building codes for climate zone 4 require no more than $3 \mathrm{ACH} 50$, but a ventilation system must be installed to add fresh air into the house. Older homes are very leaky-10 ACH50 or higher is very common. This much leakage wastes energy and causes comfort problems. The goal of the GHI pilot program was to reduce energy-wasting leakage to around $7 \mathrm{ACH} 50$.

Largely because of the method and material of construction, the CMU B buildings were the most airtight as a group and required very little air sealing beyond the best practice details associated with installing new windows, doors, and fans. The frame walls of the FB and FV buildings allow air leakage between the house and the attic because of wiring holes through wall top plates and continuous balloon framing. In balloon-framed construction the exterior wall studs extend from the first floor to the second-level ceiling as one length. The sheathing on these homes is usually 1 $\times 6$ in. or $1 \times 8$-in. boards that allow air leakage where boards meet. The FV homes also had air leakage to the crawlspace via abandoned wiring holes and gaps in the wood flooring's tongueand-groove joints. (The flooring served as sheathing and finished floor.) The closed-cell SPF installed at the crawlspace ceiling in November 2011 should have stopped air leakage through the floor. In fact, the FV and FB homes showed an average 15\% improvement in air sealing after the crawlspace insulation was installed.

Table 6 summarizes the results of all blower door tests conducted on the homes after the floor insulation was upgraded (November 2011) in the FV homes, the attic insulation upgrades (November 2012) in the FB and FV homes, and finally the window and wall upgrades (November 2013) performed to some extent in all pilot homes. A lower ACH50 number indicates less air leakage into and out of the home.

For each unit, an unguarded blower door test was performed to first measure total house leakage, and then a modified guarded blower door test ${ }^{3}$ was performed with the adjacent unit(s)

\footnotetext{
${ }^{3}$ In this case, a modified guarded test was performed that refers to a test with one adjacent unit at a time depressurized, which eliminates any leakage between units. The leakage measured in a guarded test will be the leakage to outside.
} 
depressurized to measure net leakage to outdoors. All reported blower door test results are net leakage to outdoors (Table 6).

Table 6. Results of Guarded Blower Door Testing-Net Leakage to the Outside

\begin{tabular}{|c|c|c|c|c|c|}
\hline Pilot Home & $\begin{array}{c}\text { Original } \\
\text { Test-In } \\
\text { Data } \\
\left(\mathrm{ACH}_{50}\right) \\
\end{array}$ & $\begin{array}{l}\text { Following } \\
\text { Crawlspace } \\
\text { Upgrades } \\
\left(\mathrm{ACH}_{50}\right)\end{array}$ & $\begin{array}{l}\text { Following } \\
\text { Attic } \\
\text { Upgrades } \\
\left(\text { ACH }_{50}\right) \\
\end{array}$ & $\begin{array}{c}\text { Following } \\
\text { Window and } \\
\text { Wall Upgrades } \\
\left(\mathrm{ACH}_{50}\right)\end{array}$ & $\begin{array}{c}\text { Percent } \\
\text { Change } \\
\text { From } \\
\text { Original }\end{array}$ \\
\hline B-1 & 4.7 & & & 2.7 & $43 \%$ \\
\hline B-2 & 3.3 & & & 2.9 & $13 \%$ \\
\hline B-3 & 2.4 & & & 1.7 & $30 \%$ \\
\hline B-4 & 4.8 & & & 2.9 & $40 \%$ \\
\hline BV-1 & 7.2 & & & 5.9 & $18 \%$ \\
\hline B-5 & 4.3 & & & 2.8 & $34 \%$ \\
\hline B-6 & 8.4 & & & 4.3 & $48 \%$ \\
\hline BV-2 & 4.8 & & & 3.2 & $33 \%$ \\
\hline BV-3 & 7.5 & & & 4.8 & $36 \%$ \\
\hline BV-4 & 3.5 & & & 3.2 & $10 \%$ \\
\hline BV-5 & 4.3 & & & 3.6 & $17 \%$ \\
\hline BV -6 & 4.0 & & & 2.9 & $26 \%$ \\
\hline FB-1 & 10.4 & & 8.8 & 9.2 & $11 \%$ \\
\hline FB-2 & 6.8 & & 6.4 & 6.5 & $4 \%$ \\
\hline FB-3 & 7.4 & & 6.4 & 5.8 & $21 \%$ \\
\hline FB-4 & 8.0 & & 7.7 & 7.2 & $10 \%$ \\
\hline FB-5 & 6.1 & & 5.9 & 6.2 & $-2 \%$ \\
\hline FB-6 & 8.8 & & 7.4 & 7.8 & $11 \%$ \\
\hline FB-7 & 11.9 & & 10.2 & 10.0 & $16 \%$ \\
\hline FB-8 & 5.5 & & 5.4 & 5.5 & $0 \%$ \\
\hline FV-1 & 9.7 & 9.6 & 8.6 & 7.4 & $24 \%$ \\
\hline FV-2 & 13.1 & 10.7 & 8.4 & 8.5 & $35 \%$ \\
\hline FV-3 & 9.3 & 9.7 & 8.4 & 6.8 & $27 \%$ \\
\hline FV-4 & 14.1 & 10.6 & 10.5 & 8.6 & $39 \%$ \\
\hline FV-5 & 14.0 & 13.3 & 11.4 & 10.4 & $26 \%$ \\
\hline FV-6 & 14.8 & 8.3 & 7.0 & 5.8 & $61 \%$ \\
\hline FV-7 & 10.1 & 9.2 & 7.9 & 7.1 & $30 \%$ \\
\hline FV-8 & 11.2 & 10.4 & 9.5 & 6.8 & $39 \%$ \\
\hline All Block & 4.9 & & & 3.4 & $31 \%$ \\
\hline Frame-Brick & 8.1 & & 7.3 & 7.3 & $10 \%$ \\
\hline Frame-Vinyl & 12.0 & 10.2 & 9.0 & 7.7 & $36 \%$ \\
\hline
\end{tabular}

Note: Windows were not replaced in FB-1 and FB-5. Bath fans were added to the homes, which will slightly add to infiltration losses. 
After the floor was insulated in the FV buildings, the average reduction in air infiltration rates was about $15 \%$ across all eight FV homes. After the crawlspace was air sealed, the range of reduction was quite large; one home sustained a small increase in infiltration rate, a few homes experienced little change, and one home retested with a large decrease in infiltration. However, following the attic air sealing and insulation upgrades all the FV homes showed a decrease in the infiltration rate compared to the original tests; the overall average reduction was $26 \%$. For the FB homes, the average reduction in the infiltration rate was $10 \%$ after the attic upgrades.

After the window, door, and wall insulation upgrades, the final infiltration tests showed a significant decrease in infiltration rates across all homes. Twenty-two of the 28 homes remained at or achieved the $7 \mathrm{ACH} 50$ or lower goal. Homes with limited air sealing opportunities caused by inaccessibility in additions or attics had higher air leakage rates. Figure 46 graphically summarizes the infiltration test results.

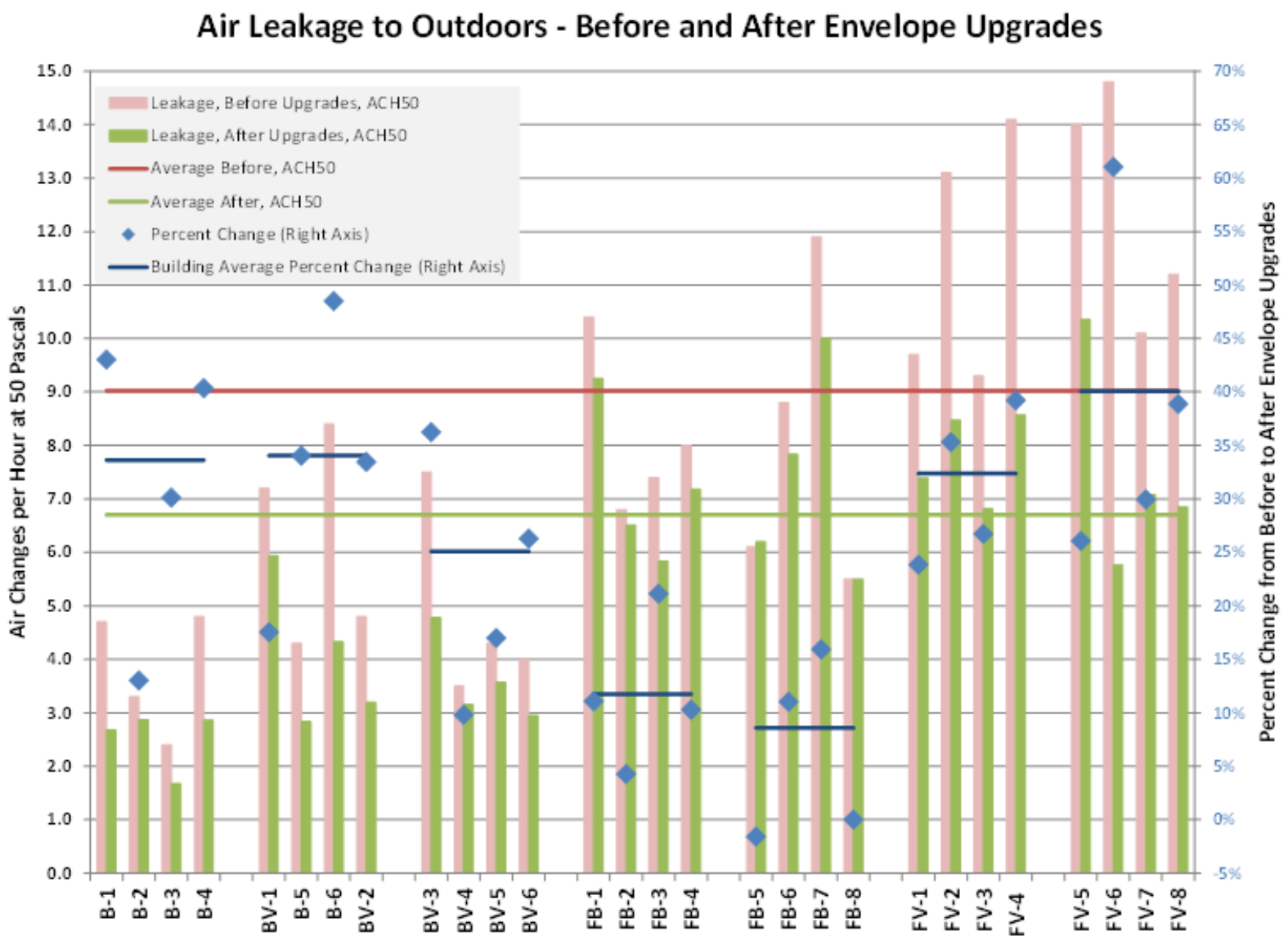

Figure 46. Graphical representation of air leakage in pilot homes 


\section{Heating Season Comparison}

Comparing energy data gathered over multiple heating seasons requires an analysis of the severity of the heating season during which the data are gathered. A review of average temperature data over a span of three winter periods shows that not all heating seasons are alike. The variations between winter seasons are shown in Figure 47 (2010-2011), Figure 48 (20112012), Figure 49 (2012-2013), and Figure 50 (2013-2014) range from below normal to much above normal the next winter season and back to above normal during the third winter period to below normal in the most recent winter period (National Oceanic and Atmospheric Administration). For the 2013-2014 heating season, the time period is 1 month earlier to keep the similar formatting in previous years.

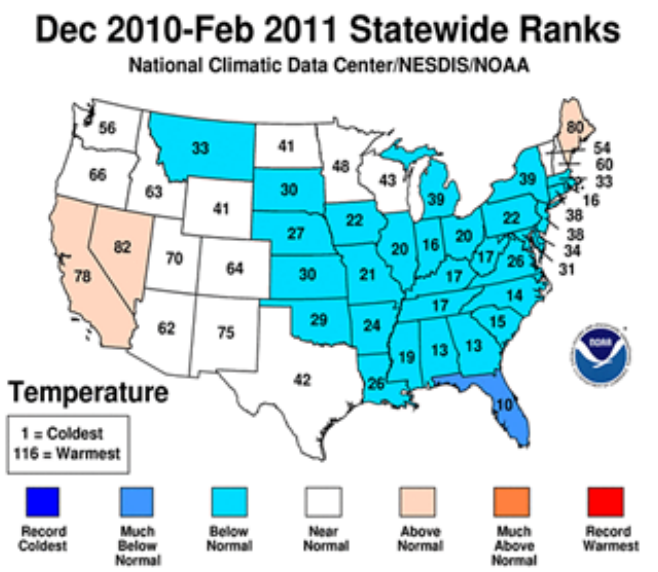

Figure 47. NOAA heating ranks-2010-2011

Dec 2012-Feb 2013 Statewide Ranks National Climatic Data Center/NESDIS/NOAA

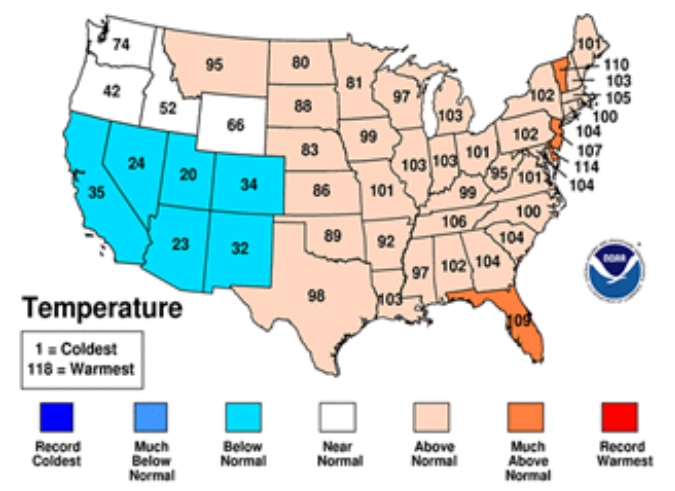

Figure 49. NOAA heating ranks-2012-2013
Dec 2011-Feb 2012 Statewide Ranks National Climatic Data Center/NESDIS/NOAA

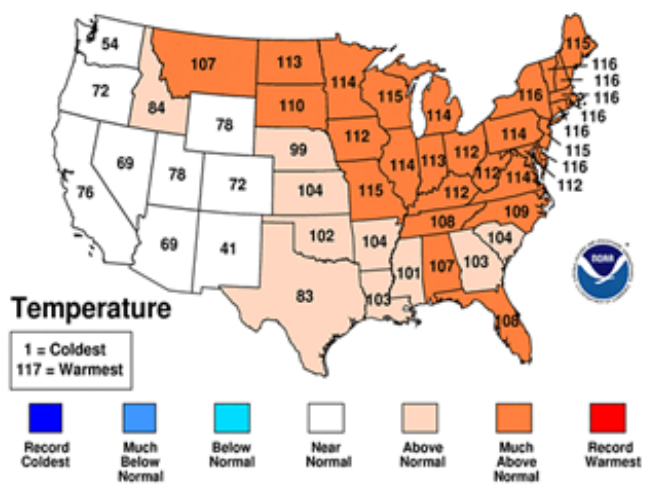

Figure 48. NOAA heating ranks-2011-2012

\section{Nov 2013-Jan 2014 Statewide Ranks} National Climatic Data Center/NESDIS/NOAA

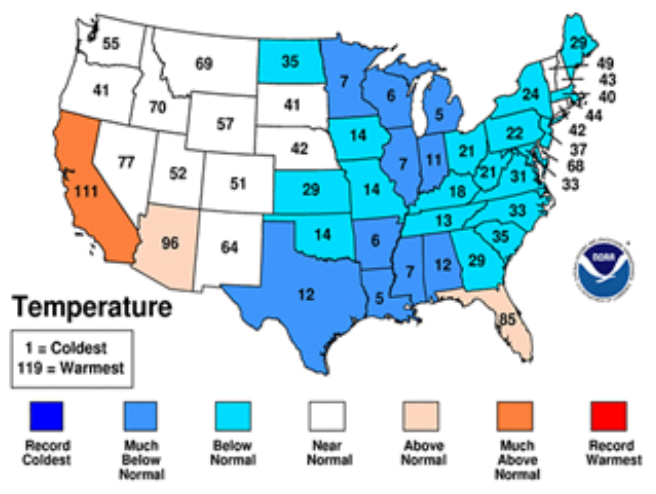

Over the past 4 years of the pilot program, GHI members experienced significantly different heating seasons during which the energy use for heating an occupied home was also expected to vary considerably. Therefore, temperature severity was commonly reported in context with energy use for heating. Calculating heating degree-days (HDDs) is a common method used to 
establish a perspective for gauging energy usage for heating a home. To calculate an HDD the average of the daily maximum and daily minimum temperatures is subtracted from $65^{\circ} \mathrm{F}$ and the difference is aggregated throughout the heating season. The more HDDs in a season, the colder the daily average temperatures are. The baseline used to compute HDDs is $65^{\circ} \mathrm{F}$, which is a moderate temperature thought to require neither supplemental heating nor cooling. The weather data for this report were obtained from a National Weather Service station located at College Park Airport, which is within 5 miles of the GHI project center (station KCGS) and verified to the data from measurements made near the GHI main office. Table 7, Table 8, and Figure 51 summarize the weather data for each of the four heating seasons monitored through Phases 1 and 2 of the pilot program.

Table 7. Monthly Ambient Temperature for Four Heating Seasons

\begin{tabular}{|c|c|c|c|c|}
\hline & $\begin{array}{c}\text { Average } \\
\text { Temperature } \\
{ }^{\circ} \mathrm{F}, \mathbf{2 0 1 0}-\mathbf{2 0 1 1}\end{array}$ & $\begin{array}{c}\text { Average } \\
\text { Temperature } \\
{ }^{\circ} \mathrm{F}, \mathbf{2 0 1 1 - 2 0 1 2}\end{array}$ & $\begin{array}{c}\text { Average } \\
\text { Temperature } \\
{ }^{\circ} \mathrm{F}, \mathbf{2 0 1 2}-\mathbf{2 0 1 3}\end{array}$ & $\begin{array}{c}\text { Average } \\
\text { Temperature } \\
{ }^{\circ} \mathrm{F}, \mathbf{2 0 1 3}-\mathbf{2 0 1 4}\end{array}$ \\
\hline October & 59.8 & 56.6 & 60.0 & 59.9 \\
\hline November & 48.6 & 51.2 & 44.3 & 44.9 \\
\hline December & 34.8 & 43.3 & 44.7 & 41.4 \\
\hline January & 33.1 & 39.6 & 39.4 & 29.9 \\
\hline February & 41.3 & 41.9 & 37.6 & 35.4 \\
\hline March & 46.5 & 55.4 & 43.4 & 40.4 \\
\hline April & 60.2 & 55.7 & 57.6 & 54.2 \\
\hline Average & 46.3 & 49.1 & 46.7 & 43.7 \\
\hline
\end{tabular}

Table 8. Monthly HDDs for Four Heating Seasons

\begin{tabular}{c|c|c|c|c}
\hline & $\begin{array}{c}\text { Monthly HDDs } \\
\text { 2010-2011 }\end{array}$ & $\begin{array}{c}\text { Monthly HDDs } \\
\text { 2011-2012 }\end{array}$ & $\begin{array}{c}\text { Monthly HDDs } \\
\text { 2012-2013 }\end{array}$ & $\begin{array}{c}\text { Monthly HDDs } \\
\mathbf{2 0 1 3}-\mathbf{2 0 1 4}\end{array}$ \\
\hline October & 191 & 264 & 143 & 217 \\
November & 493 & 413 & 629 & 609 \\
December & 940 & 676 & 626 & 736 \\
January & 993 & 787 & 795 & 1089 \\
February & 666 & 671 & 797 & 828 \\
March & 570 & 314 & 667 & 761 \\
April & 213 & 304 & 255 & 338 \\
Total & $\mathbf{4 , 0 6 4}$ & $\mathbf{3 , 4 2 7}$ & $\mathbf{3 9 1 1}$ & $\mathbf{4 5 7 8}$ \\
\hline
\end{tabular}

HDDs represent the number of degrees that a day's average temperature is below $65^{\circ} \mathrm{F}$, in this table summed over a monthly period. For example, October 2010 with 191 HDDs averaged $6.2^{\circ} \mathrm{F}$ per day below $65^{\circ} \mathrm{F}$; January 2014 with $1089 \mathrm{HDDs}$ averaged $35.1^{\circ} \mathrm{F}$ per day below $65^{\circ} \mathrm{F}$. 
For the heating period analyzed, the second winter season had about $20 \%$ fewer HDDs than the first season, the third heating season had about 4\% fewer HDDs than the first season, and this last heating season had about $9 \%$ more HDDs than the baseline first heating season.

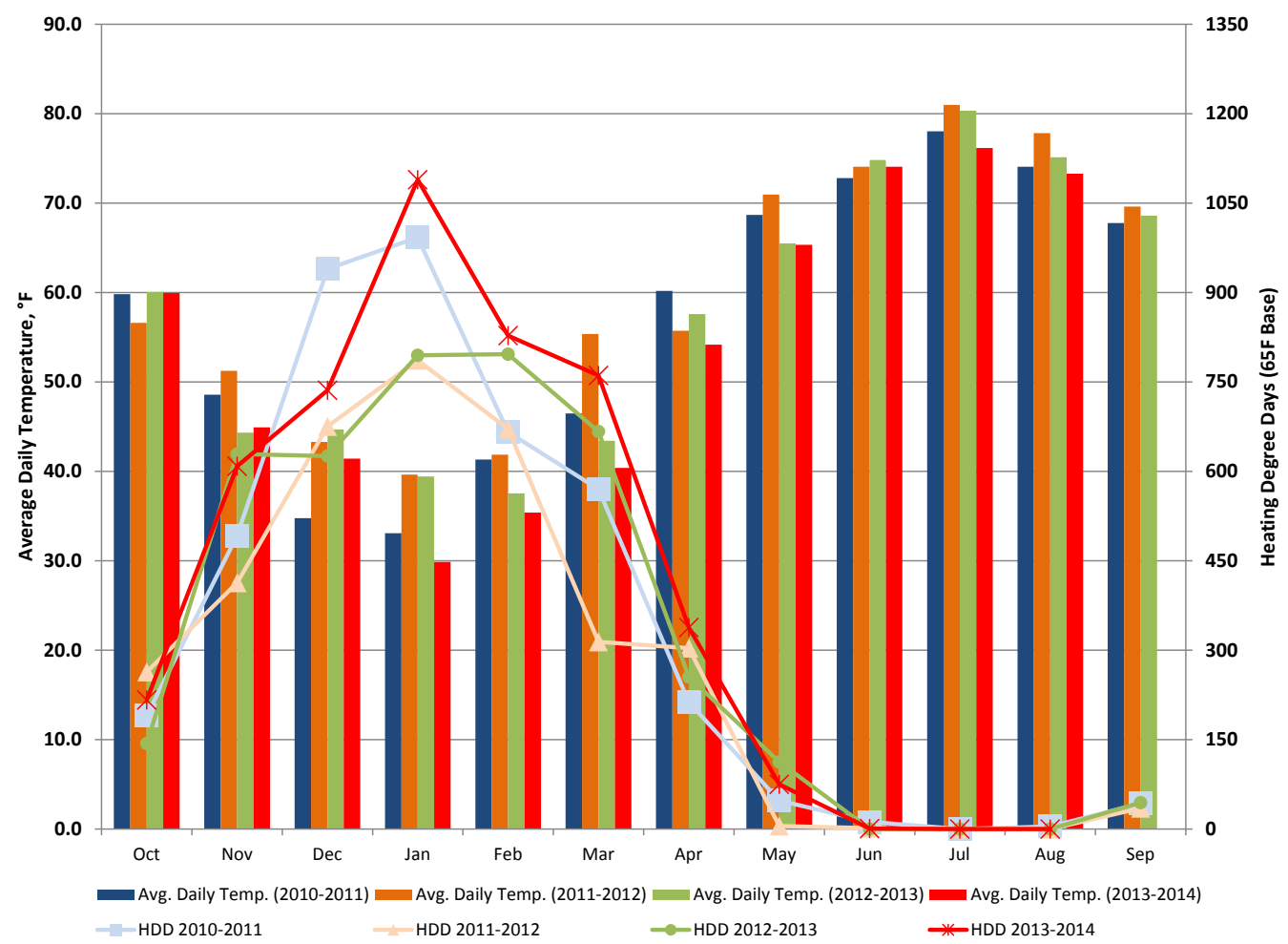

Figure 51. Graphical representation of ambient weather factors 


\section{Monitored Data-Indoor Temperature and Energy Use}

The GHI pilot program has now been through four heating seasons that have been monitored to catalog energy use, interior temperatures, and relative humidity. The baseline heating season (2010-2011) was the second most severe that the area has seen in the last 4 years. This latest heating season had colder average temperatures than the previous three winters. The recorded indoor conditions (temperature and humidity) and the measured energy use during the winter periods followed several phases of building improvements that were implemented in the homes. A summary of improvements for each unit by construction type is covered in Table 2 and Appendix B. An overall summary of the building improvements made before each heating season include:

- Season 1, 2010-2011: baseline year, no improvements made

- Season 2, 2011-2012: crawlspace improvements to all 28 pilot homes

- Season 3, 2012-2013: attic upgrades to 16 pilot homes (FB and FV only), one ductless (mini-split) heat pump installed in one block home

- Season 4, 2013-2014: window upgrades in all pilot homes, exterior insulation added to FV (8) homes and one block home building (four homes-BV-1, B-5, B-6, and BV-2).

\subsection{Monitoring Summary}

Temperature and humidity were monitored in each home on the first and second floors and in the basement where applicable (BV-5 and BV-6). Crawlspaces were also monitored. Because the pilot study had 28 homes, an effort was made to incorporate a wireless system to record temperatures. The first system selected consisted of wireless transmitters from Onset, the Hobo ZW series of data loggers. These loggers communicated with a receiver that was located in the crawlspace of the homes and required biweekly data downloads via a site visit. This technology proved to be somewhat unreliable and these sensors were eventually replaced by wireless sensors from Omnisense. The Omnisense sensors communicate with a gateway that was installed in each building. The gateway connects to the Internet and transmits data to online storage immediately. This technology obtained a much more reliable and consistent data stream.

Energy data were recorded through use of Wattnode energy transducers that were installed in the electrical panel. Current transformers connected to specific circuits were used to measure the whole-house energy, the primary heating circuits, water heaters, and dryers. The pulse output was connected to a Campbell Scientific data logger that transmitted data to National Renewable Energy Laboratory offices. In addition to the energy data recorded, utility meters were generally read biweekly.

Not all homes could have direct energy monitoring because of the electrical panel's location; in many cases heating was supplied by portable heaters that could not be monitored. Therefore, the total energy use of the home was used as the primary energy metric for analysis. An estimate of heating energy was developed using swing season estimates of baseline energy use where the data were consistent. 
Energy data analysis is based on the measured electrical energy data and the electricity meter data. Measured electrical energy was reconciled with the utility meter data in all cases. Where measured data were not available for a particular home, the biweekly utility data were used.

All homes have EBB heaters. Some homes have wall thermostats to control some heaters; the rest of the heaters are controlled by an integral thermostat. One home has a ducted heat pump system and another home had a ductless heat pump that was installed before winter 2012. The homes are all-electric; natural gas is not available in the community.

The timeframe for the heating season analysis was December 1 through March 21, a period of 111 days. This timeframe was selected to minimize variations caused by warm periods when windows might be open for part of the day.

\subsection{Indoor Temperature Measurements in Pilot Homes}

All 28 pilot homes were instrumented with temperature and humidity recorders for four heating seasons beginning with 2010-2011. In most cases, the first-floor sensor was in the living room near a wall thermostat. The second-floor sensor was installed in the main bedroom. As expected, the variation in temperatures between levels varied widely among homes; therefore, an average of the first- and second-floor temperatures is summarized for the most useful information. Table 9 summarizes the indoor temperatures and relative humidity for each pilot home. The change in the average temperature from Season 1 (baseline) to each of the subsequent seasons is shown in the columns on the right. 
Table 9. Average Seasonal Indoor Temperature and Relative Humidity for Pilot Homes

\begin{tabular}{|c|c|c|c|c|c|c|c|c|c|c|c|}
\hline \multirow{3}{*}{$\begin{array}{l}\text { Pilot Home } \\
\text { Unit } \\
\text { I.D. }\end{array}$} & \multicolumn{8}{|c|}{$\begin{array}{c}\text { Heating Season Average Daily Temperatures and Relative Humidity } \\
\text { (December } 1 \text { Through March 21) }\end{array}$} & \multirow{2}{*}{\multicolumn{3}{|c|}{$\begin{array}{c}\text { Temperature Change } \\
\text { From Base }\end{array}$}} \\
\hline & \multicolumn{4}{|c|}{$\begin{array}{c}\text { Indoor Air Average of 1st and 2nd } \\
\text { Floor, }{ }^{\circ} \mathrm{F}\end{array}$} & \multicolumn{4}{|c|}{ Indoor Relative Humidity, \% } & & & \\
\hline & $\begin{array}{c}2010- \\
2011 \\
\end{array}$ & $\begin{array}{c}2011- \\
2012 \\
\end{array}$ & $\begin{array}{c}2012- \\
2013 \\
\end{array}$ & $\begin{array}{c}2013- \\
2014 \\
\end{array}$ & $\begin{array}{c}2010- \\
2011 \\
\end{array}$ & $\begin{array}{c}2011- \\
2012 \\
\end{array}$ & $\begin{array}{c}2012- \\
2013 \\
\end{array}$ & $\begin{array}{c}2013- \\
2014 \\
\end{array}$ & $\begin{array}{c}2011- \\
2012 \\
\end{array}$ & $\begin{array}{c}2012- \\
2013 \\
\end{array}$ & $\begin{array}{r}2013- \\
2014 \\
\end{array}$ \\
\hline B-1 & 69.9 & 68.3 & 70.0 & 71.9 & - & 42.2 & 40.1 & 42.5 & -1.5 & 0.1 & 2.1 \\
\hline B-2 & 68.5 & 68.0 & 67.9 & 66.9 & - & 43.1 & 43.2 & 45.2 & -0.5 & -0.6 & -1.6 \\
\hline B-3 & 59.9 & 63.2 & 64.8 & 61.0 & 67.5 & 66.7 & 68.4 & 73.0 & 3.3 & 4.9 & 1.1 \\
\hline B-4 & 72.0 & 71.5 & 71.5 & 72.5 & 32.1 & 43.2 & 41.8 & 44.3 & -0.6 & -0.5 & 0.5 \\
\hline B1/4 Crawl & 60.7 & 63.9 & 62.7 & 61.2 & 64.7 & 62.6 & 60.4 & 55.8 & 3.2 & 2.0 & 0.5 \\
\hline BV-1 & 66.3 & 66.0 & 66.7 & 68.2 & 44.3 & 49.1 & 49.2 & 45.0 & -0.3 & 0.4 & 1.9 \\
\hline B-5 & 57.4 & 58.5 & 61.4 & 70.3 & 63.4 & 62.1 & 62.4 & 43.8 & 1.1 & 4.0 & 12.9 \\
\hline B-6 & 62.1 & 65.8 & 62.3 & 66.4 & 48.3 & 45.1 & 43.9 & 46.9 & 3.8 & 0.3 & 4.4 \\
\hline BV-2 & 62.7 & 70.2 & 70.7 & 69.5 & 37.2 & 40.9 & 41.1 & 39.3 & 7.4 & 8.0 & 6.8 \\
\hline BV1/2 Crawl & 56.3 & 62.0 & 61.4 & 60.9 & - & 52.7 & 50.6 & 39.7 & 5.6 & 5.1 & 4.6 \\
\hline BV-3 & 68.7 & 69.0 & 69.2 & 70.4 & 42.8 & 48.8 & 42.0 & 46.1 & 0.3 & 0.5 & 1.7 \\
\hline BV-4 & 63.2 & 64.4 & 63.7 & 54.6 & 54.4 & 54.9 & 54.2 & 47.6 & 1.1 & 0.5 & -8.6 \\
\hline BV-5 & 68.7 & 70.5 & 69.0 & 69.3 & 29.1 & 40.0 & 42.4 & 38.8 & 1.8 & 0.2 & 0.5 \\
\hline BV-6 & 66.7 & 68.7 & 67.4 & 64.5 & 40.9 & 46.7 & 42.6 & 50.7 & 1.9 & 0.7 & -2.2 \\
\hline BV3/6 Crawl & 56.0 & 60.2 & 59.4 & 54.5 & 83.2 & 61.8 & 58.7 & 60.6 & 4.3 & 3.5 & -1.5 \\
\hline FB-1 & 69.8 & 70.9 & 69.7 & 71.8 & 26.0 & 30.8 & 32.6 & 36.5 & 1.1 & -0.2 & 2.0 \\
\hline FB-2 & 64.8 & 66.6 & 68.9 & 69.1 & 31.1 & 33.7 & 29.6 & 34.5 & 1.8 & 4.1 & 4.2 \\
\hline FB-3 & 66.5 & 68.3 & 68.5 & 65.6 & 39.1 & 46.8 & 39.8 & 40.1 & 1.8 & 2.0 & -1.0 \\
\hline FB-4 & 55.6 & 58.3 & 57.4 & 57.5 & 43.3 & 46.9 & 45.8 & 40.4 & 2.6 & 1.8 & 1.9 \\
\hline FB1/4 Crawl & 56.4 & 59.7 & 60.6 & 59.2 & 65.3 & 44.9 & 40.4 & 40.7 & 3.2 & 4.2 & 2.8 \\
\hline FB-5 & 65.4 & 67.7 & 66.8 & 62.8 & 35.8 & 44.5 & 40.5 & 42.3 & 2.2 & 1.4 & -2.6 \\
\hline FB-6 & 64.7 & 66.0 & 65.4 & 69.7 & 39.2 & 50.4 & 48.1 & 47.6 & 1.3 & 0.6 & 5.0 \\
\hline FB-7 & 52.2 & 57.3 & 56.3 & 52.8 & 37.7 & 45.5 & 41.4 & 40.2 & 5.0 & 4.0 & 0.5 \\
\hline FB-8 & 65.3 & 64.9 & 64.1 & 64.3 & 39.6 & 48.3 & 46.2 & 41.2 & -0.4 & -1.2 & -1.0 \\
\hline FB5/8 Crawl & 54.4 & 60.2 & 58.8 & 55.6 & 63.2 & 51.1 & 49.0 & 50.6 & 5.8 & 4.5 & 1.2 \\
\hline
\end{tabular}




\begin{tabular}{|c|c|c|c|c|c|c|c|c|c|c|c|}
\hline \multirow{2}{*}{$\begin{array}{c}\text { Pilot Home } \\
\text { Unit } \\
\text { I.D. }\end{array}$} & \multicolumn{8}{|c|}{$\begin{array}{c}\text { Heating Season Average Daily Temperatures and Relative Humidity } \\
\text { (December } 1 \text { Through March 21) }\end{array}$} & \multirow{2}{*}{\multicolumn{3}{|c|}{$\begin{array}{l}\text { Temperature Change } \\
\text { From Base }\end{array}$}} \\
\hline & \multicolumn{4}{|c|}{$\begin{array}{l}\text { Indoor Air Average of } 1 \text { st and } 2 \text { nd } \\
\text { Floor, }^{\circ} \mathbf{F}\end{array}$} & \multicolumn{4}{|c|}{ Indoor Relative Humidity, \% } & & & \\
\hline FV-1 & 60.0 & 63.4 & 66.4 & 69.7 & 43.6 & 45.5 & 38.8 & 37.3 & 3.5 & 6.4 & 9.7 \\
\hline FV-2 & 68.1 & 69.6 & 69.3 & 70.0 & 33.9 & 34.8 & 35.9 & 36.0 & 1.4 & 1.2 & 1.8 \\
\hline FV-4 & 68.9 & 67.2 & 67.7 & 69.1 & 35.9 & 41.0 & 39.5 & 41.7 & -1.6 & -1.2 & 0.2 \\
\hline FV1/4 Crawl & 50.7 & 55.6 & 54.5 & 53.3 & 75.0 & 71.2 & 72.8 & 70.3 & 4.9 & 3.8 & 2.6 \\
\hline FV-5 & 68.8 & 69.4 & 68.4 & 66.7 & 28.7 & 35.1 & 34.4 & 34.5 & 0.6 & -0.5 & -2.1 \\
\hline FV-6 & 64.3 & 63.2 & 59.8 & 62.8 & 37.2 & 38.9 & 46.8 & 44.5 & -1.1 & -4.6 & -1.6 \\
\hline FV-7 & 66.1 & 68.0 & 67.6 & 68.0 & 36.8 & 43.6 & 38.0 & 35.4 & 1.9 & 1.5 & 1.9 \\
\hline FV-8 & 63.1 & 64.8 & 62.5 & 63.7 & 34.8 & 46.5 & 48.2 & 45.4 & 1.7 & -0.6 & 0.6 \\
\hline
\end{tabular}

BV5 \& BV6 average includes basement; $\mathrm{n} / \mathrm{a}$ = data not available; Shaded rows indicate change in or no occupancy.

2010-2011 Heating Season truncated based on available data in some homes, subsequent heating seasons from December 1 through March 21.

* Rows shaded in yellow indicate homes omitted from the building averages. 
A summary of the temperatures and humidity for each building type for the heating period

December 1 through March 21, in the pilot program is shown in Table 10.

Table 10. Heating Period Average Indoor Temperature and Relative Humidity by Building Type

\begin{tabular}{c|c|c|c|c|c|c|c|c}
\hline & \multicolumn{3}{|c|}{ Indoor Temperature } & \multicolumn{3}{c}{ Indoor Relative Humidity } \\
\cline { 2 - 9 } & $\begin{array}{c}\text { Season } \\
\mathbf{1}\end{array}$ & $\begin{array}{c}\text { Season } \\
\mathbf{2}\end{array}$ & $\begin{array}{c}\text { Season } \\
\mathbf{3}\end{array}$ & $\begin{array}{c}\text { Season } \\
\mathbf{4}\end{array}$ & $\begin{array}{c}\text { Season } \\
\mathbf{1}\end{array}$ & $\begin{array}{c}\text { Season } \\
\mathbf{2}\end{array}$ & $\begin{array}{c}\text { Season } \\
\mathbf{3}\end{array}$ & $\begin{array}{c}\text { Season } \\
\mathbf{4}\end{array}$ \\
\hline B Uninsulated & 68.1 & 68.4 & 67.9 & 69.4 & 40.2 & 43.4 & 42.3 & 44.7 \\
\hline BV & 66.6 & 68.9 & 68.9 & 69.3 & 38.4 & 44.7 & 43.7 & 42.3 \\
FB & 64.6 & 66.1 & 65.8 & 65.8 & 36.3 & 43.0 & 40.4 & 40.4 \\
\hline FV & 66.0 & 66.7 & 65.9 & 67.8 & 36.0 & 40.9 & 40.8 & 39.1 \\
\hline Average (23 of 28) & 66.1 & 67.2 & 66.8 & 67.6 & 37.1 & 42.8 & 41.5 & 41.4 \\
\hline Average Outdoor T & 38.4 & 44.1 & 41.0 & 36.1 & & & & \\
\hline HDDs & $\mathbf{2 , 9 5 3}$ & $\mathbf{2 , 3 5 1}$ & $\mathbf{2 , 6 5 3}$ & $\mathbf{3 , 2 0 1}$ & & & & \\
\hline
\end{tabular}

\subsection{Energy Use Data}

A general rollup of the total energy use over the four heating seasons of the pilot program is shown in Table 11. As indicated previously, the time period for the heating season is from December 1 through March 21. The four heating seasons were differentiated as:

- Season 1 -Baseline season

- Season 2-Crawlspace upgrades in all pilot homes

- Season 3-Attic upgrades in FB (eight) and FV (eight) homes - one B/uninsulated in which was installed a ductless heat pump

- Season 4-window upgrades in all homes, exterior insulation in FV and on four of the 12 B homes.

Table 11. Measured Energy Use in Pilot Homes Over Four Heating Seasons

\begin{tabular}{c|c|c|c|c|c}
\hline \multirow{2}{*}{ Unit Type } & \multirow{2}{*}{$\begin{array}{c}\text { No. of } \\
\text { Units }\end{array}$} & \multicolumn{4}{|c}{ Average/Home Actual Energy Use (kWh) } \\
\cline { 3 - 6 } & 4 & 8,414 & 5,938 & 6,391 & 6,991 \\
\hline B, Uninsulated & 4 & 8,275 & 6,722 & 8,245 & 7,786 \\
BV & 7 & 6,179 & 4,591 & 4,997 & 5,403 \\
FB & 8 & 5,431 & 3,838 & 4,186 & 4,496 \\
\hline FV & & \multicolumn{4}{|c}{} \\
\hline
\end{tabular}

Notes:

Seasonal period is from December 1 through March 21.

Five homes are not included in the study because of very uncommon use patterns or changes in occupancy. 
The data in Table 11 represent actual energy use without normalization to any weather or indoor temperature factors. As noted from the weather data previously, Season 2 was much milder than any of the other heating seasons. Also, Season 4 was the coldest on average of the four heating seasons.

The data need to be normalized to compare performance across seasons, in particular to evaluate the savings associated with the energy upgrades. For this report, normalization to HDDs and to indoor-outdoor temperature difference is used to evaluate the energy use of each pilot home across seasons.

\subsubsection{Heating Energy Use}

Although an attempt was made to monitor the heating circuits in each home, portable space heaters were so common that much of the heating energy was missed. A combination of the measured heating circuits (where available) and the measured energy use during swing seasons (when little or no heating and cooling are used) were used to adjust the building energy data and estimate the heating energy. In cases where the monitored heating circuits were known to represent nearly all the heating energy, the correlations were excellent. Therefore, the methodology was used for all pilot homes. Table 12 shows the heating energy summary for the defined heating period of 111 days (December 1 through March 21) for each of the four winter periods.

Table 12. Estimated Heating Energy Use in Pilot Homes Over Four Heating Seasons

\begin{tabular}{c|c|c|c|c|c}
\hline \multirow{2}{*}{ Unit Type } & \multirow{2}{*}{ No. } & \multicolumn{4}{|c}{$\begin{array}{c}\text { Average/Home Estimated Heating Energy } \\
(\mathbf{k W h})\end{array}$} \\
\cline { 3 - 6 } & & Season 1 & Season 2 & Season 3 & Season 4 \\
\hline B, Uninsulated & 4 & 6,968 & 4,552 & 4,931 & 5,530 \\
BV & 4 & 6,095 & 4,542 & 5,605 & 5,505 \\
FB & 7 & 4,471 & 2,953 & 3,388 & 3,789 \\
FV & $\mathbf{8}$ & $\mathbf{3 , 5 5 5}$ & $\mathbf{2 , 3 0 1}$ & $\mathbf{2 , 4 1 8}$ & $\mathbf{2 , 6 9 7}$ \\
\hline
\end{tabular}

Notes:

Seasonal period is from December 1 through March 21.

Five homes were excluded from the study because of very uncommon use patterns or changes in occupancy.

\subsubsection{Heating Degree Day Normalization}

The simple ratio-based HDD normalization methodology uses a constant HDD value for all seasons applied to the normalization factor for each individual season. ${ }^{4}$ The chosen HDD constant is 3000, which for the period of the analysis (December 1 through March 21) represents about $66 \%-75 \%$ of all the annual HDD. HDD normalization uses the following formula:

$$
\mathrm{EHDD}_{3000 \mathrm{~s}}=\left(\mathrm{AE}_{\mathrm{s}} / \mathrm{HDD}_{\mathrm{s}}\right)^{*} 3000
$$

where

\footnotetext{
${ }^{4}$ For a more complete analysis of HDD normalization, refer to http://web.ornl.gov/sci/buildings/2012/1985\%20B3\%20papers/009.pdf (accessed 9/4/14)
} 
$\mathrm{EHDD}_{3000 \mathrm{~s}}=$ Energy use for $3000 \mathrm{HDD}$ in a particular season

$\mathrm{AE}_{\mathrm{s}}=$ Actual energy used in a particular season

$\mathrm{HDD}_{\mathrm{s}}=$ the heating degree days in a particular season.

An HDD normalization is most useful when the sample set is large. This methodology accounts for the changes in heating demand across seasons, but not for differences in interior temperatures. HDD normalization is commonly used because it uses readily available data; indoor temperature data across seasons are often unavailable. Table 13 summarizes the energy use of the pilot home types based on a normalized 3000 HDDs.

Table 13. HDD Normalized Heating Energy

\begin{tabular}{c|c|c|c|c|c}
\hline \multirow{2}{*}{ Unit Type } & \multirow{2}{*}{ No. } & \multicolumn{4}{|c}{$\begin{array}{c}\text { Average/Home Heating Energy 3000 HDD } \\
\text { Normalized, kWh }\end{array}$} \\
\cline { 3 - 6 } & & Season 1 & Season 2 & Season 3 & Season 4 \\
\hline B, Uninsulated, All & 4 & 7,080 & 5,808 & 5,576 & 5,183 \\
B1, B2 & 2 & 6,585 & 4,554 & 6,155 & 5,956 \\
B4 & 1 & 10,565 & 9,563 & 6,836 & 6,017 \\
B6 & 1 & 4,586 & 4,562 & 3,157 & 2,803 \\
BV, All & 4 & 6,193 & 5,796 & 6,338 & 5,159 \\
BV3, BV5 & 2 & 6,770 & 4,871 & 5,473 & 5,788 \\
FB, All & 7 & 4,543 & 3,769 & 3,831 & 3,551 \\
FV, All & $\mathbf{8}$ & $\mathbf{3 , 6 1 2}$ & $\mathbf{2 , 9 3 6}$ & $\mathbf{2 , 7 3 4}$ & $\mathbf{2 , 5 2 7}$ \\
\hline
\end{tabular}

All- - Homes in each building type, excluding five units with atypical occupancy

B1, B2 - block, original uninsulated, one outside and one inside unit, no wall insulation added B5-block, original uninsulated, interior unit, exterior insulation added during Phase 2 upgrades B4-block, uninsulated, no wall insulation added, ductless heat pump installed prior to Season 3 BV3, BV5 - block, original vinyl siding, one outside and one inside unit, no wall insulation added

Using the HDD normalized heating energy, Table 14 shows the heating energy savings by percent (for the analysis period), and Table 15 shows the savings in energy. 
Table 14. HDD Normalized Heating Energy Savings Over Base Year (\%)

\begin{tabular}{c|c|c|c|c}
\hline \multirow{2}{*}{ Unit Type } & \multicolumn{4}{|c}{ Average/Home Heating Energy HDD Normalized } \\
\cline { 2 - 5 } & Season 1 & Season 2 & Season 3 & Season 4 \\
\hline B, Uninsulated, All & - & $18 \%$ & $21 \%$ & $27 \%$ \\
B1, B2 & - & $31 \%$ & $7 \%$ & $10 \%$ \\
B4 & - & $9 \%$ & $35 \%$ & $43 \%$ \\
B6 & - & $1 \%$ & $31 \%$ & $39 \%$ \\
BV, All & - & $6 \%$ & $-2 \%$ & $17 \%$ \\
BV3, BV5 & - & $28 \%$ & $19 \%$ & $14 \%$ \\
FB, All & - & $17 \%$ & $16 \%$ & $22 \%$ \\
FV, All & - & $\mathbf{1 9} \%$ & $\mathbf{2 4 \%}$ & $\mathbf{3 0 \%}$ \\
\hline
\end{tabular}

All- - Homes in each building type, excluding five units with atypical occupancy

B1, B2 - block, original uninsulated, one outside and one inside unit, no wall insulation added

B6-block, original uninsulated, interior unit, exterior insulation added during Phase 2 upgrades

B4-block, uninsulated, no wall insulation added, ductless heat pump installed prior to season 3

BV3, BV5 - block, original vinyl siding, one outside and one inside unit, no wall insulation added

Table 15. HDD Normalized Heating Energy Savings Over Base Year (kWh)

\begin{tabular}{c|c|c|c|c}
\hline \multirow{2}{*}{ Unit Type } & \multicolumn{4}{|c}{ Average/Home Heating Energy Normalized } \\
& \multicolumn{4}{c}{ Savings (kWh) } \\
\cline { 2 - 5 } & Season 1 & Season 2 & Season 3 & Season 4 \\
\hline B, Uninsulated, All & - & 1,272 & 1,505 & 1,897 \\
B1, B2 & - & 2,031 & 430 & 630 \\
B4 & - & 1,002 & 3,729 & 4,548 \\
B6 & - & 24 & 1,429 & 1,783 \\
BV, All & - & 397 & -145 & 1,034 \\
BV3, BV5 & - & 1,899 & 1,296 & 982 \\
FB, All & - & 774 & 711 & 991 \\
FV, All & - & $\mathbf{6 7 5}$ & $\mathbf{8 7 7}$ & $\mathbf{1 , 0 8 4}$ \\
\hline
\end{tabular}

All - Homes in each building type, excluding five units with atypical occupancy

B1, B2 - block, original uninsulated, one outside and one inside unit, no wall insulation added

B6-block, original uninsulated, interior unit, exterior insulation added during Phase 2 upgrades

B4 - block, uninsulated, no wall insulation added, ductless heat pump installed prior to Season 3

BV3, BV5-block, original vinyl siding, one outside and one inside unit, no wall insulation added

\subsubsection{Temperature Difference Normalization and Take-Back Energy Use}

A known inaccuracy of the HDD normalization is the interior temperature variation across homes. The HDD normalization methodology assumes that the indoor temperature is the same in all cases; i.e., across homes and seasons. This assumption may work well with large groups of homes; however, it is less applicable to GHI homes. The large difference in construction types and the wide range of indoor temperatures make this assumption much less applicable. 
Many GHI homeowners have acknowledged that they set their thermostats lower than they might otherwise because of the high heating bills. This leads to the assumption that with lower costs for heating, homeowners would set their thermostats to a higher, more comfortable temperature. This assumption cannot be individually validated (many homes do not have central thermostats that control all the heating), but the measured data do provide perspective.

Using the average indoor and ambient temperatures for the heating period, the measured data can be normalized to this seasonal temperature difference. The methodology develops a factor based on the actual temperature difference for each season and then normalizes all homes and seasons to a $30^{\circ} \mathrm{F}$ temperature difference. A $30^{\circ} \mathrm{F}$ temperature difference is assumed from an average of $38^{\circ} \mathrm{F}$ outdoor temperature for the referenced period and a common $68^{\circ} \mathrm{F}$ interior temperature. This methodology is represented by the formula:

$$
\mathrm{EDT}_{30 \mathrm{~s}}=\left(\mathrm{AE}_{\mathrm{s}} /\left(\mathrm{T}_{\text {indoor }}-\mathrm{T}_{\text {ambient }}\right) * 30\right.
$$

where

$\mathrm{EDT}_{30 \mathrm{~s}}=$ Energy use for $30^{\circ} \mathrm{F}$ temperature difference in a particular season

$\mathrm{AE}_{\mathrm{s}}=$ Actual energy used in a particular season

$\mathrm{T}_{\text {indoor }}=$ Average indoor temperature (for the season)

$\mathrm{T}_{\text {ambient }}=$ Average outdoor temperature (for the season)

Based on the temperature difference (TD) normalization, Table 16 summarizes the results for each building type.

Table 16. TD Normalized Heating Energy

\begin{tabular}{c|c|c|c|c|c}
\hline \multirow{2}{*}{ Unit Type } & \multirow{2}{*}{ No. } & \multicolumn{5}{|c}{\begin{tabular}{c} 
Average/Home Heating Energy 30 \\
Normalized, $\mathbf{F W h}$ \\
\cline { 3 - 6 }
\end{tabular}} & & Season 1 & Season 2 & Season 3 & Season 4 \\
\hline B, Uninsulated, All & 4 & 7,390 & 5,501 & 5,379 & 4,887 \\
\hline B1, B2 & 2 & 6,298 & 4,435 & 5,808 & 5,638 \\
B4 & 1 & 9,288 & 8,207 & 5,958 & 5,305 \\
B6 & 1 & 7,678 & 4,928 & 3,941 & 2,967 \\
BV, All & 4 & 8,009 & 5,512 & 6,084 & 4,983 \\
BV3, BV5 & 2 & 7,822 & 4,429 & 5,184 & 5,518 \\
\hline FB, All & 7 & 6,021 & 3,924 & 4,055 & 3,849 \\
FV, All & $\mathbf{8}$ & $\mathbf{4 , 5 1 5}$ & $\mathbf{3 , 0 8 1}$ & $\mathbf{2 , 8 7 5}$ & $\mathbf{2 , 5 4 9}$ \\
\hline
\end{tabular}

All - Homes in each building type, excluding five units with atypical occupancy

B1, B2 - block, original uninsulated, one outside and one inside unit, no wall insulation added

B6-block, original uninsulated, interior unit, exterior insulation added during Phase 2 upgrades

B4-block, uninsulated, no wall insulation added, ductless heat pump installed prior to Season 3

BV3, BV5-block, original vinyl siding, one outside and one inside unit, no wall insulation added

Using the HDD normalized heating energy, Table 17 shows the heating energy savings by percent (for the analysis period), and Table 18 shows the savings in energy. 
Table 17. TD Normalized Heating Energy Savings Over Base Year (\%)

\begin{tabular}{c|c|c|c|c}
\hline \multirow{2}{*}{ Unit Type } & \multicolumn{4}{|c}{$\begin{array}{c}\text { Average/Home Heating Energy HDD } \\
\text { Normalized Savings }\end{array}$} \\
\cline { 2 - 5 } & Season 1 & Season 2 & Season 3 & Season 4 \\
\hline B, Uninsulated, All & - & $26 \%$ & $27 \%$ & $34 \%$ \\
B1, B2 & - & $30 \%$ & $8 \%$ & $10 \%$ \\
B4 & - & $12 \%$ & $36 \%$ & $43 \%$ \\
B6 & - & $36 \%$ & $49 \%$ & $61 \%$ \\
BV, All & & $31 \%$ & $24 \%$ & $38 \%$ \\
BV3, BV5 & & $43 \%$ & $34 \%$ & $29 \%$ \\
FB, All & & $35 \%$ & $33 \%$ & $36 \%$ \\
FV, All & & $\mathbf{3 2 \%}$ & $\mathbf{3 6 \%}$ & $\mathbf{4 4 \%}$ \\
\hline
\end{tabular}

All-Homes in each building type, excluding five units with atypical occupancy

B1, B2 - block, original uninsulated, one outside and one inside unit, no wall insulation added

B5, B6 - block, original uninsulated, interior units, exterior insulation added during Phase 2 upgrades

B4-block, uninsulated, no wall insulation added, ductless heat pump installed prior to Season 3

BV3, BV5 - block, original vinyl siding, one outside and one inside unit, no wall insulation added

Table 18. TD Normalized Heating Energy Savings From Base Year (kWh)

\begin{tabular}{c|c|c|c|c}
\hline \multirow{2}{*}{ Unit Type } & \multicolumn{4}{|c}{$\begin{array}{c}\text { Average/Home Heating Energy 30 } \\
\mathbf{( k W h} \text {. F Normalized }\end{array}$} \\
\cline { 2 - 5 } & Season 1 & Season 2 & Season 3 & Season 4 \\
\hline B, Uninsulated, All & - & 1,889 & 2,011 & 2,503 \\
B1, B2 & - & 1,862 & 489 & 659 \\
B4 & - & 1,081 & 3,330 & 3,983 \\
B6 & - & 2,751 & 3,737 & 4,711 \\
BV, All & & 2,497 & 1,925 & 3,026 \\
BV3, BV5 & & 3,394 & 2,639 & 2,305 \\
FB, All & & 2,097 & 1,966 & 2,173 \\
FV, All & & 1,435 & 1,640 & 1,966 \\
\hline
\end{tabular}

All-Homes in each building type, excluding five units with atypical occupancy

B1, B2 - block, original uninsulated, one outside and one inside unit, no wall insulation added

B6-block, original uninsulated, interior unit, exterior insulation added during Phase 2 upgrades

B4-block, uninsulated, no wall insulation added, ductless heat pump installed prior to Season 3

BV3, BV5 - block, original vinyl siding, one outside and one inside unit, no wall insulation added

Because of the colder winter of Season 4 following the upgrades and the warmer temperatures in many of the homes, normalizing to temperature difference combines the effects of the winters with the variable indoor temperatures, and demonstrates a much higher level of savings.

Summarizing the energy use measurements for the pilot homes ( 24 of 28 units), the energy reduction resulting from the envelope upgrades is obvious (Table 19). 
Table 19. Summary Heating Energy Use for Each Season, 23 of 28 Pilot Homes

\begin{tabular}{c|c|c|c}
\hline & \multicolumn{3}{|c}{ Heating Energy (kWh) } \\
\cline { 2 - 4 } & Actual Use & HDD Normalized & TD Normalized \\
\hline Season 1 (Base) & 111,982 & 113,784 & 139,868 \\
Season 2 & 75,457 & 96,287 & 96,166 \\
Season 3 & 85,204 & 96,348 & 97,243 \\
Season 4 & 92,235 & 86,443 & 86,811 \\
Season 4 Savings Over Base & $18 \%$ & $24 \%$ & $38 \%$ \\
\hline
\end{tabular}

Table 19 clearly demonstrates that overall across the pilot homes, the efficiency upgrades resulted in substantial energy savings. This is borne out even in actual consumption data, where the latest heating season was the most demanding in the study.

Breaking out each of the building types, Table 20 provides a comparative perspective on heating energy use and savings based on the building and upgrades. The project includes seven buildings, each with four attached units. The letter-identified header columns (A through I) indicate the units in a particular building type that are analyzed together. 
Table 20. Summary of Energy Savings Building Type and Upgrade

\begin{tabular}{|c|c|c|c|c|c|c|c|c|c|}
\hline & $\mathbf{A}$ & B & $\mathbf{C}$ & D & $\mathbf{E}$ & $\mathbf{F}$ & G & $\mathbf{H}$ & I \\
\hline $\begin{array}{c}\text { Building Type (Number of Units) } \\
\text { Unit ID and Location } \\
\text { Upgrade Features }\end{array}$ & 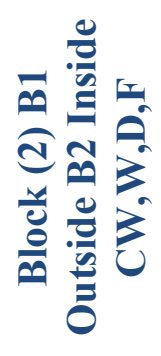 & 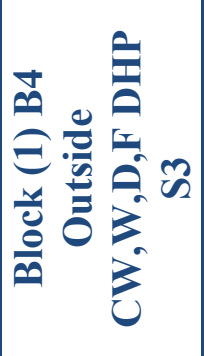 & 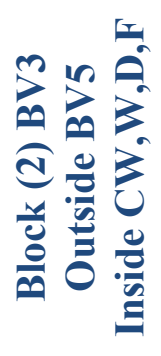 & 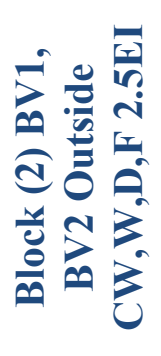 & 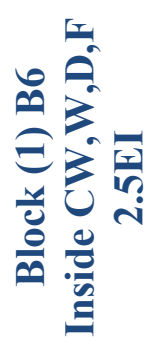 & 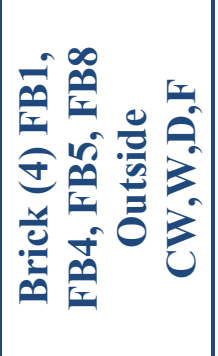 & 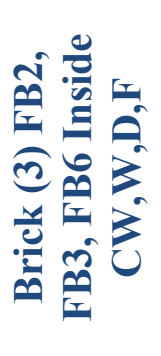 & 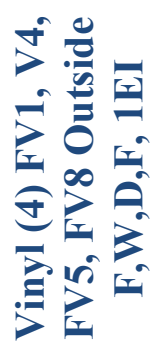 & 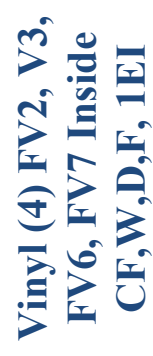 \\
\hline & \multicolumn{9}{|c|}{ Heating Energy, Actual } \\
\hline Season 1, Base Year, kWh & 12,962 & 10,398 & 13,325 & 11,054 & 4,513 & 19,282 & 12,012 & 16,499 & 11,937 \\
\hline Season 2, 2a Upgrades, kWh & 7,138 & 7,494 & 7,634 & 10,534 & 3,575 & 13,347 & 7,326 & 11,046 & 7,363 \\
\hline Season 3, 2b Upgrades, kWh & 10,886 & 6,045 & 9,680 & 12,738 & 2,792 & 13,679 & 10,039 & 12,289 & 7,055 \\
\hline Season 4, 2c Upgrades, kWh & 12,710 & 6,420 & 12,352 & 9,667 & 2,991 & 16,249 & 10,275 & 13,216 & 8,356 \\
\hline Season 4 Savings Over Base, \% & $2 \%$ & $38 \%$ & $7 \%$ & $13 \%$ & $34 \%$ & $16 \%$ & $14 \%$ & $20 \%$ & $30 \%$ \\
\hline Season 4 Savings Over Base, kWh & 253 & 3,978 & 973 & 1,387 & 1,522 & 3,034 & 1,737 & 3,283 & 3,581 \\
\hline \multirow[t]{2}{*}{ Average Savings Per Home, kWh } & 126 & 3,978 & 487 & 694 & 1,522 & 758 & 579 & 821 & 895 \\
\hline & \multicolumn{9}{|c|}{ Heating Energy $30^{\circ} \mathrm{F}$ Normalized } \\
\hline Season 1, Base Year, kWh & 12,595 & 9,288 & 15,645 & 16,392 & 7,678 & 25,803 & 16,345 & 21,830 & 14,292 \\
\hline Season 2, 2a Upgrades, kWh & 8,870 & 8,207 & 8,858 & 13,191 & 4,928 & 17,887 & 9,580 & 14,873 & 9,773 \\
\hline Season 3, 2b Upgrades, kWh & 11,617 & 5,958 & 10,368 & 13,969 & 3,941 & 17,084 & 11,303 & 14,691 & 8,312 \\
\hline Season 4, 2c Upgrades, kWh & 11,276 & 5,305 & 11,035 & 8,899 & 2,967 & 17,112 & 9,828 & 12,686 & 7,704 \\
\hline Season 4 Savings Over Base, \% & $10 \%$ & $43 \%$ & $29 \%$ & $46 \%$ & $61 \%$ & $34 \%$ & $40 \%$ & $42 \%$ & $46 \%$ \\
\hline Season 4 Savings Over Base, kWh & 1,319 & 3,983 & 4,610 & 7,493 & 4,711 & 8,691 & 6,517 & 9,143 & 6,589 \\
\hline \multirow[t]{2}{*}{ Average Savings Per Home, kWh } & 659 & 3,983 & 2,305 & 3,746 & 4,711 & 2,173 & 2,172 & 2,286 & 1,647 \\
\hline & \multicolumn{9}{|c|}{ Heating Energy 3000 HDD Normalized } \\
\hline Season 1, Base Year, kWh & 13,171 & 10,565 & 13,539 & 11,232 & 4,586 & 19,593 & 12,205 & 16,764 & 12,129 \\
\hline Season 2, 2a Upgrades, kWh & 9,109 & 9,563 & 9,741 & 13,442 & 4,562 & 17,031 & 9,349 & 14,095 & 9,395 \\
\hline Season 3, 2b Upgrades, kWh & 12,310 & 6,836 & 10,947 & 14,404 & 3,157 & 15,468 & 11,352 & 13,896 & 7,978 \\
\hline Season 4, 2c Upgrades, kWh & 11,912 & 6,017 & 11,576 & 9,060 & 2,803 & 15,228 & 9,630 & 12,386 & 7,832 \\
\hline
\end{tabular}




\begin{tabular}{|c|c|c|c|c|c|c|c|c|c|}
\hline & A & B & $\mathbf{C}$ & $\mathbf{D}$ & $\mathbf{E}$ & $\mathbf{F}$ & $\mathbf{G}$ & $\mathbf{H}$ & $\mathbf{I}$ \\
\hline $\begin{array}{c}\text { Building Type (Number of Units) } \\
\text { Unit ID and Location } \\
\text { Upgrade Features }\end{array}$ & 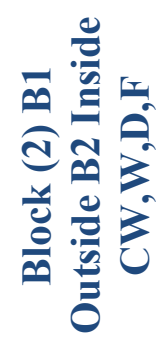 & 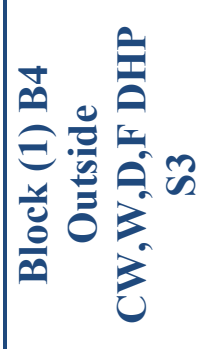 & 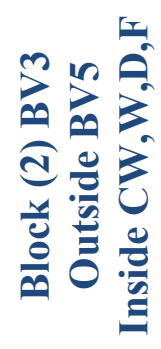 & 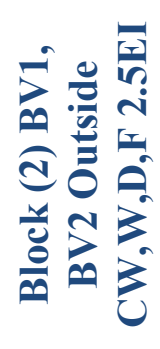 & 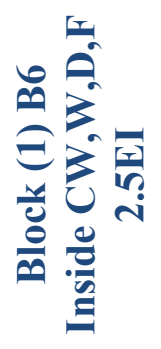 & 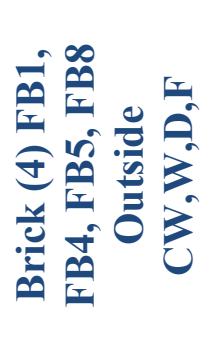 & 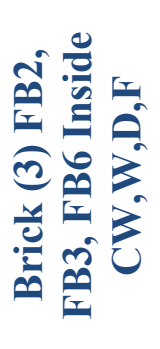 & 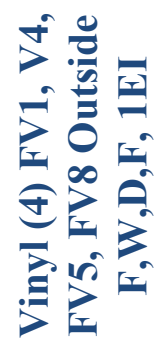 & 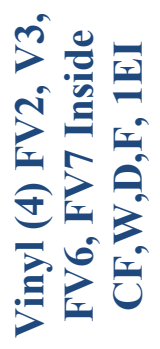 \\
\hline Season 4 Savings Over Base, \% & $10 \%$ & $43 \%$ & $14 \%$ & $19 \%$ & $39 \%$ & $22 \%$ & $21 \%$ & $26 \%$ & $35 \%$ \\
\hline Season 4 Savings Over Base, $\mathrm{kWh}$ & 1,259 & 4,548 & 1,963 & 2,172 & 1,783 & 4,364 & 2,575 & 4,378 & 4,298 \\
\hline Average Savings Per Home, kWh & 630 & 4,548 & 982 & 1,086 & 1,783 & 1,091 & 858 & 1,095 & 1,074 \\
\hline
\end{tabular}

CW-crawlspace walls; CF-crawlspace floor; W-windows; D-doors; F-bath vent fans;

2.5EI- 2.5-in. exterior insulation board; 1EI- 1-in. exterior insulation

Upgrades: 2a- crawlspace, 2b- attics, 2c- windows/doors/wall insulation where applicable

Note that BV5 has a basement foundation that was insulated similar to the crawlspace using wall insulation. 
Tables of the energy use in each pilot home across four heating periods are available in Appendix C.

The energy use summary outlined in Table 20 is divided into three sections: actual heating energy use, TD30, and normalized HDD heating energy use. Note that heating energy is estimated using a combination of measured and swing-season use. Heating energy use and savings are based on the analysis period December 1-March 21 in each heating season and generally represent a minimum level of savings for heating energy. In the following bullets summary results are given for the TD normalization; this approach accounts for the changing ambient conditions and the changing indoor temperature settings. Heating energy use results for GHI building types recorded after the pilot home upgrades and testing follow. Column data identified by the top header letter row and the middle table section Heating Energy, $30^{\circ} \mathrm{F}$ Normalized (in Table 20) were used.

- Column A: GHI uninsulated B buildings that had only crawlspace and window/door upgrades. This yielded a 10\% energy reduction, attributed primarily to the window/door upgrades and a reduction in infiltration.

- Column B: Same as column A but with a ductless heat pump added - a 43\% energy reduction, attributed primarily to the ductless heat pump and secondarily to the envelope improvements.

- Column C: GHI BV homes with $1 / 2$-in. of exterior insulation board between the furring. The homes had only crawlspace (BV3)/basement (BV5) and window/door upgrades, which yielded a $29 \%$ energy reduction, attributed primarily to the window upgrades and a reduction in infiltration.

- Column D: GHI BV homes (both end units) with $1 / 2$-in. of exterior insulation board between furring. The homes had crawlspace and window/door upgrades, all existing siding and insulation removed, and $2-1 / 2$ in. of exterior rigid insulation with new siding installed. These measures achieved a $46 \%$ energy reduction, attributed primarily to the wall insulation, window upgrades, and infiltration reduction.

- Column E: GHI B home (one interior unit), uninsulated, which had crawlspace and window/door upgrades and $2-1 / 2$ in. of rigid insulation added to the exterior, and new siding installed. This yielded a $61 \%$ energy reduction, attributed primarily to the wall insulation, window upgrades, and infiltration reduction.

- Column F: GHI FB (end units in two buildings) that had crawlspace, attic, and window/door upgrades. These improvements achieved a 34\% energy reduction, attributed to the infiltration reduction, attic insulation, and window upgrades.

- Column G: GHI FB (interior units in two buildings) that had crawlspace, attic, and window/door upgrades, which yielded a $40 \%$ energy reduction, attributed to the infiltration reduction, attic insulation, and window upgrades.

- Column H: GHI FV (end units in two buildings) that had crawlspace floor insulation and air sealing, attic, window/door, and 1 in. of exterior insulating sheathing upgrades. This achieved a $42 \%$ energy reduction, attributed to the infiltration reduction, attic and wall insulation, and window upgrades. 
- Column I: GHI FV (interior units in two buildings) that had crawlspace floor insulation and air sealing, attic, window/door, and 1 in. of exterior insulating sheathing upgrades. This yielded a $46 \%$ energy reduction, attributed to the infiltration reduction, attic and wall insulation, and window upgrades.

Table 21 summarizes the heating energy savings by the type of building in the pilot home program and combines the data from Table 20.

The data set also highlights the complexity of energy savings in existing homes, especially in the thermostat settings. That is, where high energy costs may have led to lower thermostat settings in winter to conserve energy, envelope improvements help to lower heating energy use and may therefore lead to a higher thermostat setting. This appears to be the case in some of the GHI homes (Figure 52) where the average indoor temperature is higher in the latest winter period after all of the envelope upgrades.

Table 21. Heating Energy Savings by Building Using Combined Measured Data

\begin{tabular}{c|c|c|c}
\hline \multirow{2}{*}{ Building Type (4 homes per building) } & Measurement & \multicolumn{2}{|c}{ Cost Savings } \\
\cline { 3 - 3 } & $\begin{array}{c}\text { Period kWh } \\
\text { Savings }\end{array}$ & $\begin{array}{c}\text { Measurement } \\
\text { Period HDD }\end{array}$ & $\begin{array}{c}\text { Simulation } \\
\text { HDD }^{\mathbf{c}}\end{array}$ \\
\hline $\begin{array}{c}\text { Uninsulated B Building With } \\
\text { Crawlspace, Windows, Bath Fan EEMs }\end{array}$ & $2,638(10 \%)$ & $\$ 396$ & $\$ 523$ \\
$\begin{array}{c}\text { BV Building With Crawlspace, } \\
\text { Windows, Bath Fan EEMs }\end{array}$ & $9,220(29 \%)$ & $\$ 1,383$ & $\$ 1,828$ \\
$\begin{array}{c}\text { Uninsulated BV Building With } \\
\text { Crawlspace, Windows, Walls With 2-1/2- }\end{array}$ & $16,916(53 \%)$ & $\$ 2,537$ & $\$ 3,353$ \\
in. Exterior Insulation, Bath Fan EEMs & & \\
$\begin{array}{c}\text { FB With Crawlspace, Attic, Windows, } \\
\text { Bath Fan EEMs }\end{array}$ & $8,691(37 \%)$ & $\$ 1,304$ & $\$ 1,723$ \\
\hline $\begin{array}{c}\text { FV With Crawlspace, Attic, Windows, 1- } \\
\text { in. Exterior Insulation, Bath Fan EEMs }\end{array}$ & $7,866(44 \%)$ & $\$ 1,180$ & $\$ 1,559$ \\
\hline
\end{tabular}

a This building configuration not simulated

${ }^{\mathrm{b}}$ Two homes uninsulated, two homes with vinyl siding, all upgraded with similar insulation and vinyl siding

${ }^{\mathrm{c}}$ Measured savings over period with 3,201 HDDs, Simulation HDD with 4,230 HDDs. 


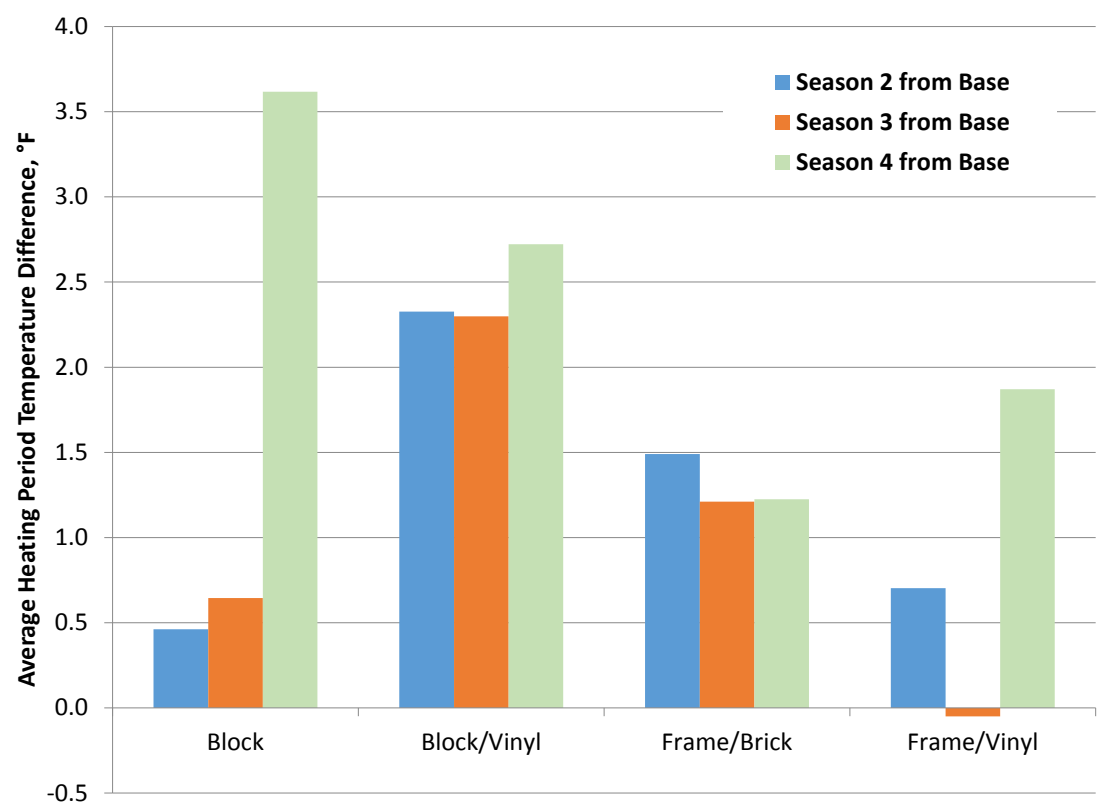

Figure 52. Average winter period temperature difference from base year 


\section{HVAC System Analysis for Phase 3 Retrofits}

One aspect of the energy upgrades for the GHI pilot program is an evaluation of heating system options. Currently the homes are heated with EBB heaters unless the homeowner has installed an alternative heating system. Typically the GHI cooperative is responsible for heating equipment, but it does not support (install or maintain) cooling equipment. In conjunction with the evaluation of the envelope upgrades, GHI wanted to consider alternatives to the EBB heating equipment.

The PHI BA team researched and analyzed alternative heating and cooling systems. PHI recently completed a report covering the technical perspective of HVAC performance for the GHI building committee. The report points out that it does not consider the comfort, livability, control, convenience, and resale of the units; these features' contributions to equipment solutions are best defined by the members. The report is contained in its entirety as Appendix D.

Air-source heat pumps and high-velocity delivery systems, ground-source heat pumps, ductless mini-split heat pumps, electric radiant panels, and EBB heat were all considered in the analysis. Propane, oil, and wood were rejected from consideration because of their high cost; natural gas was rejected because of the high cost of infrastructure expansion.

Heat gain and loss were calculated before and after the Phase 2 EEMs along with the estimated energy savings over an existing condition. Theoretical duct layouts were included in the report so that those costs could be estimated. The layouts will also help members visualize the changes to their homes' interiors posed by the ductwork bulkheads and the air handling equipment. Some of the cost estimates were derived from actual installations recently performed in other GHI members' homes. In other cases, estimates were derived from bids offered by various HVAC companies.

Table 22 contains the installed HVAC cost estimates that appear in the report.

A challenge for the community-wide effort is that most homes will require the smallest unit size manufactured, which typically is not manufactured in high efficiencies. On the other hand, a whole-building HVAC solution would have introduced a bookkeeping and allocation burden on GHI that it was reluctant to undertake.

The HVAC system analysis concludes that converting the EBB heat in the GHI homes is rarely cost-effective on purely an energy basis, even without envelope upgrades. The switch to a heat pump system, however, may be undertaken for comfort or long-term performance against rising utility prices. The switch to HVAC equipment, however, will incur much higher maintenance costs compared to EBB heating units. 
Table 22. Cost Estimates (Installed) for Heating Systems

\begin{tabular}{|c|c|c|c|c|}
\hline Type of System & Average Size & Efficiency & Estimated Cost & $\begin{array}{c}\text { Building } \\
\text { Type }\end{array}$ \\
\hline $\begin{array}{c}\text { Air-Source Heat } \\
\text { Pump }^{\text {a }}\end{array}$ & $18,000-24,000 \mathrm{Btu}$ & $\begin{array}{l}\text { 16 } \mathrm{SEER}^{\mathrm{b}} / \\
9.0 \mathrm{HSPF}^{\mathrm{c}}\end{array}$ & $\begin{array}{l}\$ 16,000- \\
\$ 18,000\end{array}$ & Any \\
\hline $\begin{array}{c}\text { Ground-Source Heat } \\
\text { Pump }\end{array}$ & $18,000-24,000 \mathrm{Btu}$ & $\begin{array}{c}18-27 \mathrm{EER}^{\mathrm{d}} / \\
4.5 \mathrm{COP}^{\mathrm{e}}\end{array}$ & $\$ 25,000$ & Any \\
\hline $\begin{array}{c}\text { Ground-Source Heat } \\
\text { Pump With Ductless } \\
\text { Fan Coils }\end{array}$ & $18,000-24,000 \mathrm{Btu}$ & $\begin{array}{c}18-27 \mathrm{EER} / \\
4.5 \mathrm{COP}\end{array}$ & $\begin{array}{l}\$ 23,000- \\
\$ 29,000\end{array}$ & Any \\
\hline $\begin{array}{c}\text { Ground-Source Heat } \\
\text { Pump With Ductless } \\
\text { Console }\end{array}$ & $18,000-24,000 \mathrm{Btu}$ & $\begin{array}{c}18-27 \mathrm{EER} / \\
4.5 \mathrm{COP}\end{array}$ & $\begin{array}{l}\$ 25,000- \\
\$ 40,000\end{array}$ & Any \\
\hline $\begin{array}{c}\text { Ductless Mini-Split } \\
\text { Heat Pump }\end{array}$ & $18,000-24,000$ Btu & 16 SEER/9.0 HSPF & $\begin{array}{l}\$ 10,000- \\
\$ 18,000\end{array}$ & Any \\
\hline $\begin{array}{l}\text { High-Velocity Split } \\
\text { System Heat Pumpa }\end{array}$ & 24,000 Btu & 15 SEER/8.2 HSPF & $\begin{array}{l}\$ 16,000- \\
\$ 18,000\end{array}$ & Any \\
\hline $\begin{array}{l}\text { Electric Radiant } \\
\text { Panels }^{f}\end{array}$ & $8-12 \mathrm{~kW}$ & $100 \%$ & $\$ 2,400-\$ 3,200$ & Any \\
\hline EBB Heat & $4-7 \mathrm{~kW}$ & $100 \%$ & $\$ 610-\$ 720$ & FV \\
\hline EBB Heat & $7-9 \mathrm{~kW}$ & $100 \%$ & $\$ 720-\$ 1,380$ & FB \\
\hline EBB Heat & $7-12 \mathrm{~kW}$ & $100 \%$ & $\$ 720-\$ 1,840$ & $\mathrm{~B}, \mathrm{BV}$ \\
\hline
\end{tabular}

${ }^{a}$ Highest efficiency available in the size.

${ }^{\mathrm{b}}$ Seasonal energy-efficiency ratio

${ }^{\mathrm{c}}$ Heating season performance factor

${ }^{\mathrm{d}}$ Energy-efficiency ratio

${ }^{\mathrm{e}}$ Coefficient of performance

${ }^{\mathrm{f}}$ Unit size (1.5 kW) times the quantity required per home (6-8). 


\section{Cost Savings of Building Envelope Improvements}

The cost of the Phase 2 envelope improvements came in considerably higher than originally estimated. GHI staff members are compiling actual costs, with the intention of isolating those associated with various envelope upgrades. Several factors are involved in pricing estimates, especially for the unique circumstances of the GHI cooperative:

- Contractors were asked to bid on a wide range of building envelope improvements from crawlspace insulation using SPF to vent fans installed through block walls to foam insulation installed on exterior walls using furring strips. A wide range of work scopes can drive up costs because of uncertainty in any one area.

- The community has established hours during which work can be conducted to accommodate the membership and administrative staff. Weekends and every other Friday were not allowable workdays.

- Demolition and disposal costs can vary significantly from area to area- these costs were difficult to capture independently of the retrofit work.

- Procuring uncommon materials for the jobsite increased time and cost.

- Uncommon work scopes increase costs. One example was installing furring over foam into block.

- Home occupants (GHI members) and the administrative staff interacted with contractors, adding a layer of oversight not common in residential retrofits.

Identifying factors unique to the GHI cooperative that may have affected estimates for the retrofit work will help GHI determine opportunities to lower costs in future community-wide retrofits.

\subsection{Retrofit Cost Complexity}

The GHI pilot program was initiated as an opportunity to evaluate the cost of upgrades in comparison with the energy cost savings and isolate the highest performing, lowest cost upgrades to deploy. This approach is used in BA and other programs to help in the decision process to invest in energy-saving technologies. The investment is expected to demonstrate a payback based solely on energy savings. This approach is reasonable and common for many homeowners and informs the decision process. However, this approach masks a number of complexities of the energy retrofit market:

- Some upgrades, such as windows and doors, have an energy benefit; however, costs are affected by other factors such as aesthetics, frame quality, and ease of use.

- Siding may be replaced in a home regardless of any concerns over insulation. Separating the siding costs from the insulation installation can be difficult, especially if more than a thin layer of foam is used, which requires other trim details (as was the case with GHI).

- Installation of siding over insulation on a building that did not previously have siding is considered an energy upgrade and is thus included in the cost of the upgrade. In this case, the cost of the finish has a large implication on affordability. 
- Crawlspace upgrades will be performed to improve durability and insulation. However, crawlspace upgrades often show little benefit, especially for the GHI concrete monolithic foundations that required insulation repair. Durability improvements come at a cost that does not accrue to energy savings.

- Ventilation fans, a necessary upgrade during some energy retrofits, will not contribute to energy savings, and may in fact reduce savings.

- Retrofit upgrades in older homes that do not have air conditioning and have EBB heating (GHI homes) may not demonstrate the full range of energy savings achievable in new homes.

- Home resale value from appreciation that may result from improved energy efficiency is yet to be defined adequately.

For these and other reasons, such as homeowner comfort, associating the cost of upgrades with energy savings is a complex process in which separating energy cost upgrades from other costs is a significant challenge.

\subsection{Energy Savings Investment}

The GHI pilot program aimed to evaluate the cost of each envelope upgrade with its attendant energy savings. However, because of the broad scope of each activity in the construction phases that were involved in the upgrades and the different types of buildings, costs are hard to flesh out and assign to a specific energy-efficient feature and its accompanying energy savings.

Table 23 shows an initial compilation of the costs and a comparison with the energy savings.

The last two Simple Payback rows in Table 23 highlight the importance of timing this energy retrofit project with the wider home improvement project that is in progress at GHI members' homes. When EEMs are included with planned renovations, the cost of the energy-efficient component is more easily isolated from the expense of cladding, window, and door removal and installation. The additional costs of insulation and air sealing was less than $50 \%$ of the gross project cost, for all but the B building (BV1, B5, B6, BV2), which included the cost of siding. The energy savings, based on an estimated full heating season (which added $20 \%$ to the number of HDDs) have been realized from the EEM investments. These savings will pay for the unfunded project costs in 9.5 to 28.6 years, depending on building type and installation details. The high end of the payback range is also the cycle for exterior component replacements used by GHI in establishing reserve accounts; thus, the cycle presents a logical high end of the range that should be set for acceptable payback metrics for this project. 
Table 23. Cost Analysis of Building Upgrades

\begin{tabular}{|c|c|c|c|c|c|}
\hline & \multicolumn{5}{|c|}{ Building Types } \\
\hline General Upgrade Category & BV3-BV6 & B1-B4 & $\begin{array}{l}\text { BV1, B5, } \\
\text { B6, BV2 }\end{array}$ & FB1-FB8 & FV1-FV8 \\
\hline Number of Homes & 4 & 4 & 4 & 8 & 8 \\
\hline Crawlspace & $\$ 12,003$ & $\$ 8,288$ & $\$ 8,681$ & $\$ 16,331$ & $\$ 32,325$ \\
\hline Attic & & & & $\$ 12,419$ & $\$ 9,904$ \\
\hline Ventilation Fan & $\$ 5,740$ & $\$ 6,925$ & $\$ 6,900$ & $\$ 12,220$ & $\$ 10,910$ \\
\hline Wall Insulation & & & $\$ 28,630$ & & $\$ 31,885$ \\
\hline Siding & & & $\$ 18,695$ & & $\$ 35,115$ \\
\hline Ductless Heat Pump & & $\$ 12,000$ & & & \\
\hline Permits & $\$ 1,000$ & $\$ 1,000$ & $\$ 1,000$ & $\$ 2,000$ & $\$ 2,000$ \\
\hline Windows/Doors & $\$ 23,242$ & $\$ 22,784$ & $\$ 26,951$ & $\$ 32,271$ & $\$ 43,732$ \\
\hline Total Upgrade Cost & $\$ 41,985$ & $\$ 50,997$ & $\$ 90,857$ & $\$ 75,241$ & $\$ 165,871$ \\
\hline Less Windows/Doors/Siding ${ }^{\mathrm{a}, \mathrm{b}}$ & $(\$ 23,242)$ & $(\$ 22,784)$ & $(\$ 26,951)$ & $(\$ 32,271)$ & $(\$ 78,847)$ \\
\hline $\begin{array}{c}\text { Less Crawlspace Vapor } \\
\text { Retarder }^{c}\end{array}$ & $(\$ 3,000)$ & $(\$ 3,000)$ & $(\$ 3,000)$ & $(\$ 6,000)$ & $(\$ 6,000)$ \\
\hline Net Cost of Energy Upgrades & $\$ 15,743$ & $\$ 25,213$ & $\$ 60,906$ & $\$ 36,970$ & $\$ 81,024$ \\
\hline $\begin{array}{c}\text { Energy Features as Percent of } \\
\text { Total }\end{array}$ & $37 \%$ & $49 \%$ & $67 \%$ & $49 \%$ & $49 \%$ \\
\hline TD30 Normalized Savings ${ }^{\mathrm{d}, \mathrm{e}}$ & $\$ 1,383$ & $\$ 915$ & $\$ 2,537$ & $\$ 2,607$ & $\$ 2,360$ \\
\hline $\begin{array}{c}\text { TD30 Normalized Savings }{ }^{\mathrm{d}, \mathrm{e}} \\
+\mathbf{2 0} \mathrm{f}^{\mathrm{f}}\end{array}$ & $\$ 1,660$ & $\$ 1,098$ & $\$ 3,045$ & $\$ 3,129$ & $\$ 2,832$ \\
\hline Simple Payback, All Upgrades & 25.3 & 46.4 & 29.8 & 24.0 & 58.6 \\
\hline $\begin{array}{c}\text { Simple Payback, Energy } \\
\text { Upgrades }\end{array}$ & 9.5 & 23.0 & 20.0 & 11.8 & 28.6 \\
\hline
\end{tabular}

${ }^{a}$ Windows and doors and frame buildings with siding have a recurring reserve fund for replacement and are not included in the cost of the additional energy feature upgrades.

${ }^{\mathrm{b}}$ Siding is included when installed new as a necessary part of the wall insulation upgrade.

${ }^{\mathrm{c}}$ Crawlspace vapor barrier is estimated at $\$ 3,000$ per building.

${ }^{\mathrm{d}}$ Temperature normalized energy savings, estimated for unoccupied/change occupancy units; energy costs at $\$ 0.15 / \mathrm{kWh}$.

e Savings for Unit B1 and B2 (B2 used for atypical B3) and added to B4 (unit where ductless heat pump added) for building savings.

${ }^{\mathrm{f}}$ Adjust savings based on full heating season.

Upgrades for each building type:

BV3-BV6: crawlspace walls, windows, doors, bath fan

B1-B4: crawlspace walls, windows, doors, bath fan, B4 ductless heat pump

BV1, B5, B6, BV2: crawlspace walls, windows, doors, bath fan, remove siding BV1 and 2, add 2-1/2 in.

exterior insulation.

FB1-FB8: crawlspace walls, attic, windows, doors, bath fan

FV1-FV8: crawlspace floor, attic, windows, doors, bath fan, remove siding, add 1-in. exterior insulation. 
This simple payback analysis doesn't account for the cost of money or its availability, but GHI could either finance the EEM upgrades for its members or expect its members to pay for them in total when installed, as it did with pilot program participants who ordered upgraded windows. To present the figures in Table 23 for individual consumption (the level at which these decisions may be made), the savings and the costs were broken down to the averages at the unit level in Table 24. Once the average individual monthly savings were calculated, a comparable mortgage payment at $4.5 \%$ annual interest rate and a term of 30 years was calculated and the principal for that payment noted.

Table 24. Individual Unit Savings and Cost

\begin{tabular}{|c|c|c|c|c|c|}
\hline \multirow[b]{2}{*}{ Unit ID } & \multicolumn{5}{|c|}{ Individual Unit Analysis Based on Building Type } \\
\hline & BV3-BV6 & B1-B4 & $\begin{array}{l}\text { BV1, B5, } \\
\text { B6, BV2 }\end{array}$ & FB1-FB8 & FV1-FV8 \\
\hline No. Units & 4 & 4 & 4 & 8 & 8 \\
\hline $\begin{array}{c}\text { TD30 Normalized } \\
\text { Savings/Building } \\
\text { (\$ at } 0.15 / \mathrm{kWh})\end{array}$ & 1,660 & 1,098 & 3,045 & 3,129 & 2,832 \\
\hline Annual Savings/Unit (\$) & 414.89 & 274.48 & 761.21 & 391.07 & 353.97 \\
\hline Monthly Utility Bill Savings (\$) & 34.57 & 22.87 & 63.43 & 32.59 & 29.50 \\
\hline $\begin{array}{c}\text { Matching Mortgage Payment } \\
\text { at } 4.5 \% / 30 \text { years }(\$)\end{array}$ & $(34.45)$ & $(22.80)$ & $(63.34)$ & $(32.43)$ & $(29.39)$ \\
\hline $\begin{array}{c}\text { Amount Financed in Matching } \\
\text { Mortgage Payment (\$) }\end{array}$ & 6,800 & 4,500 & 12,500 & 6,400 & 5,800 \\
\hline $\begin{array}{c}\text { EEM Cost (Net Project Cost) } \\
\text { per Unit (\$) }\end{array}$ & 3,936 & 6,303 & 15,227 & 4,621 & 10,128 \\
\hline $\begin{array}{c}\text { Difference Between Financing } \\
\text { Limit and EEM Cost (\$) }\end{array}$ & 2,864 & $(1,803)$ & $(2,726)$ & 1,779 & $(4,328)$ \\
\hline
\end{tabular}

If the homeowner secures a mortgage to pay for the EEMs, two of the five building types indicate that the EEMs selected are fiscally prudent investments within the established parameters. In particular, no fuel cost escalation has been included in the energy savings estimate and no tax benefit has been assumed to accrue to the mortgage payment. Thus, the financing/savings calculations shown in Table 24 represent a conservative approach to the EEM analysis. Three building types will not be paid for in a 30-year mortgage payment that matches the energy savings - B (with heat pump), BV with $2-1 / 2$ in. continuous foam and cladding, and FV with SPF floor insulation and 1-in. continuous foam. These types will require some revision to the EEM package because of costs. In all cases there is an even tradeoff of an expense (utility bill) for amortization of a debt acquired for investment in EEMs; this is a prudent metric for decision making.

\subsection{Prioritizing Energy-Efficiency Measures}

Based on the GHI bid process, which required a fairly detailed breakout of cost estimates, and the resultant implementation sequencing of the Phase 2 envelope upgrades, it should be possible to evaluate cost estimates in terms of energy and other benefits. For example, the crawlspace upgrades presented considerable bid deviation from estimates because contractors did not want to 
remediate the ground vapor barriers and insulation; they preferred removal and replacement. Because the B and FB foundations were $75 \%$ insulated and naturally sealed from the home interiors by the monolithic slab and stem wall construction, these improvements will likely be set at a lower priority in future funding decisions. The issues could be remediated by the GHI maintenance department. An alternative would be GHI establishing a reserve for crawlspaces and limit independent contractors' unsupervised access to these spaces; much of the debris collection and degradation within the crawlspaces appear to have been caused by cable, electrical, and plumbing trades hired to perform work for GHI or an individual member occupant.

Similarly, the FV crawlspaces will likely require the same level of detail as the pilot buildings. The SPF insulation in the floor assembly will provide vital air sealing at the plank-sheathed floors and a durable long-lasting thermal barrier. If the crawlspace floors and ground vapor barriers cannot be repaired concurrently with the insulation installation, a reserve fund should be established for a near-term retrofit.

All upgrades will be evaluated as final costs are compiled and energy savings for the 2013-2014 heating season are logged. 


\section{Energy-Efficiency Measure Lessons Learned}

Based on the envelope upgrades implemented in the pilot program, a number of details have been identified as critical to the long-term success of the community-wide upgrade. Some issues fall into the category of "lessons learned"; others still need solutions. All these factors will require an ongoing careful review of the costs to achieve an optimized approach to specific upgrades.

\subsection{Crawlspace Upgrades}

Original simulation estimates indicated modest energy savings from upgrades to the crawlspace, especially for the B and FB buildings, where some insulation was already installed and where air leakage to the home is minimal because the foundation and the slab construction are integrated. Conversely, retrofitting the FV buildings is expected to produce higher energy savings and incur higher cost because a large amount of SPF was used and the crawlspaces presented tight working quarters. Assessment details for the crawlspaces that pertain to the community-wide upgrades follow:

- Evaluate the cost of the concrete foundation upgrades in B, BV, and FB buildings, the scope of work, and the expected benefits to determine their priority.

- Evaluate the drainage issues encountered in the FV crawlspaces to determine if additional remediation is necessary.

- Break out costs and savings for the FV crawlspaces to determine if alternative approaches would provide similar benefits at a lower cost.

- Separate ground vapor barrier costs from the insulation improvement costs and investigate avenues for including the barriers and insulation in GHI's regular home maintenance procedures and schedule.

\subsection{Attic Upgrades}

Attic upgrades included air sealing, insulation, and storage area maintenance and are applicable to the FB and FV buildings only. These improvements appear to have reasonable costs relative to the estimated benefits (especially when air leakage to the attic is included in the scope). Assessment details for the attics that pertain to the community-wide upgrades follow:

- Re-evaluate the cost of the attic upgrades to identify any possible cost optimizations.

- Solicit the GHI membership for interest in maintaining the storage space, the area of storage needed, and any optional approaches such as a minimal level versus an enhanced level (whose cost would be borne independently by the member).

- Develop specific air sealing details for the attic including sequencing and material selections.

- Consider alternative attic insulation options such as exterior roof panels. ${ }^{5}$

\footnotetext{
${ }^{5} \mathrm{SPF}$ in the roof was originally considered and not recommended because of the cost, loss of headroom, ignition barrier requirements, and potentially lower overall insulating levels.
} 
- Review attic access options and detail upgrades based on the specific type of access and condition.

\subsection{Windows}

Window replacements have proven to be the most difficult detail to define for the communitywide upgrade. A cost and energy analysis was initially not as critical for windows because window replacements have been built into the replacement reserves. Although no performance specifications are part of the window replacement reserves, GHI did need to include a minimum performance specification ( $0.30 \mathrm{U}$-value/ 0.30 solar heat gain coefficient) into the bid process. Estimates for the window costs to match the reserve replacement funds did not appear to be adversely affected by the window specifications. However, the performance specifications were in line with the manufacturer's typical product selection. If higher performing windows had been specified (R5 or higher), there would very likely be a significant discrepancy between reserve estimates and window costs.

The window costs are likely to be revisited because during installation the windows were integrated with new wall insulation, which necessitated large amounts of aluminum coil stock and the use of self-adhering window and sill pan flashing unfamiliar to the window manufacturer. Cost estimates for future window installations are expected to increase. Assessment details for the windows that pertain to the community-wide upgrades follow:

- A detailed review of window installation options for each building type is required. In particular for buildings that receive exterior insulation, review whether windows are installed as "innies" or "outies" and the required commensurate trim details.

- Review exterior window trim details for the FV buildings and standardize an approach.

- Review the window type (flanged or replacement) for the B buildings when the windows are integrated with exterior insulation. If an "innie" window option is selected, determine the window trim flashing details by the window installer versus those of the cladding installer.

- Clearly specify the window flashing details for all building types and develop a quality control mechanism for ensuring installation consistency.

- Review flashing details for second-story window head flashing that is integrated with siding and eave soffits.

- Review sequencing of window removal, replacement, and flashing.

- Review architectural details for exterior trim that is integrated with new wall insulation and the WRB.

- Provide clear options for homeowners for window styles and cost differences well in advance of planned retrofits to take advantage of bulk purchases.

\subsection{Exterior Insulation and Weather-Resistive Barriers}

Exterior insulation is expected to demonstrate a large benefit in the overall pilot program. In addition to the higher levels of insulation, the air sealing benefits will further support energy savings and indoor comfort. Imperfections in the existing cavity insulation from the 1980s 
retrofit caused by settling or framing factors will be mitigated with the exterior continuous insulation alternative. Assessment details for continuous exterior insulation that pertain to the community-wide upgrades follow:

- Review costs and energy savings associated with exterior insulation and specify the preferred insulation board for all building types to receive exterior insulation.

- Define the approach to the WRB, the material options, and the installation requirements based on the specific materials.

- Clearly specify the integration of the window flashing with the WRB.

- Review insulation thicknesses for each building type and the specific attachment methodology based on the insulation thickness.

- Identify all flashing details at the roof, adjacent wall, decks, and chimneys.

- Identify building details where roofing systems intersect with wall insulation systems and catalog areas with crossover that may need to be addressed in future maintenance or repair work.

\subsection{Claddings}

Direct attachment of cladding, in particular vinyl siding, over 1-in. foam board is generally permitted based on manufacturers' recommendations and warranty requirements. Beyond this thickness furring strips may be required to provide the nail base for the cladding. For the B homes that are retrofitted with exterior foam board, furring must be installed to serve as the nail base for the cladding. However, design details must be addressed in this case to identify the drainage plane and the integration of the furring. Furring is often considered merely as the "nailer" for siding and trim; this encourages the installation of more wood than is required, including horizontal furring. The horizontal furring can then interrupt the drainage plane that is provided by the taped rigid foam. If horizontal furring absolutely must be installed, it must be flashed if the rigid foam is also serving as the drainage plane. To flash the horizontal furring and the rigid foam plane, the vertical furring must stand off from the horizontal furring, or the flashing must be installed unencumbered by perpendicular furring directly above the horizontal piece.

Vinyl siding manufacturers require a continuous rigid backing for the product that isn't met with furring only. According to CertainTeed (2013):

1. Install all siding and accessories over a smooth, flat surface. Always install siding over a rigid sheathing, and never install it over open studs. 2. Vinyl siding is not a watertight material. Install a weather-resistant barrier, like CertainTeed CertaWrap, and flash around all windows and doors before installing vinyl siding and trim.

When the voids between the spacing of the furring are filled with additional rigid foam, the drainage plane location becomes obscured and interrupted by all of the smaller foam panels that fit between the furring. The contractor used 2-in. foam and furring at 16-in. spacing on the block building and then filled in between the furring with $1 / 2$-in. rigid foam panels adhered and tacked to the underlying foam. Alternative sidings and rigid foam details are under investigation. 
Furthermore, rigid foam can provide sufficient edge definition (or architectural relief) and support against denting under polyvinyl chloride-coated aluminum coil stock that has been brake-folded into trim just as well as wood at window sills and frames. The added benefit of the thermal resistance and the lower cost (than the 1x pine trim) recommends its use for future buildings. Assessment details for the cladding that pertain to the community-wide upgrades follow:

- Review details and scope of work to attach cladding directly over foam board (for FV buildings) and to attach cladding over furring (for B and BV buildings).

- Identify the drainage plane location for each system and identify a continuous pathway for various trade contractors.

- Review architectural relief options that use alternatives to wood products.

- Review window trim details to optimize the requirements for the community-wide upgrade.

\subsection{Ventilation Fan}

Bath exhaust fans were identified as an important feature in the energy retrofits. Most GHI homes have no exhaust fans. The upgrades to the insulation and the reduction in infiltration rates make exhaust fans much more critical to the home's long-term performance and the occupants' comfort. Assessment details for the exhaust fan that pertain to the community-wide upgrades follow:

- Plan to install the exhaust fan before the attic upgrades are started.

- Establish a fan and control specification that can be met with a wide range of products.

- Establish multiple ducting paths and hood locations to accommodate field conditions.

- Provide the homeowners instructions on the use of the fans and controller.

- Evaluate the operation of the fan to determine if a higher level of automation is necessary.

\subsection{Design and Implementation Process}

Retrofit upgrades of this breadth and magnitude highlight the shortcomings of the design-bidbuild process flow in which construction modifications are made after the work has been initiated. In this case, because building types vary and the scope of work is broad, the challenge to define all details of the upgrades before the bid process began was significant. Bid costs were complicated by the wide range of retrofit technologies on three building types. Unfamiliarity with technologies, such as exterior insulation over concrete block, led to field decisions for attachment, air sealing, and integration with other components. Fortunately, the design of the pilot program helped to identify these issues before the community-wide upgrade took place. 


\section{Summary of Research Questions}

1. How does the energy use for the homes with energy retrofits compare with the preretrofit energy use for space heating and total consumption?

For the homes that had typical use throughout the study and were occupied without change, the heating energy during the selected 111-day heating period from December 1-March 21, was reduced by $10 \%-53 \%$, depending on the extent of the efficiency features and using a TD normalization. Total energy use was reduced by $12 \%-46 \%$ using the same normalization methodology. Without any normalization methods, either based on HDDs or using the TD between the interior and exterior, the actual energy savings was positive for all buildings even with a colder winter and generally warmer indoor temperature settings.

2. Can either enhanced energy savings or "take-back" energy consumption be identified from the pre- and post-retrofit measurements?

3. What is the difference in the average indoor air temperatures for the homes with energy retrofits compared with the pre-retrofit home (and occupants) measurements?

Question 2 is answered by an analysis of the indoor temperatures (Question 3) over multiple monitoring periods. Generally, the indoor temperatures were measured warmer by $1^{\circ}-3^{\circ} \mathrm{F}+$ from the base year before any retrofit measures were installed. The warmer indoor temperatures during the last heating season occurred when average outdoor temperatures were on average $2^{\circ} \mathrm{F}$ colder over the measurement period and represent a "take-back" effect in which more comfortable indoor temperatures are selected, presumably because of the lower energy costs.

4. How does the realized energy savings for the efficiency retrofits compare with the realized installation cost of the retrofits?

When looking at the overall cost of the upgrades implemented during the pilot program and evaluating these costs solely on the basis of energy savings, the simple paybacks are long, 29-70 years. However, for the costs of the upgrades, which include new crawlspace vapor barriers, windows, and siding that are replaced on a regular schedule and financed separately, the payback periods are markedly reduced by 11-34 years. Based on the type of upgrades, payback periods of 30 or more years are acceptable, given the more than 30 -year periods between major improvements.

5. What is the homeowner perspective on the home comfort following the energy retrofits? GHI pilot homeowners were asked to complete a questionnaire developed by the GHI buildings committee to provide qualitative feedback on the retrofits installed during Phase 2 of the pilot program for the cooperative membership. Table 25 summarizes the homeowner responses by building type. 
Table 25. Homeowner Reponses to Energy and Comfort Questionnaire

\begin{tabular}{|c|c|c|c|}
\hline Question/Response & FB & FV & $B$ and $B V$ \\
\hline \multicolumn{4}{|c|}{ Does your home feel any different since the replacements were installed? } \\
\hline No & $29 \%$ & $0 \%$ & $17 \%$ \\
\hline Yes & $71 \%$ & $100 \%$ & $83 \%$ \\
\hline \multicolumn{4}{|c|}{ Does your home feel less drafty? } \\
\hline No & $14 \%$ & $13 \%$ & $4 \%$ \\
\hline Yes & $71 \%$ & $88 \%$ & $22 \%$ \\
\hline \multicolumn{4}{|c|}{ Does your home feel warmer? } \\
\hline No & $14 \%$ & $13 \%$ & $8 \%$ \\
\hline Yes & $86 \%$ & $88 \%$ & $92 \%$ \\
\hline \multicolumn{4}{|c|}{ How do you find the fan sound? } \\
\hline Quiet & $43 \%$ & $75 \%$ & $17 \%$ \\
\hline Moderate & $29 \%$ & $13 \%$ & $50 \%$ \\
\hline Loud & $0 \%$ & $0 \%$ & $0 \%$ \\
\hline Very Loud & $0 \%$ & $0 \%$ & $0 \%$ \\
\hline Do not notice it & $29 \%$ & $0 \%$ & $17 \%$ \\
\hline $\begin{array}{c}\text { N/A (no fan } \\
\text { installed) }\end{array}$ & $0 \%$ & $13 \%$ & $0 \%$ \\
\hline
\end{tabular}

Overall, the comments provided by the pilot home members were very positive. As expected, many comments focused on logistics, selections, and aesthetics, which are aspects of retrofit work that is important for homeowners. Feedback on utility costs has not been compiled as of this writing.

6. How does the relative humidity within the home change from the pre- to the post-retrofit conditions?

Measured indoor relative humidities have remained fairly consistent over the last three of the four monitored winter periods, averaging during the latest heating period from $39 \%$ to $45 \%$. The first-year measured data, which is missing some data early in the heating season, shows a 3\%$5 \%$ lower humidity across all homes on average. The combination of envelope improvements, including low-e windows and bath fans, appears to have resulted in satisfactory moisture performance.

7. What is the change in the crawlspace environmental conditions from the pre- to postretrofit conditions?

Although some data are unavailable for the first season for the crawlspaces, the average seasonal relative humidity has remained consistent across all of the monitored periods at about 55\%. Dew point temperatures average approximately $15^{\circ} \mathrm{F}$ lower than the average air temperatures.

8. What is the comparison between the metered energy use data (electric utility meter) and the measured daily energy use, and can this relationship be standardized for similar analysis in homes in heating climates to avoid costly instrumentation? 
Excellent agreement was found between measured data and utility meter data. Utility meter data were compiled biweekly. These data can help to isolate the energy used for heating. Generally, the estimated heating energy was higher when using the daily data than with estimates made using utility meter data, but the differences were not significant. The average range of heating percentage using the daily data was $62 \%-66 \%$ and $57 \%-66 \%$ when using the utility meter data estimates. The range, however, was $18 \%-96 \%$ for the daily data and $14 \%-85 \%$ for the utility meter data. This extensive data set indicates that use of higher resolution utility data will be sufficient for ongoing monitoring efforts at GHI. Furthermore, because all GHI utility meters have been converted to smart meters, the resolution of whole-house electric data will be much higher should access be given to the data. 


\section{Next Steps}

GHI staff, the GHI buildings committee, and the PHI BA team plan to review the results of the Phase 2 upgrades, including the energy use during the heating season, the pilot homeowner anecdotal responses to the upgrades, the performance of the house following the upgrades, and the architectural details that may drive some changes in the selected upgrades for the community. The homes will continue to be monitored through the Phase 3 heating system upgrades on specific units.

All of these review and analysis efforts are focused on achieving recommendations for the community-wide upgrade of the GHI portfolio to provide energy savings and durable housing for the members. 


\section{References}

CertainTeed (2013). CertainTeed Vinyl Siding Installation Guide, p.70. CTS205. Valley Forge, PA: CertainTeed Corporation. Accessed October 28, 2013:

www.certainteed.com/resources/CTS205.pdf.

Del Bianco, M.; Wiehagen, J.; Wood, A. (2013). Energy Efficient Crawlspace Foundation Retrofit: Mixed Humid Climate. Golden, CO: National Renewable Energy Laboratory. Accessed April 1, 2015:

apps1.eere.energy.gov/buildings/publications/pdfs/building_america/crawlspace found retrofit.pdf.

"Building America: Bringing Building Innovations to Market." U.S. Department of Energy. Accessed October 28, 2013: http://www1.eere.energy.gov/buildings/residential/ba_index.html.

“GHI Bylaws 2003-2012.” Greenbelt Homes, Inc. Accessed October 28, 2013: http://ghi.coop/content/ii-purpose-and-powers.

Guide to Attaching Sheathing, Furring, and/or Cladding through Continuous Foam Insulation to Wood Framing, Steel Framing, Concrete and CMU Substrates with TRUFAST SIP TP, SIP LD and Tru-Grip Fasteners. (2012). TRU110910-21. Nappanee, IN: NTA, Inc.

Accessed October 28, 2013: www.trufast.com/links/pdf/NTA inc Engineering_Evaluation Report TRU110910-21.pdf.

International Code Conference (2012). International Residential Code 2012.

Excerpt from TABLE R703.4, page 366; “[footnote] z. Where approved by the manufacturer's instructions or test report [vinyl] siding shall be permitted to be installed with fasteners penetrating not less than 0.75 inches through wood or wood structural sheathing with or without penetration into the framing."

Maryland Historic Trust. Property Name: Greenbelt Historic District. Accessed October 28, 2013: http://mht.maryland.gov/nr/NRDetail.aspx?NRID=658\&FROM=NRNHLList.aspx

NAHBRC (2011). Greenbelt Homes, Inc. Pilot Project Energy Analysis. Upper Marlboro, Maryland: NAHB Research Center. Accessed March 30, 2015:

http://ghi.coop/sites/default/files/attachments/GHI\%20Pilot $\% 20$ Home $\% 20$ Energy $\% 20$ Analysis $\%$ 20Report $\% 20 \mathrm{by} \% 20 \mathrm{NAHBRC} . \mathrm{pdf}$.

"National Temperature and Precipitation Maps." National Oceanic and Atmospheric Administration. Accessed April 1, 2015: http://www.ncdc.noaa.gov/temp-and-precip/usmaps/3/201202.

Pepco, Residential Rate Schedule R. Accessed October 28, 2013: http://www.pepco.com/rate$\underline{\text { schedules.aspx }}$

"BEopt.” National Renewable Energy Laboratory. Accessed March 30, 2015:

http://beopt.nrel.gov/downloadBEopt2.

Wiehagen, J.; Del Bianco M.; Wood A. (2013). Greenbelt Homes Pilot Energy Efficiency Program Phase 1 Summary: Existing Conditions and Baseline Energy Use. Golden, CO:

National Renewable Energy Laboratory. Accessed March 30, 2015:

http://apps1.eere.energy.gov/buildings/publications/pdfs/building_america/greenbelt_homes_pilo t.pdf. 


\section{Bibliography}

Dow Building Materials. Installing...Residential Sheathing... Accessed October 28, 2013:

http://building.dow.com/na/en/tools/installations/duramate.htm.

McIlvaine, J., Sutherland, K., and Martin, E. of Florida Solar Energy Center. (2013). Energy

Retrofit Field Study and Best Practices in a Hot-Humid Climate. Cocoa, FL: BA-PIRC/Florida Solar Energy Center.

www.nrel.gov/docs/fy13osti/57827.pdf

Neuhauser, Ken (2013). Evaluation of Two CEDA Weatherization Pilot Implementations of an Exterior Insulation and Over-Clad Retrofit Strategy for Residential Masonry Buildings in Chicago. Somerville, MA: Building Science Corporation.

apps1.eere.energy.gov/buildings/publications/pdfs/building america/evaluation ceda pilots.pdf 
Appendix A: Pilot Program Retrofit Options, Estimated Costs, and Estimated Energy Savings

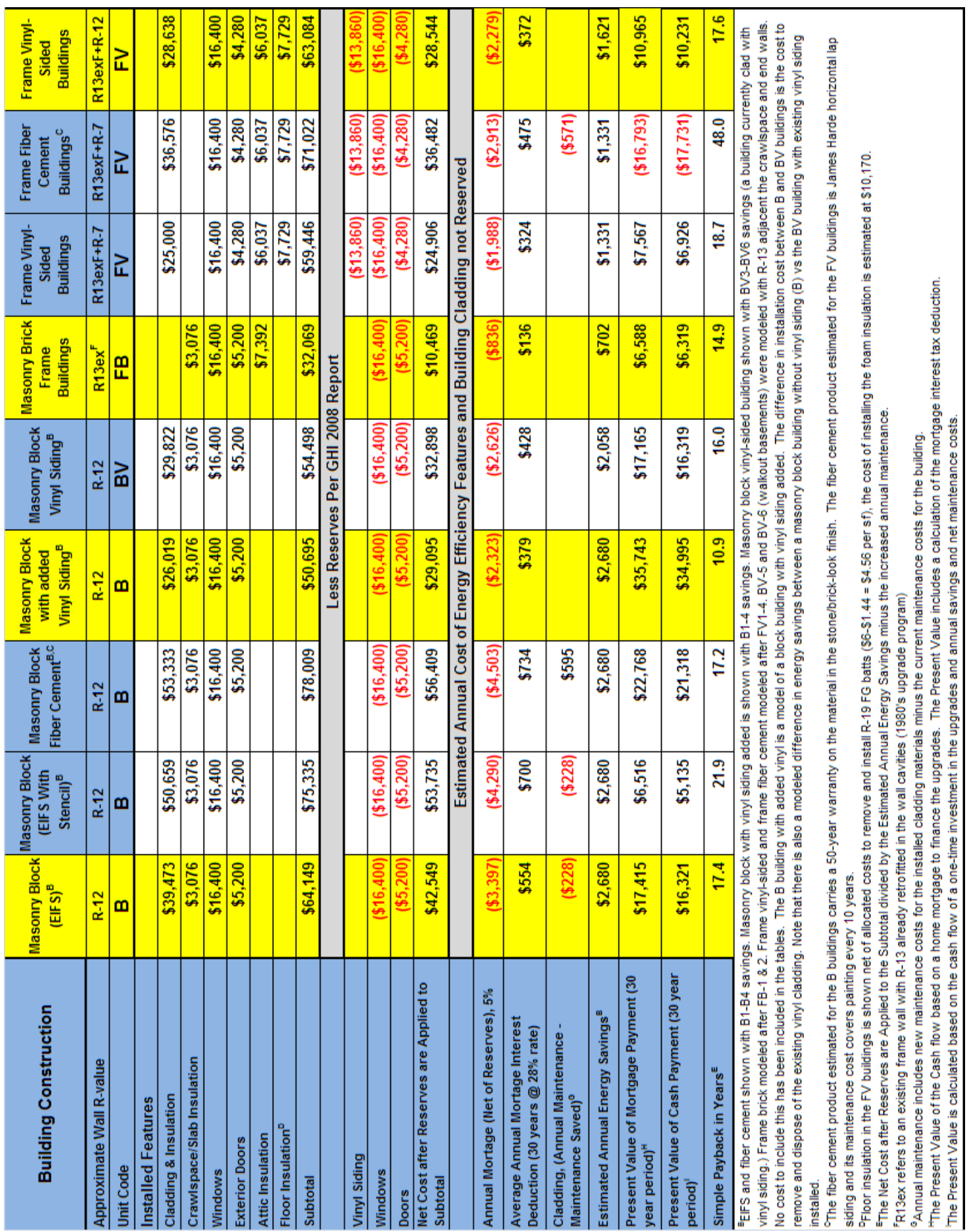




\section{Appendix B: Units by Construction Type}

\begin{tabular}{|c|c|c|}
\hline $\begin{array}{c}\text { Construction } \\
\text { Type }\end{array}$ & General Conditions & $\begin{array}{c}\text { Total No. of } \\
\text { Units }\end{array}$ \\
\hline $\begin{array}{c}\text { B or BV } \\
\text { 8-in. CMU }\end{array}$ & $\begin{array}{l}\text { - Formed concrete crawlspace foundation }{ }^{*} \text {, with structural } \\
\text { concrete first floors over common crawlspaces } \\
\text { - Crawlspaces are } 4 \mathrm{ft} \text { and retrofitted as closed crawlspaces with } \\
\text { 1-2 in. of rigid XPS foam applied to the perimeter walls } \\
\text { - Crawlspace walls extend under front and rear porch slabs } \\
\text { (many exposed to ambient conditions) } \\
\text { - Structural concrete floors (1st and } 2 \text { nd levels) } \\
\text { - Main house and porch slabs lack thermal breaks } \\
\text { - CMU walls, finished with plaster } \\
\text { - Some interior common walls are wood framed (where party } \\
\text { walls breach the adjacent units footprint). } \\
\text { - Double-glazed vinyl windows (1980) } \\
\text { - Exterior walls are painted (B) or have vinyl siding (BV) } \\
\text { - Flat concrete roofs retrofitted with } 3-3 / 4 \text { in. of polyisocyanurate } \\
\text { insulating tapered sheathing and Ethylene propylene diene } \\
\text { monomer roofing, R-26 } \\
\text { - EBB heating } \\
\text { - Room through-the-wall air conditioning } \\
\text { - Electric water heat }\end{array}$ & 256 \\
\hline FB Veneer & $\begin{array}{l}\text { - Formed concrete crawlspace foundations, with structural } \\
\text { concrete first floors over common crawlspaces } \\
\text { - Crawlspaces are } 4 \mathrm{ft} \text { and retrofitted as closed crawlspaces with } \\
1-2 \text { in. of rigid XPS foam applied to the perimeter walls } \\
\text { - Crawlspace walls extend under front and rear porch slabs } \\
\text { (many exposed to ambient conditions) } \\
\text { - Structural concrete first floor } \\
\text { - Main house and porch slabs lack thermal breaks } \\
\text { - Balloon- framed } 2 \times 416 \text { in. o.c. walls with plasterboard } \\
\text { interior finish } \\
\text { - Blown-in cellulose/rock wool insulation in walls }(1980) \\
\text { - Board wall and roof sheathing }(1 \times 6 / 1 \times 8) \\
\text { - Exterior brick veneer, no WRB } \\
\text { - Double-glazed vinyl windows }(1980) \\
\text { - Gable roofs with slate shingles } \\
\text { - Ventilated attic with rock wool, cellulose, or fiberglass floor } \\
\text { insulation, R-16 (1980) } \\
\text { - EBB heating } \\
\text { - Room through-the-wall air conditioning } \\
\text { - Electric water heat }\end{array}$ & 318 \\
\hline
\end{tabular}




\begin{tabular}{|c|c|c|}
\hline $\begin{array}{c}\text { Construction } \\
\text { Type }\end{array}$ & General Conditions & $\begin{array}{c}\text { Total No. of } \\
\text { Units }\end{array}$ \\
\hline FV Sided & $\begin{array}{l}\text { - Common ventilated crawlspace of } 8 \text {-in. CMU block, } 4-1 / 2 \\
\text { courses high }(3 \mathrm{ft}) \\
\text { - } 2 \times 816 \text { in. o.c. floor joists with midspan dropped beam } 3,2 \times \\
10 \text { in. on CMU piers } \\
\text { - R-11 kraft-faced fiberglass batt insulation in floor joists }(1980) \\
\text { - Balloon-framed } 2 \times 416 \text { in. o.c. walls } \\
\text { - Blown-in cellulose insulation in walls }(1980) \\
\text { - Board wall and roof sheathing }(1 \times 6 / 1 \times 8) \\
\text { - Double-glazed vinyl or aluminum windows }(1980) \\
\text { - Vinyl siding, no WRB } \\
\text { - Gable roof with asphalt shingles } \\
\text { - Ventilated attic } \\
\text { - Attics insulated with rock wool, cellulose, or fiberglass floor } \\
\text { insulation, R-16 (1980) } \\
\text { - EBB heating } \\
\text { - Room through-the-wall air conditioning } \\
\text { - Electric water heat }\end{array}$ & $\begin{array}{c}992 \\
\text { (140 of } \\
\text { these are } \\
\text { apartments) }\end{array}$ \\
\hline
\end{tabular}

${ }^{*}$ Several units have full, rear walkout basements of CMU 
Appendix C: Total Energy Use and Heating Energy Use in Each Pilot Home 
Table 26. Heating Season Total Energy Use in Each Pilot Home

\begin{tabular}{|c|c|c|c|c|c|c|c|c|c|c|c|c|}
\hline \multirow{3}{*}{$\begin{array}{l}\text { Pilot } \\
\text { Home }\end{array}$} & \multicolumn{12}{|c|}{ Heating Season Total Energy Use (December 1 Through March 21) } \\
\hline & \multicolumn{4}{|c|}{ Total Heating Season Energy Use, kWh } & \multicolumn{4}{|c|}{$30^{\circ}$ F Temperature Difference Normalized } & \multicolumn{4}{|c|}{3000 HDD Normalized } \\
\hline & $\begin{array}{c}2010- \\
2011\end{array}$ & $\begin{array}{c}2011- \\
2012\end{array}$ & $\begin{array}{c}2012- \\
2013\end{array}$ & $\begin{array}{c}2013- \\
2014\end{array}$ & $\begin{array}{c}2010- \\
2011\end{array}$ & $\begin{array}{c}2011- \\
2012\end{array}$ & $\begin{array}{c}2012- \\
2013\end{array}$ & 2013-2014 & $\begin{array}{c}2010- \\
2011\end{array}$ & $\begin{array}{c}2011- \\
2012\end{array}$ & $\begin{array}{c}2012- \\
2013\end{array}$ & $\begin{array}{r}2013 \\
2014\end{array}$ \\
\hline B-1 & 9,436 & 5,314 & 8,336 & 9,697 & 9,009 & 6,566 & 8,646 & 8,140 & 9,587 & 6,781 & 9,427 & 9,088 \\
\hline B-2 & 6,252 & 4,244 & 5,073 & 5,472 & 6,237 & 5,312 & 5,671 & 5,348 & 6,352 & 5,416 & 5,737 & 5,128 \\
\hline B-3 & 1,956 & 1,774 & 1,886 & 2,869 & 2,737 & 2,784 & 2,384 & 3,466 & 1,987 & 2,264 & 2,133 & 2,689 \\
\hline B-4 & 12,472 & 9,634 & 8,088 & 8,595 & 11,140 & 10,551 & 7,971 & 7,102 & 12,672 & 12,294 & 9,145 & 8,055 \\
\hline BV-1 & 8,212 & 6,799 & 9,444 & 7,143 & 11,257 & 9,278 & 11,041 & 6,701 & 8,344 & 8,676 & 10,680 & 6,694 \\
\hline B-5 & 3,174 & 3,112 & 4,601 & 6,176 & 7,330 & 6,453 & 6,785 & 5,436 & 3,225 & 3,971 & 5,202 & 5,788 \\
\hline B-6 & 5,497 & 4,559 & 4,067 & 4,199 & 9,352 & 6,283 & 5,741 & 4,165 & 5,585 & 5,817 & 4,599 & 3,935 \\
\hline BV-2 & 6,044 & 6,938 & 8,483 & 7,020 & 9,907 & 7,977 & 8,577 & 6,321 & 6,142 & 8,853 & 9,593 & 6,579 \\
\hline BV-3 & 8,677 & 6,353 & 7,716 & 8,525 & 10,200 & 7,652 & 8,231 & 7,480 & 8,816 & 8,106 & 8,725 & 7,990 \\
\hline BV-4 & 4,399 & 3,290 & 3,720 & 1,284 & 6,579 & 4,865 & 4,922 & 2,091 & 4,470 & 4,199 & 4,206 & 1,203 \\
\hline BV -5 & 10,166 & 6,799 & 7,335 & 8,455 & 11,926 & 7,702 & 7,888 & 7,667 & 10,329 & 8,676 & 8,294 & 7,924 \\
\hline BV-6 & 8,851 & 7,750 & 8,909 & 8,875 & 11,261 & 9,448 & 10,148 & 9,402 & 8,994 & 9,890 & 10,074 & 8,317 \\
\hline FB-1 & 7,576 & 6,214 & 5,458 & 6,770 & 8,946 & 6,948 & 5,727 & 5,699 & 7,698 & 7,929 & 6,172 & 6,344 \\
\hline FB-2 & 4,727 & 3,378 & 5,017 & 5,248 & 7,434 & 4,489 & 5,404 & 5,074 & 4,803 & 4,310 & 5,674 & 4,918 \\
\hline FB-3 & 6,405 & 4,564 & 5,169 & 4,246 & 8,684 & 5,638 & 5,649 & 4,332 & 6,508 & 5,823 & 5,846 & 3,979 \\
\hline FB-4 & 3,230 & 2,058 & 2,434 & 3,242 & 8,637 & 4,350 & 4,473 & 4,554 & 3,282 & 2,626 & 2,752 & 3,038 \\
\hline FB-5 & 6,490 & 5,196 & 5,401 & 5,059 & 7,214 & 6,608 & 6,292 & 5,696 & 6,594 & 6,630 & 6,108 & 4,742 \\
\hline FB-6 & 7,320 & 5,638 & 5,951 & 6,946 & 8,454 & 7,699 & 7,346 & 6,221 & 7,438 & 7,194 & 6,729 & 6,510 \\
\hline FB-7 & 1,322 & 1,113 & 1,448 & 739 & 2,781 & 2,530 & 2,855 & 1,337 & 1,343 & 1,420 & 1,637 & 692 \\
\hline FB-8 & 7,507 & 5,087 & 5,546 & 6,310 & 8,463 & 7,331 & 7,229 & 6,727 & 7,628 & 6,492 & 6,271 & 5,914 \\
\hline FV-1 & 4,627 & 3,519 & 4,777 & 5,588 & 8,933 & 5,448 & 5,665 & 5,007 & 4,702 & 4,490 & 5,402 & 5,237 \\
\hline FV-2 & 4,995 & 3,716 & 3,985 & 4,010 & 6,315 & 4,371 & 4,229 & 3,561 & 5,075 & 4,742 & 4,507 & 3,758 \\
\hline FV-3 & 4,664 & 3,133 & 3,170 & 3,945 & 5,861 & 3,998 & 3,879 & 3,237 & 4,739 & 3,997 & 3,585 & 3,697 \\
\hline FV-4 & 6,042 & 4,594 & 5,065 & 5,192 & 7,414 & 5,949 & 5,704 & 4,736 & 6,139 & 5,862 & 5,728 & 4,866 \\
\hline FV-5 & 6,362 & 4,818 & 4,557 & 4,830 & 6,371 & 5,703 & 5,002 & 4,745 & 6,464 & 6,148 & 5,153 & 4,527 \\
\hline FV-6 & 4,674 & 2,152 & 2,284 & 2,626 & 5,498 & 3,376 & 3,664 & 2,963 & 4,749 & 2,746 & 2,583 & 2,461 \\
\hline
\end{tabular}




\begin{tabular}{|c|c|c|c|c|c|c|c|c|c|c|c|c|}
\hline \multirow{3}{*}{$\begin{array}{l}\text { Pilot } \\
\text { Home }\end{array}$} & \multicolumn{12}{|c|}{ Heating Season Total Energy Use (December 1 Through March 21) } \\
\hline & \multicolumn{4}{|c|}{ Total Heating Season Energy Use, kWh } & \multicolumn{4}{|c|}{$30^{\circ}$ F Temperature Difference Normalized } & \multicolumn{4}{|c|}{3000 HDD Normalized } \\
\hline & $\begin{array}{c}2010- \\
2011\end{array}$ & $\begin{array}{c}2011- \\
2012\end{array}$ & $\begin{array}{c}2012- \\
2013\end{array}$ & $\begin{array}{c}2013- \\
2014\end{array}$ & $\begin{array}{c}2010- \\
2011\end{array}$ & $\begin{array}{c}2011- \\
2012\end{array}$ & $\begin{array}{c}2012- \\
2013\end{array}$ & 2013-2014 & $\begin{array}{c}2010- \\
2011\end{array}$ & $\begin{array}{c}2011- \\
2012\end{array}$ & $\begin{array}{c}2012- \\
2013\end{array}$ & $\begin{array}{c}2013- \\
2014\end{array}$ \\
\hline FV-7 & 6,905 & 5,089 & 5,799 & 5,855 & 7,570 & 6,378 & 6,562 & 5,528 & 7,016 & 6,494 & 6,558 & 5,487 \\
\hline FV-8 & 5,177 & 3,686 & 3,848 & 3,923 & 6,384 & 5,322 & 5,386 & 4,275 & 5,260 & 4,704 & 4,352 & 3,677 \\
\hline
\end{tabular}

BV5 and BV6 average includes Basement; $\mathrm{n} / \mathrm{a}=$ data not available

Shaded rows excluded from analysis in the report body. 
Table 27. Heating Season Estimated Energy Use

\begin{tabular}{|c|c|c|c|c|c|c|c|c|c|c|c|c|}
\hline \multirow{3}{*}{$\begin{array}{l}\text { Pilot } \\
\text { Home }\end{array}$} & \multicolumn{12}{|c|}{ Heating Season Estimated Heating Energy Use (December 1 Through March 21) } \\
\hline & \multicolumn{4}{|c|}{ Total Heating Season Energy Use, $\mathrm{kWh}$} & \multicolumn{4}{|c|}{$30^{\circ} \mathrm{F}$ Temperature Difference Normalized } & \multicolumn{4}{|c|}{3000 HDD Normalized } \\
\hline & $\begin{array}{c}2010- \\
2011\end{array}$ & $\begin{array}{c}2011- \\
2012\end{array}$ & $\begin{array}{c}2012- \\
2013\end{array}$ & $\begin{array}{c}2013- \\
2014\end{array}$ & $\begin{array}{c}2010- \\
2011\end{array}$ & $\begin{array}{c}2011- \\
2012\end{array}$ & $\begin{array}{c}2012- \\
2013\end{array}$ & $\begin{array}{c}2013- \\
2014\end{array}$ & $\begin{array}{c}2010- \\
2011\end{array}$ & $\begin{array}{c}2011- \\
2012\end{array}$ & $\begin{array}{c}2012- \\
2013\end{array}$ & $\begin{array}{c}2013- \\
2014\end{array}$ \\
\hline B-1 & 7,847 & 3,923 & 6,840 & 8,305 & 7,493 & 4,846 & 7,094 & 6,971 & 7,974 & 5,005 & 7,735 & 7,784 \\
\hline B-2 & 5,115 & 3,216 & 4,046 & 4,404 & 5,102 & 4,024 & 4,523 & 4,305 & 5,197 & 4,103 & 4,576 & 4,128 \\
\hline B-3 & 792 & 686 & 746 & 1,135 & 1,108 & 1,076 & 943 & 1,372 & 805 & 875 & 844 & 1,064 \\
\hline B-4 & 10,398 & 7,494 & 6,045 & 6,420 & 9,288 & 8,207 & 5,958 & 5,305 & 10,565 & 9,563 & 6,836 & 6,017 \\
\hline BV-1 & 6,436 & 5,023 & 6,897 & 5,167 & 8,823 & 6,854 & 8,063 & 4,847 & 6,540 & 6,409 & 7,799 & 4,842 \\
\hline B-5 & 637 & 575 & 1,864 & 3,214 & 1,471 & 1,193 & 2,748 & 2,829 & 647 & 734 & 2,107 & 3,012 \\
\hline B-6 & 4,513 & 3,575 & 2,792 & 2,991 & 7,678 & 4,928 & 3,941 & 2,967 & 4,586 & 4,562 & 3,157 & 2,803 \\
\hline BV-2 & 4,618 & 5,511 & 5,841 & 4,500 & 7,569 & 6,337 & 5,906 & 4,052 & 4,692 & 7,033 & 6,605 & 4,217 \\
\hline BV-3 & 5,253 & 2,929 & 4,942 & 5,608 & 6,176 & 3,528 & 5,272 & 4,920 & 5,338 & 3,738 & 5,589 & 5,255 \\
\hline BV-4 & 1,894 & 785 & 1,214 & 1,117 & 2,832 & 1,160 & 1,606 & 1,820 & 1,924 & 1,001 & 1,373 & 1,047 \\
\hline BV-5 & 8,071 & 4,705 & 4,738 & 6,744 & 9,469 & 5,330 & 5,095 & 6,115 & 8,201 & 6,003 & 5,358 & 6,320 \\
\hline BV-6 & 2,576 & 1,475 & 5,879 & 5,710 & 3,277 & 1,798 & 6,697 & 6,049 & 2,617 & 1,882 & 6,648 & 5,352 \\
\hline FB-1 & 6,371 & 5,009 & 4,253 & 5,564 & 7,523 & 5,600 & 4,463 & 4,684 & 6,474 & 6,392 & 4,809 & 5,215 \\
\hline FB-2 & 3,561 & 2,109 & 3,667 & 3,860 & 5,601 & 2,804 & 3,950 & 3,732 & 3,618 & 2,692 & 4,147 & 3,617 \\
\hline FB-3 & 4,900 & 2,674 & 3,614 & 2,813 & 6,644 & 3,304 & 3,949 & 2,870 & 4,979 & 3,412 & 4,086 & 2,636 \\
\hline FB-4 & 2,459 & 1,327 & 1,666 & 2,418 & 6,573 & 2,805 & 3,062 & 3,396 & 2,498 & 1,693 & 1,884 & 2,266 \\
\hline FB-5 & 4,878 & 3,675 & 4,005 & 3,663 & 5,422 & 4,674 & 4,666 & 4,124 & 4,956 & 4,690 & 4,529 & 3,433 \\
\hline FB-6 & 3,550 & 2,543 & 2,758 & 3,602 & 4,100 & 3,473 & 3,405 & 3,226 & 3,608 & 3,245 & 3,119 & 3,376 \\
\hline FB-7 & 838 & 669 & 974 & 329 & 1,764 & 1,521 & 1,920 & 594 & 852 & 854 & 1,101 & 308 \\
\hline FB-8 & 5,575 & 3,336 & 3,754 & 4,603 & 6,285 & 4,808 & 4,893 & 4,907 & 5,665 & 4,257 & 4,245 & 4,314 \\
\hline FV-1 & 3,659 & 2,172 & 3,270 & 3,741 & 7,065 & 3,363 & 3,878 & 3,352 & 3,718 & 2,772 & 3,698 & 3,506 \\
\hline FV-2 & 2,644 & 1,910 & 2,093 & 2,090 & 3,343 & 2,246 & 2,221 & 1,856 & 2,687 & 2,437 & 2,367 & 1,958 \\
\hline FV-3 & 3,451 & 1,647 & 1,503 & 2,205 & 4,337 & 2,101 & 1,839 & 1,809 & 3,507 & 2,101 & 1,700 & 2,067 \\
\hline FV-4 & 4,465 & 3,156 & 3,643 & 3,765 & 5,478 & 4,088 & 4,102 & 3,434 & 4,536 & 4,028 & 4,119 & 3,529 \\
\hline FV-5 & 4,492 & 3,200 & 2,692 & 2,997 & 4,498 & 3,788 & 2,955 & 2,945 & 4,564 & 4,083 & 3,044 & 2,809 \\
\hline FV-6 & 2,598 & 2,075 & 714 & 1,105 & 3,056 & 3,255 & 1,146 & 1,247 & 2,640 & 2,647 & 808 & 1,036 \\
\hline
\end{tabular}




\begin{tabular}{|c|c|c|c|c|c|c|c|c|c|c|c|c|}
\hline \multirow{3}{*}{$\begin{array}{l}\text { Pilot } \\
\text { Home }\end{array}$} & \multicolumn{12}{|c|}{ Heating Season Estimated Heating Energy Use (December 1 Through March 21) } \\
\hline & \multicolumn{4}{|c|}{ Total Heating Season Energy Use, kWh } & \multicolumn{4}{|c|}{$30^{\circ}$ F Temperature Difference Normalized } & \multicolumn{4}{|c|}{3000 HDD Normalized } \\
\hline & $\begin{array}{c}2010- \\
2011 \\
\end{array}$ & $\begin{array}{r}2011- \\
2012 \\
\end{array}$ & $\begin{array}{r}2012- \\
2013 \\
\end{array}$ & $\begin{array}{c}2013- \\
2014\end{array}$ & $\begin{array}{c}2010- \\
2011 \\
\end{array}$ & $\begin{array}{c}2011- \\
2012 \\
\end{array}$ & $\begin{array}{c}2012- \\
2013 \\
\end{array}$ & $\begin{array}{c}2013- \\
2014 \\
\end{array}$ & $\begin{array}{c}2010- \\
2011 \\
\end{array}$ & $\begin{array}{c}2011- \\
2012 \\
\end{array}$ & $\begin{array}{c}2012- \\
2013 \\
\end{array}$ & $\begin{array}{r}2013- \\
2014 \\
\end{array}$ \\
\hline FV-7 & 3,244 & 1,732 & 2,744 & 2,957 & 3,556 & 2,170 & 3,105 & 2,791 & 3,296 & 2,210 & 3,103 & 2,771 \\
\hline FV-8 & 3,883 & 2,517 & 2,684 & 2,713 & 4,788 & 3,635 & 3,757 & 2,956 & 3,945 & 3,212 & 3,035 & 2,542 \\
\hline
\end{tabular}

BV5 \& BV6 average includes Basement; $\mathrm{n} / \mathrm{a}=$ data not available

Shaded rows excluded from analysis in the report body. 
Appendix D: Greenbelt Homes, Inc. Pilot Program Phase 3: Heating Systems Overview 
Greenbelt Homes, Inc. Pilot Program

Phase 3: Heating

Systems Overview

Phase 3 - Report \#1, Rev. 2

Prepared for

Greenbelt Homes Inc. (GHI)

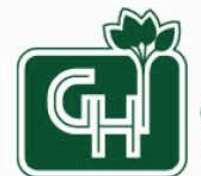

Greenbelt Homes Inc.

A COMMUNITY FOR PEOPLE WHO VALUE COMMUNITY

Prepared by

Home Innovation Research Labs

(Formerly NAHB Research Center)

400 Prince Georges Boulevard

Upper Marlboro, MD 20774-8731

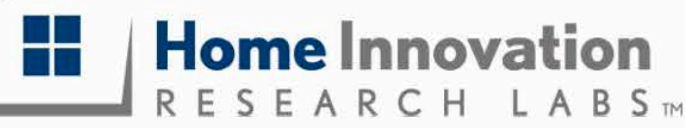




\section{Disclaimer}

Neither the Home Innovation Research Labs, Inc. nor any person acting on its behalf, makes any warranty, expressed or implied, with respect to the use of any information, apparatus, method, or process disclosed in this publication or that such use may not infringe privately owned rights, or assumes any liabilities with respect to the use of, or for damages resulting from the use of, any information, apparatus, method or process disclosed in this publication, or is responsible for statements made or opinions expressed by individual authors. 


\section{CONTENTS}

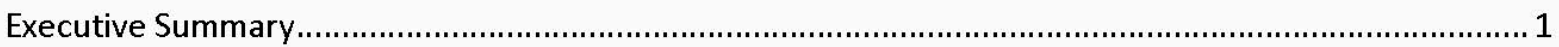

Definitions

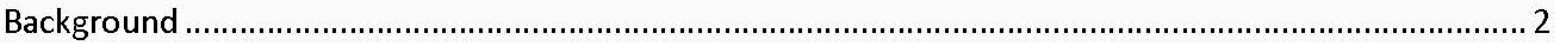

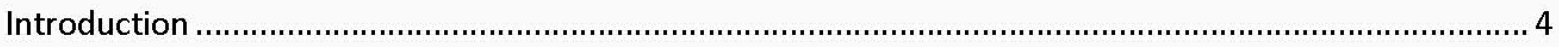

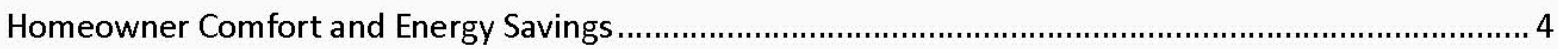

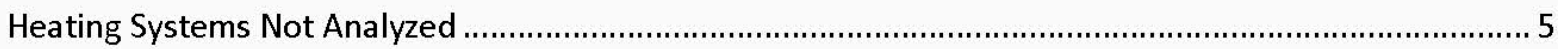

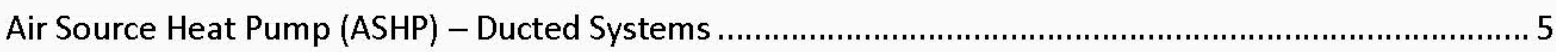

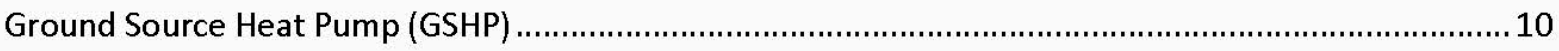

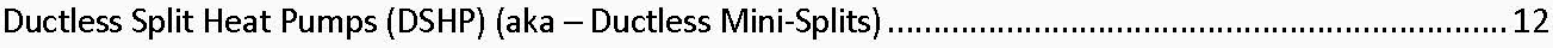

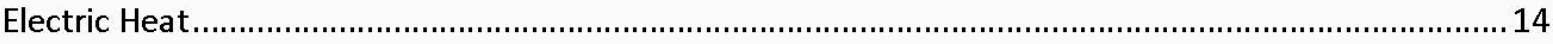

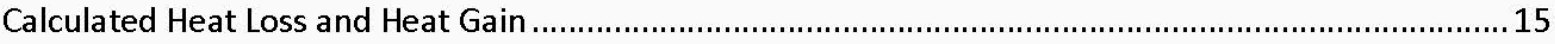

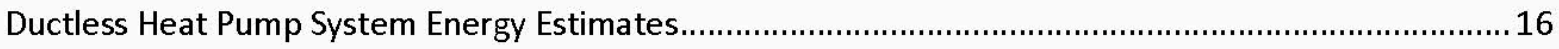

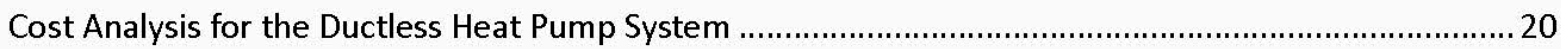

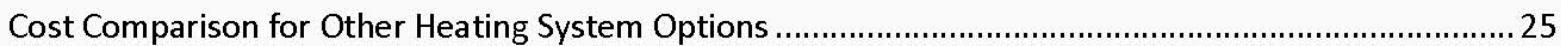

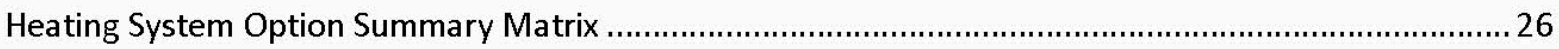

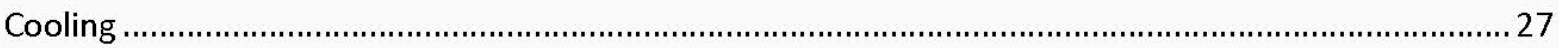

Summary Conclusions

Heating (and Cooling) System Recommended Strategies for the Pilot Program ...................................29 


\section{TABLES}

Table 1. GHI Heating and Cooling Load Calculations (ACCA Manual J8) …......................................... 16

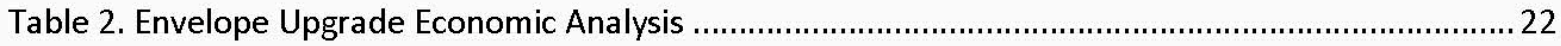

Table 3. Envelope Plus Heat Pump Upgrade Economic Analysis ....................................................... 23

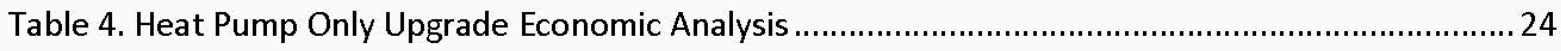

Table 5. Summary of Heating System Options Compared with the Ductless HP Option .........................25

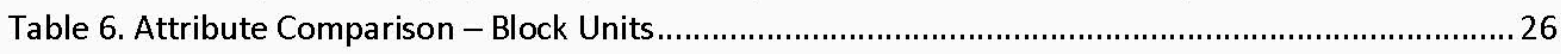

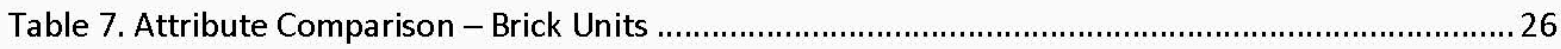

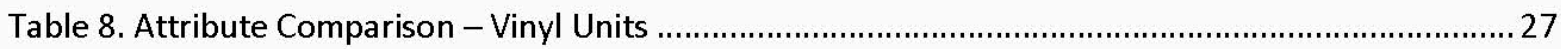

\section{FIGURES}

Figure 1. Major Heat Pump Equipment Components, Outdoor Unit, Indoor Air Handler, and Coil ............ 5

Figure 2. Example of an Air Handler and Duct Layout in a Brick Unit................................................... 7

Figure 3. Example of an Air Handler and Duct Layout in a Frame Unit ................................................ 8

Figure 4. Description of a GSHP System (courtesy of geoexchange.org) .............................................. 10

Figure 5. Components of a Mini-Split Heat Pump ….................................................................. 12

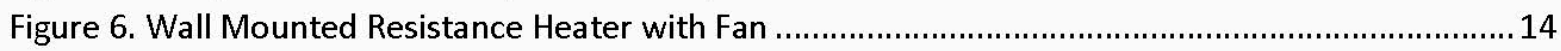

Figure 7. Radiant Heat Panel Typically Ceiling Mounted ….......................................................... 14

Figure 8. Example Ceiling Layout for Radiant Panels ....................................................................... 14

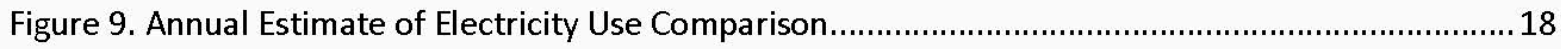

Figure 10. Percent Savings over Existing Conditions ..................................................................... 19 


\section{Executive Summary}

Options for changes and upgrades to the heating systems in the GHI Pilot program homes were investigated and promising alternatives were analyzed. The investigation combined a review of common and uncommon technologies used in residential housing, meetings and field evaluations at both Greenbelt Homes, Inc. (GHI) and at Home Innovation Research Labs (formerly NAHB Research Center), simulations to estimate the energy use of various technologies, and cost analysis to provide one perspective on costs and savings.

Two important influential but non-technical themes underlie this investigation and must be recognized throughout the analysis and conclusions presented and when considering changes to the heating systems. The first is ongoing comfort and livability in the homes and the second is the value provided to the members in terms of control, convenience, and resale. These themes are not addressed directly in this investigation as they are in the purview of GHI members; however, the information provided here is meant to offer technical perspective and as such is only one part of the decision process.

Technical aspects of the heating and in some cases cooling, equipment and systems were evaluated based primarily on:

- Installation - how complex and/or disruptive to the member and permanent modifications to the interior space;

- Performance - how effective is the system design in conditioning the entire home, expected use of back-up heating, and noise;

- Energy Savings - what is the estimated energy savings based on system ratings;

- Cost - what is the estimated cost for installation, operation, and maintenance; and

- Timing - how do energy savings and costs relate to the envelope upgrades in each of the types of houses in the pilot program?

Other factors such as the equipment size, the availability of components, and the house construction and layout also inform the analysis. In the case of the block homes for instance, without wall insulation improvements, it would be very difficult to size a heat pump system to provide both adequate heating and cooling. In the case of the ground source heat pump technology, the selection of components is critical to long-term performance and satisfaction. Factors such as these are interwoven throughout the investigation.

The GHI pilot program is organized to evaluate envelope upgrades, recognizing that these upgrades continue to perform over the lifetime of the home, and much longer than any mechanical system such as a heat pump. The original report on envelope upgrades was evaluated for installation cost and energy savings and for all building types; one or more upgrade options were found to be cost effective based simply on energy savings. This same result is not achievable with the upgrades to the heating systems. 
In most cases, when evaluating the upgrade to a much more efficient heating system, the cost analysis does not demonstrate sufficient heating energy savings to provide a cost-effective solution based on estimated installation costs and current energy prices. The only building type that shows a marginal energy-savings based cost-effectiveness is with the block buildings when the exterior insulation system is the least expensive option available. However, this result does not lead to the decision to "do nothing."

The "do nothing" heating system option is simply to continue on the current maintenance/replacement track for the electric baseboard heaters. This option is always available and energy savings attributed to the envelope improvements will continue to accrue. This option however does not take into account the non-economic benefits of reduced energy use, enhanced comfort, and cooling/dehumidification, among others.

Given the range of both cost and other benefits with upgrades to the heating systems, this report concludes with a set of proposed strategies for each building type. The purpose of these strategies is to garner both installation and performance experience, and including member feedback, regardless of the estimated energy savings. These strategies cover a range of heating technologies and focus on specific learning outcomes, and are provided as options as information for the decision process.

\section{Definitions}

\begin{tabular}{ll}
\hline COP & $\begin{array}{l}\text { Coefficient of Performance. A measure of heating efficiency at a specified set of indoor } \\
\text { and outdoor conditions, measured as a ratio of heat energy output to energy input } \\
\text { using consistent units. }\end{array}$ \\
EBB & $\begin{array}{l}\text { Electric Baseboard Heat } \\
\text { EER }\end{array}$ \\
& $\begin{array}{l}\text { Energy Efficiency Ratio. A measure of cooling efficiency (may also be used for heating) } \\
\text { at a specified set of indoor and outdoor conditions, measured as a ratio of cooling } \\
\text { output per electrical input (Btuh/Watt). }\end{array}$ \\
GSHP & Ground Source Heat Pump \\
HSPF & $\begin{array}{l}\text { Heating Seasonal Performance Factor. The total seasonal heating output (Btu's) divided } \\
\text { by the total electrical input during the same period (Watt-hours), at a specified set of } \\
\text { indoor conditions. The HSPF }\end{array}$ \\
SEER & $\begin{array}{l}\text { Seasonal Energy Efficiency Ratio. The total seasonal cooling output (Btu's) divided by } \\
\text { the total electrical input during the same period (Watt-hours), at a specified set of } \\
\text { indoor and outdoor conditions. SEER is the cooling performance equivalent } \\
\text { measurement of HSPF. The SEER rating is typically about } 3 \text { to } 4 \text { points higher than the } \\
\text { corresponding EER rating. }\end{array}$ \\
\hline
\end{tabular}

\section{Background}

Greenbelt Homes, Inc. (GHI) is investigating opportunities to cost-effectively enhance the energy performance of its portfolio of homes. The goals of GHI Buildings Committee's work on the pilot program and subsequent community upgrade program are the following: 
- Reduce overall energy consumption and costs in the homes;

- Improve member comfort and "livability";

- Emphasize use of sustainable, environmentally friendly energy sources, technologies, and products where economically feasible;

- Reduce overall life cycle costs, including preventive and corrective maintenance, for heating, cooling and domestic hot water systems;

- Minimize disruption to households as improvements are being made; and

- Implement the program while maintaining the unique and historic character of the GHI homes.

The pilot project is a three-phase, two-year effort. The first phase, Phase 1, of the pilot involves a yearlong effort to establish baseline data on the 28 pilot homes and to identify specific retrofit building envelope (not equipment) solutions for each of the building types in the pilot home study. Baseline measurements included a walk-through evaluation of each pilot home, short-term testing (e.g., blower door test), and longer term monitoring (e.g., temperature, humidity, energy use, etc.) of the current conditions of the home. The building characteristics identified in the walk-through evaluation were used to develop simulation models to estimate whole-house energy use.

Phase 2 of the pilot home program consists of retrofitting the building envelopes and continued monitoring of the indoor environment and energy use. This will enable GHI to determine the difference that building envelope upgrades can make by themselves in terms of temperature, humidity, energy use, and member comfort. During the year that the envelope improvements are installed and measurements are taken, $\mathrm{GHI}$ will develop specifications for the third phase of the pilot-investigating opportunities to improve the heating (and potentially, cooling) systems in each of the pilot homes. GHI continues to implement Phase 2 upgrades.

Phase 3 of the pilot study will enable GHI to compare the energy efficiency and payback periods for the alternative HVAC (heating, ventilation, and air conditioning) systems tested, as well as for the entire pilot project of envelope and mechanical system upgrades. Detailed measurements will enable GHI to determine which features and systems provide the most benefit for the least cost over a long-term period that includes estimated maintenance and replacement costs. Based on the results of the pilot, GHI's Buildings Committee will draft recommendations for the GHI-wide upgrades to the membership and the GHI Board of directors in late 2013.

Since October 2010, GHI has partnered with the Home Innovation Research Labs (Home Innovation), through the U.S. Department of Energy's Building America Program. Home Innovation, with support from the National Renewable Energy Laboratory (NREL), provides design guidance and logistical support to $\mathrm{GHI}$ for the investigation, testing, monitoring, and analysis of energy improvements for $\mathbf{2 8}$ homes that have been selected for the three-phase pilot project. The role of Home Innovation researchers is to evaluate the current features of the pilot homes and using various research tools including inspections, software models, and field measurements to develop upgrade packages for improving the energy performance of the homes. Home Innovation will continue to support GHI throughout all phases of the pilot project. 
To date, the crawlspaces of the pilot homes have been retrofitted to improve the insulation and reduce air leakage losses from the home. Unrelated to direct energy savings, the crawlspace floors have been sealed with a vapor barrier to reduce moisture loads into the crawlspaces and ultimately, the homes. The attics of the brick and vinyl frame homes have been improved to air seal leakage from the home to the attic space and to add insulation while maintaining the necessary storage space for the homeowners.

The purpose of this report is to detail the investigation into the options and requirements for changing the heating system from the current electric baseboard heaters common to GHI housing. This investigation summarizes the options for equipment to heat the homes, the installation requirements for the equipment, and the estimated energy savings and the commensurate economic analysis of the improvement costs and energy savings.

\section{Introduction}

Multiple heating (and cooling) equipment and installation methods to heat and cool the GHI pilot homes were considered for the investigation into improving the space conditioning equipment for the pilot homes. Some approaches were rejected as impractical based on the technology and others were rejected after an evaluation of the hardware and installation requirements. This report highlights the approaches that are feasible based on the technology, installation, and performance. Some of these approaches have a track record in GHI homes and can provide an experience base from which to garner anecdotal evidence. Evaluation factors for any heating system option may include installation, performance ranges, maintenance expectations, and cost investment and savings estimates. Other factors which were considered but are less quantifiable include the practical implementation of the system and occupant disruption during installation. Though less important in this stage of the pilot program, any heating system solution should be based on the calculated heating (and cooling) load requirements, including mechanical fresh air ventilation loads, after the energy efficiency improvements have been made to the building enclosures.

\section{Homeowner Comfort and Energy Savings}

While an important goal of the GHI pilot program is to reduce energy use, there is a complementary goal of homeowner comfort, especially during the winter heating season. Previously reported data has shown that in the pilot homes, the average indoor temperature during the winter period was between $65^{\circ} \mathrm{F}$ and $67^{\circ} \mathrm{F}$. This indoor temperature is somewhat below the $70^{\circ} \mathrm{F}$ to $72^{\circ} \mathrm{F}$ range typically used in energy programs and for HVAC system sizing. Based on homeowner feedback in GHI, energy costs play a significant role in maintaining lower indoor temperatures.

There is a general assumption that when homes are made more efficient there is often a "take-back" effect where higher efficiency devices can lead to a change in behavior in operating equipment. This behavior change can lead to for example, not bothering to turn off lights as often, taking longer showers, or in setting the thermostat at a more comfortable temperature. 
A brief analysis of this take back effect for the heating and cooling system shows that heating energy savings could be reduced by between $15 \%$ and $20 \%$ when the indoor temperature estimate is changed from $68^{\circ} \mathrm{F}$ to $72^{\circ} \mathrm{F}$. However, this aspect of energy use and savings is under the control of the homeowner at all times and as such is simply acknowledged, but not used, in this analysis.

\section{Heating Systems Not Analyzed}

Natural gas service is not available to most of the GHI homes; therefore, natural gas options for heating were not evaluated. If natural gas was available, a method for heating could be one central boiler (high efficiency, direct vent with modulating capacity) per building that would require radiators (baseboard convectors or low-profile, compact wall mounted radiators) or hydronic fan-coils (ducted or nonducted), requisite piping, zone controls, and metering for the individual units. A central boiler type system would require some type of metering that likely would need to be coordinated through GHI staff or its designee. Natural gas could also be used in each home using a single-point, direct-vent appliance that could be wall mounted and service the entire unit. This approach may require openings to be cut through the floor above or some type of fan system to distribute heat. Multiple appliances per unit could also be considered but although very effective heaters, such appliances are generally not as efficient (70 to $75 \%$ AFUE ratings) as other options.

Similarly, propane, oil, and wood-fired heating systems were rejected for analysis due to the cost of the fuel and the requirement for the installation of a large infrastructure to store and deliver the fuel to the appliances. This infrastructure cost would be added to the cost of installing high efficiency heating appliances in each of the homes. Furthermore, since the GHI homes are all electric, the installation of combustion appliances would require special attention to venting and the supply of combustion air and protection of storage tanks from damage.

Packaged terminal heat pumps were also not evaluated. These ductless, through-the-wall packaged units, commonly used in motels, require a large opening through the exterior wall for each unit and are generally not available in high efficiency models. Similarly, ducted packaged heat pumps are available; these units are installed in a closet adjacent to an exterior wall and require a duct system. These also require a large opening through the exterior wall (for the condenser coil) and are relatively inefficient.

The systems that are considered practical solutions for heating and cooling are ducted air source heat pumps, ground source heat pumps, ductless split heat pumps, and electric resistance heating.

\section{Air Source Heat Pump (ASHP) - Ducted Systems}

Conventional split system heat pumps are comprised of an outdoor heat pump, indoor air handling unit (or fancoil), refrigerant piping between, and a duct distribution 
system. Capacities range from 1.5-ton through 5-ton (1 ton of refrigeration equals 12,000 BTUH). A 2-ton system is the smallest capacity for higher efficiency two-stage compressors and variable speed compressors (variable refrigerant flow using inverter technology, not yet common for conventional systems). The availability of even lower capacity equipment is extremely important for the smaller footprint GHI homes, and in particular following envelope upgrades that result in reduced demand on the heating (and cooling) system. Heat pump system efficiencies range from the federal minimum 13 SEER, 7.7 HSPF through 20 SEER, $12 \mathrm{HSPF}$ and even higher. ${ }^{1}$ A common price point for conventional split systems is 16 SEER, 9 HSPF. Efficiencies exceeding this level generally require two-stage or variable capacity equipment, and come at a higher cost. Conventional heat pumps are generally sized in this climate to meet the cooling loads; an electric resistance heating element is installed in the air handler to provide supplemental heat as the outdoor temperature drops below the balance point (where building heat loss equals equipment capacity), and during heat pump defrost operation. More advanced inverter technology systems, and to a limited extent, two-stage equipment, may be sized for the heating load because these can turn-down (the output capacity) to provide sufficient cooling and dehumidification.

Standard split systems shown in Figure 1 require a conventional ducted air distribution design to supply conditioned air to the rooms from the air handler. As some GHI members are familiar, the duct system layout presents several challenges in the typical GHI floor plan. Among the most prominent are that the indoor air handling unit must be installed in a closet, corner of a room, attic, or crawl space. Use of the crawlspace was ruled out for the frame homes since they are often inaccessible for larger equipment and are vented to the exterior increasing the losses from any system installed. For the block and brick homes, the crawlspace is sufficiently tempered but penetrating the concrete floor with large ducted openings does not appear practical. Installing air handlers and ducts in the attic of brick and frame units is a credible option, but doing so increases the calculated heating and cooling loads and operating costs, and reduces attic storage area. For this pilot program, the most practical and efficient option for the split system would be to utilize closet space or the corner of a room for the indoor air handler unit to which the duct system must be connected.

Duct installation in any of the homes would require some duct runs below the ceiling plane which will require bulkheads to conceal them. Installing duct above first floor ceilings (frame and brick units) requires some demolition and finish work. The actual supply duct layout will vary by floor plan and numerous iterations would be required. The supply duct design must effectively mix the air without creating drafts, stagnant zones, and excessive noise. Central return ducts must be designed to minimize equipment noise and noise due to air velocity and turbulence and may call for bedroom transfer grilles to allow for an adequate return air path to the central return. Figure 2 and Figure 3 provide an example layout of a duct system in two of the pilot homes.

\footnotetext{
${ }^{1}$ SEER and HSPF ratings for equipment are based on standardized industry testing methodologies. Higher SEER and HSPF rating values indicate higher efficiency and thus reduced operating costs.
} 


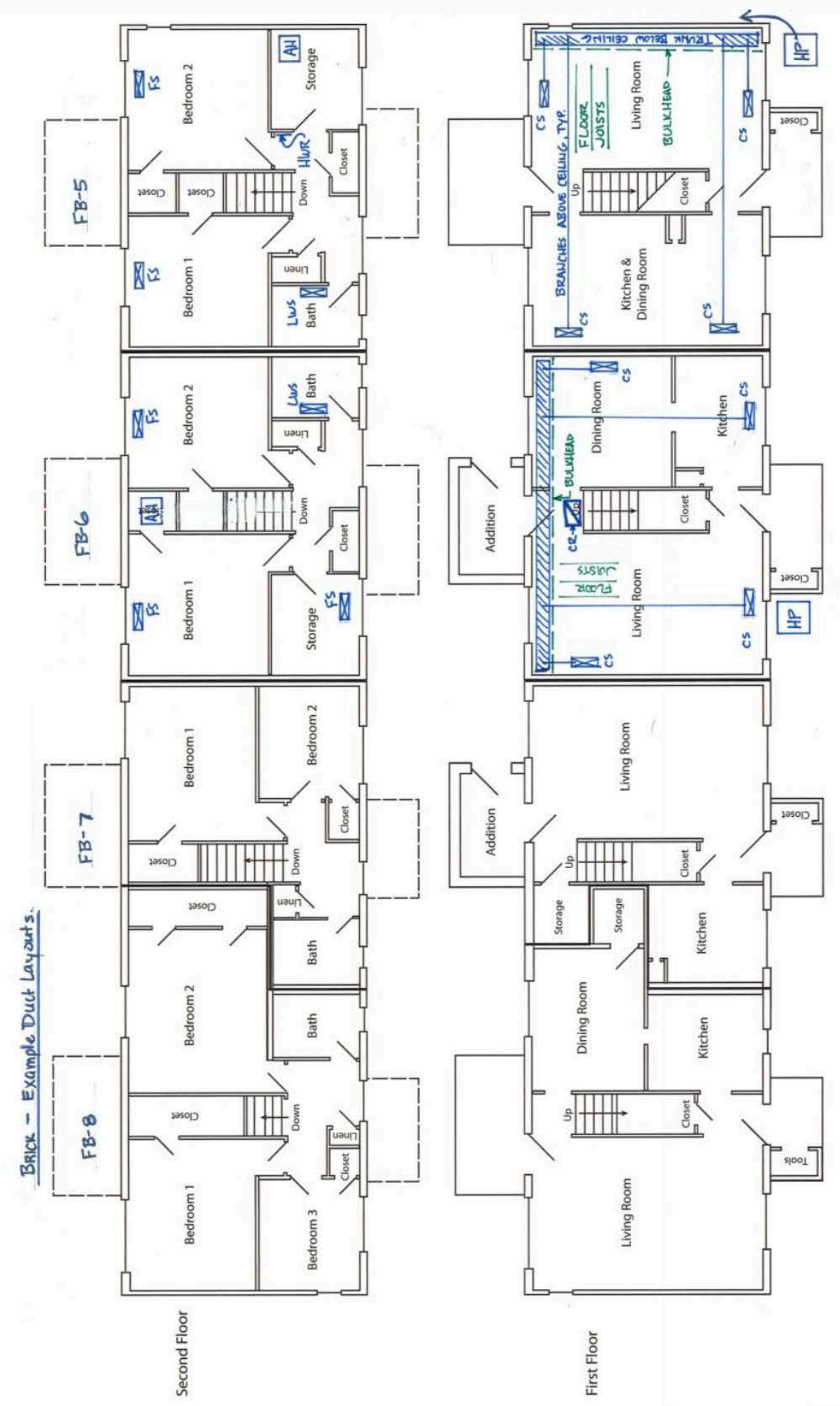

Figure 2. Example of an Air Handler and Duct Layout in a Brick Unit 

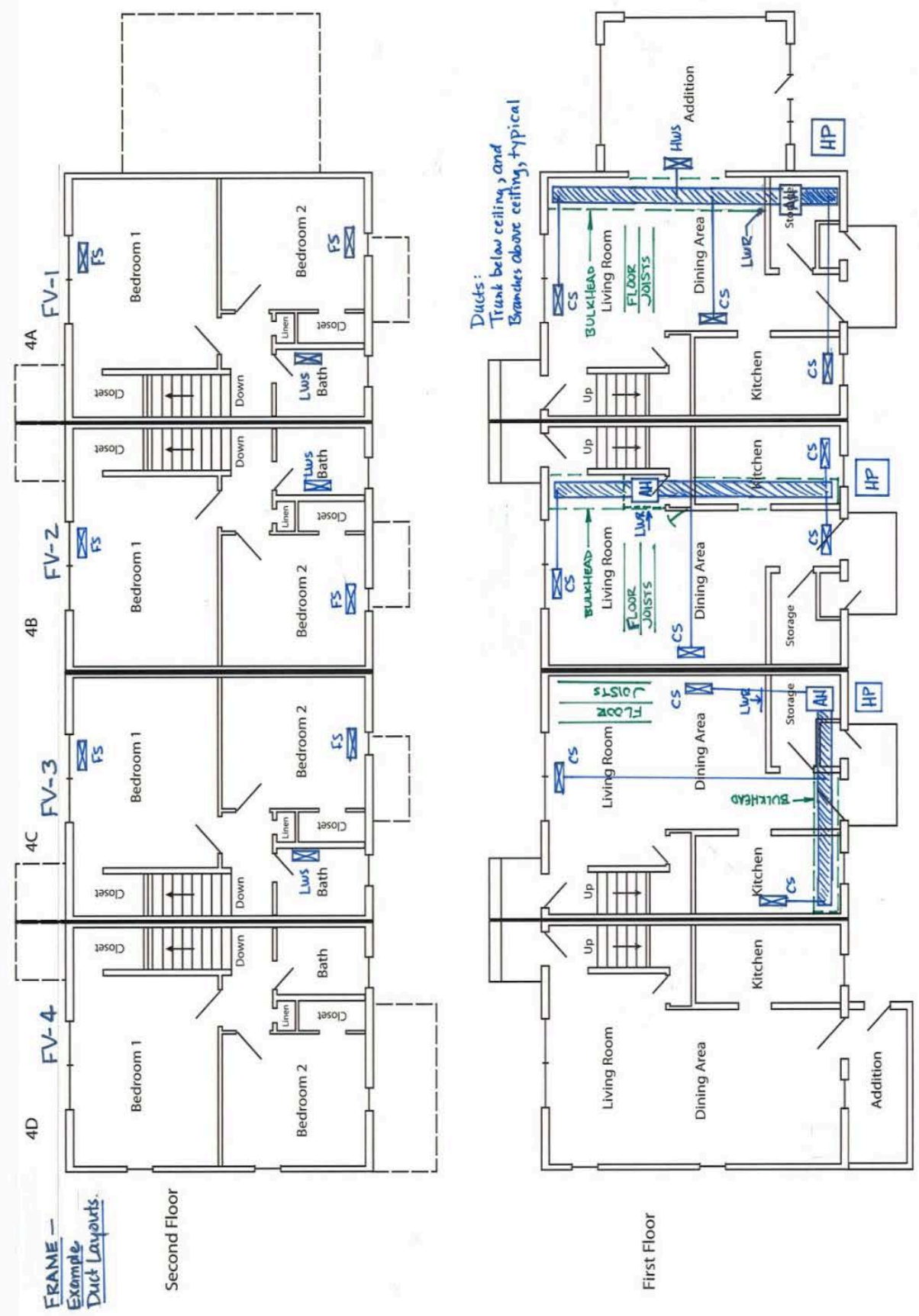

Figure 3. Example of an Air Handler and Duct Layout in a Frame Unit 
The example duct layouts demonstrate the complexity of planning the duct system and the obvious disruption to the interior of the home. Duct runs perpendicular to the floor framing must be boxed in (typically called a bulkhead) and result in an aesthetic challenge for many rooms. Some duct runs; however, may be cut into the floor joist space (except for the block homes) to minimize bulkheads.

Generally, the conventional ducted heat pump system requires significant indoor space for the airhandler, an effective duct layout is an installation and aesthetic challenge (block units are particularly difficult due to concrete beams and necessary cutting through concrete floors), and installation of the split system and ducts is likely very disruptive to occupants unless the home is unoccupied. Additionally, the smallest capacity systems are oversized for many of the GHI units, especially after thermal enclosure upgrades are complete. A rough budget estimate range for these systems is $\$ 16$ to 18,000 installed per unit, including finish work to conceal the duct. Attic installation of equipment results in higher losses and therefore reduces the cost benefit of installing the system.

One option for reducing the impact of the duct system is to consider a high velocity split system heat pump. These systems are very similar to the conventional ducted split system heat pump, except that the air distribution system is comprised of smaller ducts, typically 4 " diameter including the insulated flexible branch ducts. This is a large reduction from the standard 6 " to $12^{\prime \prime}$ diameter trunk ducts. The high velocity duct systems require less space but otherwise have similar challenges as conventional duct systems. A high velocity system is comprised of a conventional outdoor heat pump connected to a proprietary air handler and duct system. SpacePak and Unico are two common manufacturers of the high velocity air handler and duct systems. The smallest available capacity is 2 -ton, and efficiencies are similar to conventional heat pumps, but limited at the higher efficiency levels due to higher energy use in developing the high velocity air flow. A budgetary installed cost will be similar to a conventional ducted heat pump; the air handler and duct material costs tend to cost more, but the labor and finish work to conceal the ducts may offset these.

One other option briefly reviewed for application to the GHI homes is a packaged heat pump. The packaged heat pump system combines the outdoor heat pump and indoor air handler into one package that is installed outdoors on the ground or roof and ducted into the house through the wall or roof. These systems are most common for commercial applications. No indoor space is required for the air handler, but a duct system is still required. The smallest capacity commonly available is a 2-ton system, and efficiencies range from 13 SEER, 7.7 HSPF through approximately 15 SEER, 8.2 HSPF, somewhat lower than split system heat pumps. An economizer that allows for "free" air conditioning is a common option on commercial systems but adds cost that is often not recouped in residential applications. Since these systems are installed outdoors, avoiding the use of indoor floor space is attractive, but these systems are oversized for most GHI homes and still require duct systems. The installation of the main portion of the system on the exterior of the home will reduce the overall efficiency of the system, but does provide for easy serviceability. Due to the lower efficiencies and small cost differences from other ducted systems, this option was not considered further. 
A summary of the Pros and Cons of the Ducted Air Source Heat Pump Systems -

Pros

- Provides all heating, cooling, and dehumidification

- Energy efficiency ranges from good to very good (best for the most efficient systems)

- Conventional equipment allows greater flexibility to arrange for service

- Integral electric supplementary and back-up heat

- Conventional duct layout provides best distribution

- Future replacement costs relatively low (duct system already in place)

Cons

- Smallest available units may be oversized, particularly for high efficiency systems

- Indoor air handler takes valuable space

- Outdoor unit takes space and may be objectionable (high efficiency units are quieter)

- Duct system design and layout is a challenge and varies by unit

- Duct system may not be possible in block units

- Some demolition is required in most units to install the ducts

- Bulkheads are required to conceal the ducts

- Installation is most disruptive to occupants

- Expensive initial cost

\section{Ground Source Heat Pump (GSHP)}

A GSHP system consists of the GSHP equipment, a ground loop that transfers heat with the earth, and a distribution system to heat and cool the house. The equipment is most commonly a water-to-air unit, an indoor packaged unit that contains both the heat pump and air handler that relies on a duct system to distribute conditioned air, and a pump installed near the GSHP that circulates the water mixture through the ground loop piping. The duct system is the same as a conventional air source heat pump system, and has the same installation challenges.

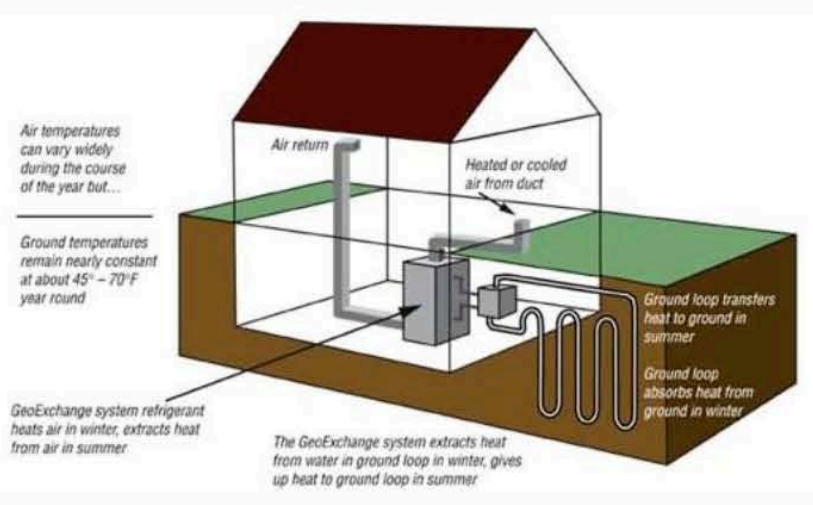

Figure 4. Description of a GSHP System (courtesy of geoexchange.org) An alternative water-to-air system is the ductless console GSHP. The console GSHP provides conditioned air without ducts, so a number of these are required at different locations in the house to provide adequate distribution. Alternatively, a water-towater GSHP can provide hot water and chilled water to any number of ducted or ductless fan coils, or hot water to radiators or convectors. The smallest available capacities are 1-ton (for single-stage compressors) or 2-ton (for 2-stage compressors) for ducted systems, and 0.75-ton and 1-ton for ductless console systems. Generally, efficiency ranges are 16 to 27 EER and 4 to 5 COP. 
The ground loop consists of piping installed in the ground that circulates a water-glycol mix to transfer heat from the ground to the equipment for heating, and the reverse for cooling (see Figure 4). The ground loop piping is most commonly installed in vertical wells. Each GSHP typically has a dedicated ground loop, but a community loop or whole-building loop (consolidated bore field) is an option. The ground loop is installed by a well drilling company that is familiar with the local geology. The well drilling truck requires access to the well site, and this access may be difficult for some GHI buildings. Multiple loops for a set of homes (a common well field) could be installed in one area reducing the access requirements to a site. The well drilling costs can vary by location.

The ground loop piping is installed into the building and connected to the ground loop pump (each GSHP requires a dedicated pump). For a consolidated bore field, the ground loop water may be distributed using a manifold or a storage tank. For a manifold layout, each individual pump can circulate water through the ground loop. If an additional common ground loop pump is part of the design, a method to meter that shared energy use is required. Each housing unit generally requires its own GSHP equipment because one unit may require cooling at the same time another unit may require heating, and one GSHP cannot provide both at the same time.

Staff from the Home Innovation met with a GSHP manufacturer and two GSHP installation contractors in order to investigate practical applications and prepare budget estimates for GHI. A budget estimate for a typical high efficiency GSHP (water-to-air equipment, ground loop, conventional duct system, and bulkheads to conceal ducts) is approximately $\$ 25,000$ installed, per unit. For a ductless console GSHP system with three consoles, a budget estimate is approximately $\$ 25,000$ to $\$ 40,000$ per unit. These costs do not include either state or federal incentives that may be available.

After numerous calls and two site visits with an installation contractor, a GSHP system was developed specifically for GHI. That system includes a high efficiency, nominal 2-ton, 2-stage, water-to-water GSHP (one per unit) to provide heated or chilled water to high-wall ductless fan coils (quantity of three to six depends on unit size and layout), the ground loop, ground loop pump, installing the GSHPs in the boiler room area of the crawl spaces, and insulated piping from the GSHP to a manifold; each fan coil would require two pipes from the manifold, a condensate drain, and electrical wiring (these would need to be covered using a wood frame with drywall or other method). This system would provide individual thermostats and zone control and does not require ducts. Estimated installed price: $\$ 23,000$ to $\$ 29,000$ per unit, including the electrical work but not including the costs to conceal the piping.

For comparison purposes, a conventional air source heat pump system with the air handler in the attic was investigated. For example, a 2-ton, 16 SEER, 2-stage outdoor unit, air handler with EC motor and 8 or 10 kW supplemental heat, refrigerant and condensate piping, programmable thermostat, and duct system: (1) return filter grille in the second floor ceiling, (4) ceiling registers for the first floor, and (4) ceiling registers for the first floor (installed from the attic and through the second floor). Estimated installed price: $\$ 17,000$ per unit, including bulkheads to conceal the duct drops through the second floor.

Also for comparison, new simulation models were developed for two brick homes (one end and one middle unit) to estimate the energy savings of the GSHP system relative to an air source heat pump 
system. Both systems were estimated to have the ducts installed in the house to simplify the models. Comparing a high efficiency GSHP with a high efficiency ASHP resulted in about a $3 \%$ heating energy savings for the GSHP ( $1 \%$ whole house energy savings). As an added point of reference, the installation contractor is planning to make energy savings estimates.

A summary of the Pros and Cons of the Ground Source Heat Pump Systems -

Pros

- Provides heating, cooling, and dehumidification

- Most energy efficient system

- No outdoor unit

- Moderately disruptive to occupants (depending on distribution method)

\section{Cons}

- Requires either a conventional ducted distribution system (and corresponding design challenges, demolition, and bulkheads), or multiple ductless console or ductless fan coil equipment (and corresponding piping)

- The ductless fan coil option that uses heated or chilled water from a water-to-water GSHP is a custom design using equipment from two different manufacturers. This can be problematic in the event of a service or performance issue.

- May require some operation of existing electric heaters during cold weather, depending on the distribution system selected

- Efficiency ratings provided by manufacturers do not take into account ground loop pump energy (or circulator pump or fan power for the ductless fan coil option)

- Ground loop installation is critical to realize the energy efficiency advantages of GSHP systems.

- Most expensive initial cost

\section{Ductless Split Heat Pumps (DSHP) (aka - Ductless Mini-Splits)}

The ductless split heat pump (DSHP), also known as a ductless mini-split, consists of one outdoor heat pump, one indoor fan coil or multiple indoor fan coils (zones), refrigerant and condensate piping, electrical wiring, and a thermostat (Figure 5 shows the primary components of the mini split with the indoor fan coil shown at the top). Total system capacities are commonly 0.75-ton (9,000 BTUH), 1-ton, 1.5-ton, 2-ton, and larger. The indoor fan coil capacities start at $6,000 \mathrm{BTUH}$. Efficiency ranges are 13 to 26 SEER and 7.7 to 10.5 HSPF. DSHPs are available with standard compressors or inverter-driven compressors; the inverter technology with variable refrigerant flow provides much higher efficiencies, higher discharge air

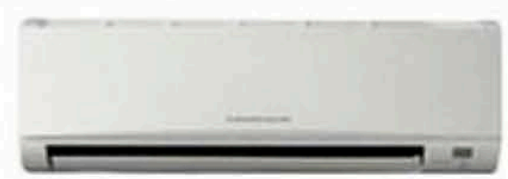

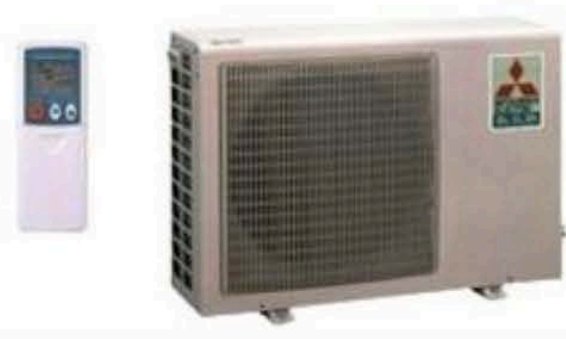

Figure 5. Components of a Mini-Split Heat Pump 
temperatures, and consistent heating capacities at lower outdoor temperatures. The inverter heat pump capacities are commonly selected to meet heating requirements; these systems can ramp-down to about $25 \%$ capacity so that latent cooling performance is not sacrificed during the humid summer months.

The ductless indoor fan coils distribute the conditioned air through oscillating fan blades and are most commonly installed high on a wall. Floor and ceiling consoles are available but are not as common for residential applications. Ducted indoor fan coils are also available and these could be a solution for the second floor bedrooms and bath, or for the entire unit, if space could be made for the air handler and duct system as described above.

For the typical unit with a central stairway, one fan coil installed in the living room may or may not provide adequate comfort to the dining room and kitchen. In some cases, a second fan coil may be required for the first floor or in larger additions. Similarly, one fan coil in each of the two bedrooms may not provide the same temperature in the bath room or in a third bedroom or hallway (for smaller two bedroom units, one fan coil in one bedroom may not provide the same comfort in the other bedroom). As the outdoor temperature drops during the heating season, the existing electric baseboard or ceiling heaters would likely be required for supplemental heat in rooms without a fan coil.

Generally, the DSHP systems are quiet, efficient, and provide zone control. The single-point heating and cooling strategy on the first floor and single-point or two-point strategy on the second floor is most effective and comfortable in well insulated houses. Occupant disruption is minimal during the installation of DSHP systems.

A budget estimate for a 2 -ton inverter heat pump with three fan coils (zones) is $\$ 10$ to 13,000 installed, including the electric circuit to the outdoor unit. A 3-ton inverter heat pump with four zones is estimated at $\$ 18,000$. A 1.5 -ton or 2 -ton inverter heat pump with two zones is estimated at $\$ 8$ to 10,000 .

An unconventional approach using a DSHP would be to install one fan coil in the living room, sized to heat and cool the entire unit, with an independent fan to distribute air upstairs. This fan, for example, could be ducted from a return grille in the first floor ceiling to supply registers in the bedrooms. Transfer grilles through the bedroom walls above the doors would be recommended to provide a low-resistance return air path when doors are closed. This would be the least expensive DSHP approach (budgetary installed cost of $\$ 7,000-\$ 8,000)$, but it is important to identify such a system as experimental until the design details are developed and the performance tested.

A summary of the Pros and Cons of the Ductless Heat Pump Systems -

Pros

- Provides heating, cooling, and dehumidification

- Very energy efficient

- Very quiet operation

- Least disruptive to occupants during installation

- Zone control (but not each individual room, for rooms without a fan coil) 
- Inverter DSHP systems modulate for optimum energy efficiency and occupant comfort

- Compact outdoor unit may be installed on a frame attached to the wall

- Initial cost - compared to other solutions

\section{Cons}

- Indoor fan coil may be aesthetically objectionable

- Fan coils are commonly not installed with electric supplemental heat, so existing electric baseboard and ceiling heaters may operate during colder weather, particularly in rooms without a fan coil.

- Initial cost

\section{Electric Heat}

Most GHI homes are heated with electric resistance heat using electric baseboard heaters in all rooms except some kitchens and baths that use electric ceiling heaters. This method is inexpensive to install and provides heat to each room and zone control since each heater may be controlled separately. Unfortunately, this heating system is more expensive to operate than a heat pump system. Since the baseboard heaters rely on natural convection for air mixing, the heating operation may result in less comfort than with forced air systems. Electric heating options include leaving the existing electric baseboard heaters which is the low cost option. While keeping the same technology, the electric baseboard heaters can be replaced with fan-powered heaters (Figure 6) installed on a wall away from curtains and furniture to enhance comfort. These units can be more easily controlled using wall mounted or wireless thermostats (some are even programmable).

A less conventional electric heating option is to use radiant panel (Figure 7) technology in place of the electric baseboard heaters. The radiant panel technology is designed to heat the individual directly through radiant heat transfer. Similar to feeling the warmth of direct sun on a cold clear day, the panels use the similar physical principal. As with the electric baseboard heaters, each panel would be controlled independently. A simple layout (Figure 8) was provided by the manufacturer. Since the effectiveness of the panels increases significantly with ceiling installation, wiring would need to be run from a wall location to the ceiling. In most cases, the existing electric circuits used for the electric baseboard heaters could be repurposed for use with the radiant panels.

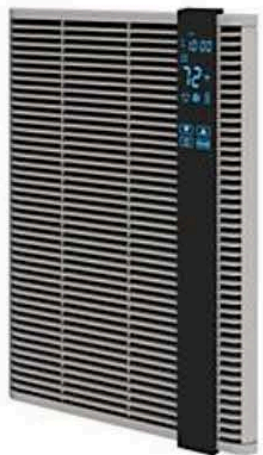

Figure 6. Wall Mounted Resistance Heater with Fan

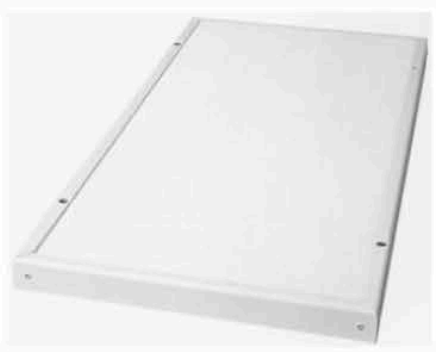

Figure 7. Radiant Heat Panel Typically Ceiling Mounted

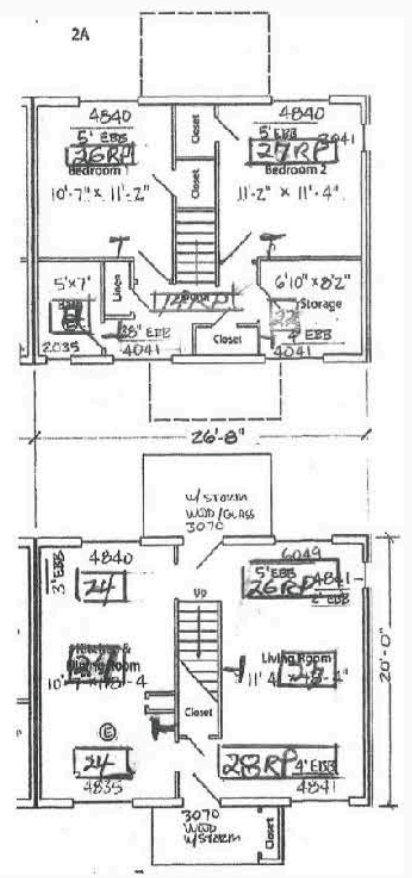

Figure 8. Example Ceiling Layout for Radiant Panels 
While electric resistance heating has been the more expensive option for heating costs, the improved thermal enclosures resulting from the pilot program may reduce heat losses to the point where the cost of operating straight electric heat is affordable compared to the installation and operating costs of the alternatives.

A budget estimate for fan-powered heaters is $\$ 200$ to $\$ 400$ per heater (a typical unit would require six to eight heaters), plus installation and electrical wiring. Alternatively, substitute plug-in 5,200 Btuh $(1,500 \mathrm{Watt})$ infrared quartz heaters with blowers, three or four required per unit, at $\$ 200$ to $\$ 300$ per heater, plus electrical wiring as required. The radiant panel option is estimated at similar costs to the wall mounted fan-powered heaters.

A summary of the Pros and Cons of Electric Heat -

Pros

- Quiet operation

- Least disruptive to occupants during installation

- Provides zone control

- Lowest installation cost

- Lowest maintenance cost

- Fan-powered and plug-in heaters may be more effective and flexible than electric baseboard heaters

- More precise room-by-room control

Cons

- Most expensive heat to operate

- Does not address cooling and dehumidification

- Fan-powered and radiant electric heaters would require re-wiring

\section{Calculated Heat Loss and Heat Gain}

Home Innovation engineers calculated the heat loss (winter) and heat gain (summer) for a few units that were selected as representative of the range of current home performance for the $\mathrm{GHI}$ community. The space conditioning loads were calculated for both the before and after the building enclosure energy efficiency improvements are implemented. The results of the estimated loads are summarized in Table 1.

For the brick homes which were previously modeled as having lower loads than the other building types shows a much smaller improvement in reduced loads following the envelope upgrades $(18 \%$, both end and interior units) than the block unit (66\% end unit, $56 \%$ interior unit). The effectiveness of the envelope upgrades is much larger for the block buildings and would result in a significantly different size for any heating system upgrades. The importance of proper design sizing of the heating (and cooling) system is essential to a successful application of the technology. Also, the sizing exercise demonstrates the similarity in required heating and cooling capacities for the brick homes and the large discrepancy between the heating and cooling capacities for the uninsulated block buildings. 
Table 1. GHI Heating and Cooling Load Calculations (ACCA Manual J8)

\begin{tabular}{|c|c|c|c|c|c|c|c|}
\hline Unit & Construction & Orient & & $\begin{array}{c}\text { Heat loss } \\
\text { (winter) } \\
\text { BTUH }\end{array}$ & $\begin{array}{c}\text { Sensible } \\
\text { heat gain } \\
\text { BTUH }\end{array}$ & $\begin{array}{c}\text { Latent } \\
\text { heat gain } \\
\text { BTUH }\end{array}$ & $\begin{array}{c}\text { Total gain } \\
\text { (summer) } \\
\text { BTUH }\end{array}$ \\
\hline \multirow[t]{2}{*}{ FB-5 } & Brick & SW & Before $^{A}$ & 16,626 & 16,802 & 1,356 & 18,158 \\
\hline & & & After $^{B}$ & 13,592 & 10,318 & 1,845 & 12,163 \\
\hline \multirow[t]{2}{*}{ FB-6 } & Brick & SW & Before $^{c}$ & 15,426 & 15,038 & 1,400 & 16,438 \\
\hline & & & After $^{D}$ & 12,613 & 9,555 & 1,868 & 11,423 \\
\hline \multirow[t]{2}{*}{ B-3 } & Block & S & Before $^{E}$ & 20,614 & 11,130 & 1,289 & 12,419 \\
\hline & & & After $^{F}$ & 9,067 & 4,928 & 1,758 & 6,686 \\
\hline \multirow[t]{2}{*}{ B-4 } & Block & S & Before $^{G}$ & 41,672 & 22,355 & 1,674 & 24,029 \\
\hline & & & After $^{H}$ & 14,056 & 8,932 & 2,307 & 11,239 \\
\hline \multicolumn{8}{|c|}{$\begin{array}{l}\text { R-19 attic, R-11 walls, U55/SHGC70 windows, R- } 5 \text { closed crawl, semi-tight ( } 0.39 \mathrm{ACH} \text { winter, } 0.21 \mathrm{ACH} \text { summer), no } \\
\text { mechanical ventilation }\end{array}$} \\
\hline \multicolumn{8}{|c|}{$\begin{array}{l}{ }^{B} \text { R-38 attic, R-11 walls, U30/SHGC30 windows, R-10 closed crawl, tight ( } 0.20 \mathrm{ACH} \text { winter, } 0.11 \mathrm{ACH} \text { summer), } 34 \text { CFM } \\
\text { exhaust mechanical ventilation (ventilation loads (BTUH): } 1918 \text { heat, } 592 \text { sensible, } 849 \text { latent) }\end{array}$} \\
\hline \multicolumn{8}{|c|}{ 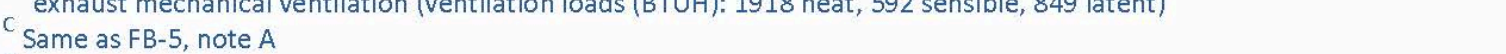 } \\
\hline \multicolumn{8}{|c|}{${ }^{D}$ Same as FB- 5 , note B } \\
\hline \multicolumn{4}{|c|}{$\begin{array}{l}\text { R-26 roof, uninsulated walls approximately R-3, U55/SHGC70 windows, R- } 5 \text { closed crawl, semi-tight (0.47 ACH winter, } 0.25 \\
\text { ACH summer), no mechanical ventilation }\end{array}$} & & & & \\
\hline \multicolumn{8}{|c|}{$\begin{array}{l}\text { R-26 roof, R-12 walls, U30/SHGC30 windows, R-10 closed crawl, tight (0.24 ACH winter, } 0.13 \mathrm{ACH} \text { summer, } 32 \text { CFM exhaust } \\
\text { ventilation (ventilation loads (BTUH): } 1805 \text { heat, } 557 \text { sensible, } 800 \text { latent) }\end{array}$} \\
\hline \multicolumn{8}{|c|}{${ }^{\mathrm{G}}$ Same as B-3, note $\mathrm{E}$, except semi-tight (0.39 ACH winter, $0.21 \mathrm{ACH}$ summer) } \\
\hline \multicolumn{8}{|c|}{$\begin{array}{l}\text { Same as B-3, note F, except tight ( } 0.20 \mathrm{ACH} \text { winter, } 0.11 \mathrm{ACH} \text { summer) and } 42 \mathrm{CFM} \text { mechanical ventilation (ventilation } \\
\text { loads (BTUH): } 2369 \text { heat, } 732 \text { sensible, } 1049 \text { latent) }\end{array}$} \\
\hline
\end{tabular}

Anecdotal information from a GHI homeowner has indicated that in a block home, the ductless heat pump system provides sufficient heating until the outdoor temperature drops below around $30^{\circ} \mathrm{F}$. During very cold outdoor periods, use of the existing baseboard heat is necessary to supplement the heat pump system. While only an anecdotal result, this homeowner experience highlights two important points:

1. Sizing the heat pump system to meet loads is necessary; however, as shown Table 1 above, matching the heating load and cooling load to properly size the system can be difficult, especially in less insulated homes (i.e., block homes).

2. Air distribution is an important aspect of the heating and cooling system. Currently, GHI homes have heating in each room. Use of a ductless or even ducted heat pump system may not serve every room of the home and therefore still require use of electric heat.

\section{Ductless Heat Pump System Energy Estimates}

Based on the range of equipment types, installation methods, and efficiency options, the Ductless Heat Pump technology was selected for the energy and cost analysis. This system was selected because of its:

- overall performance to distribute conditioned air with little loss;

- high efficiency equipment options available; and

- generally lower installed costs compared with the next best options. 
Based on the original building data that was compiled for the envelope upgrade energy efficiency simulations, new simulations were performed to include the use of heat pump technology for space heating. Simulations were configured to substitute a ductless heat pump for the resistance heat used in the original simulations. The simulations were run under the assumption that the ductless heat pump will condition the entire living space without distribution losses, similar to the assumption for the baseboard electric heat. This approach provides the most optimistic outcome for energy and cost savings when using electric heating options.

As an example of possible distribution losses, heat pump units installed in the attic space of the brick or vinyl homes and with ducting through the attic to the rooms will have both air leakage and conduction losses. In some HVAC systems, these losses can be large, exceeding $20 \%$ of the system output. For this reason, heat pumps installed in the attic space were not analyzed for this analysis but are a viable alternative should the homeowner prefer a ducted system.

Other potential energy penalties not included in the simulation are those for example in the block homes employing an efficient heat pump strategy without completion of building envelope thermal improvements. Without the added thermal resistance on the outside (or inside) of the block walls, the heat loss toward the exterior may be sufficiently high that on very cold days some supplemental heat (from remaining baseboard units) may be required. Any supplemental heat that may be required has not been estimated in these simulations.

Simulations were run for representative pilot homes in each of the given building configurations. For example the simulation model developed for unit B-2 also applies to unit B-3. Where multiple homes were unique in a building, more simulation models were utilized.

These new simulations were run to evaluate the addition of an efficient ductless heat pump system to the homes with the envelope upgrades and without the envelope upgrades. This approach allows for energy and cost savings to be assessed for both the pre- and post- (building envelope) retrofit condition of the homes.

Energy use simulation estimates for selected modeled homes is shown in Figure 9. The energy use estimates are for heating energy only and does not include air conditioning the homes in the summer. 


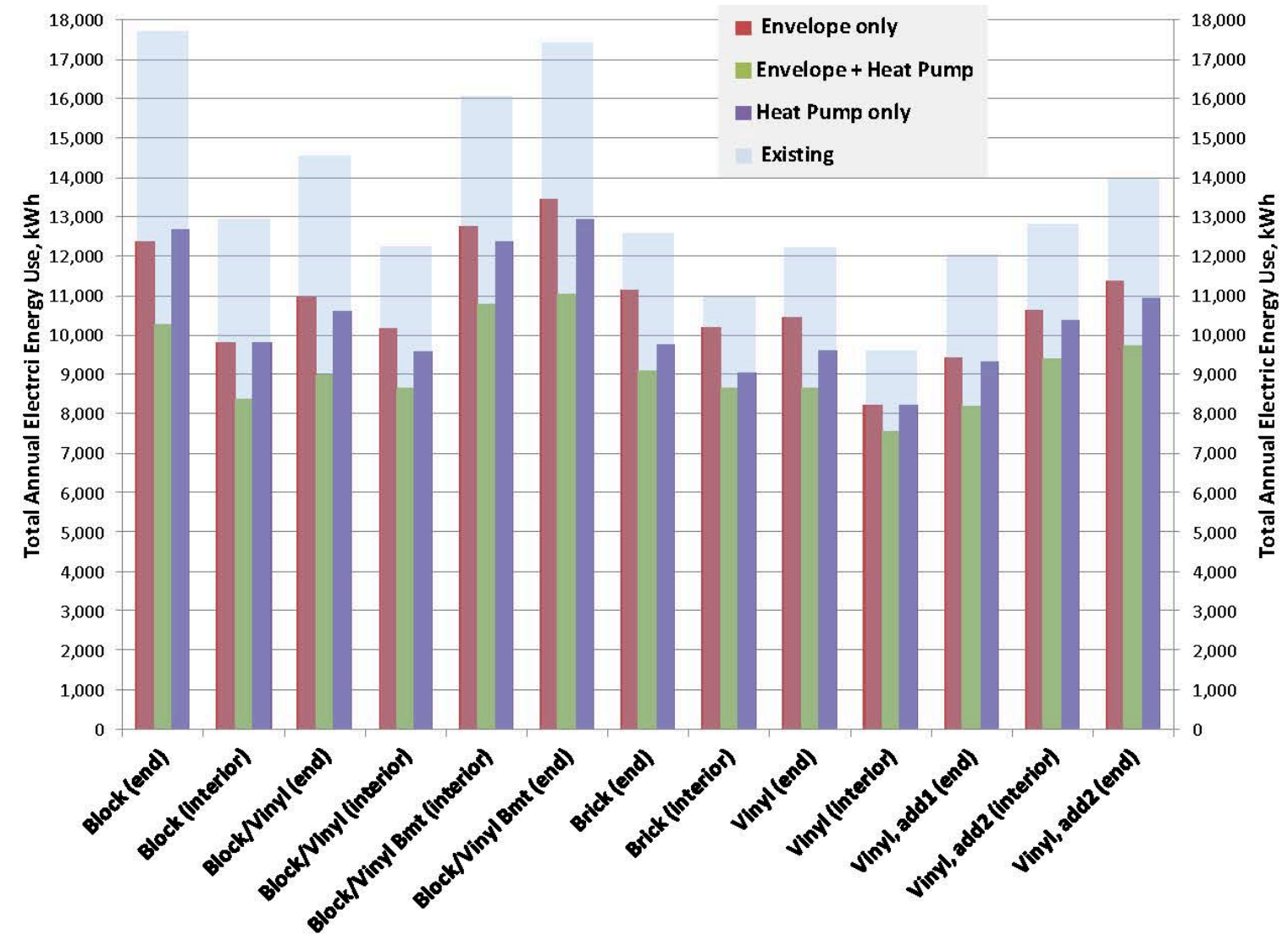

Figure 9. Annual Estimate of Electricity Use Comparison

The light blue (background) column indicates the energy use of the exiting home. The red column shows the projected energy use when only the building envelope upgrades are employed whereas the purple column shows the simulated energy use when the heat pump, only is upgraded. The green column between these two shows expected energy use after the pilot program upgrades (building envelope and HVAC) have been fully deployed.

Figure 10 shows another representation of the building envelope, HVAC, and full pilot program upgrade simulation estimates using the percent energy savings relative to the existing condition without any upgrades. 


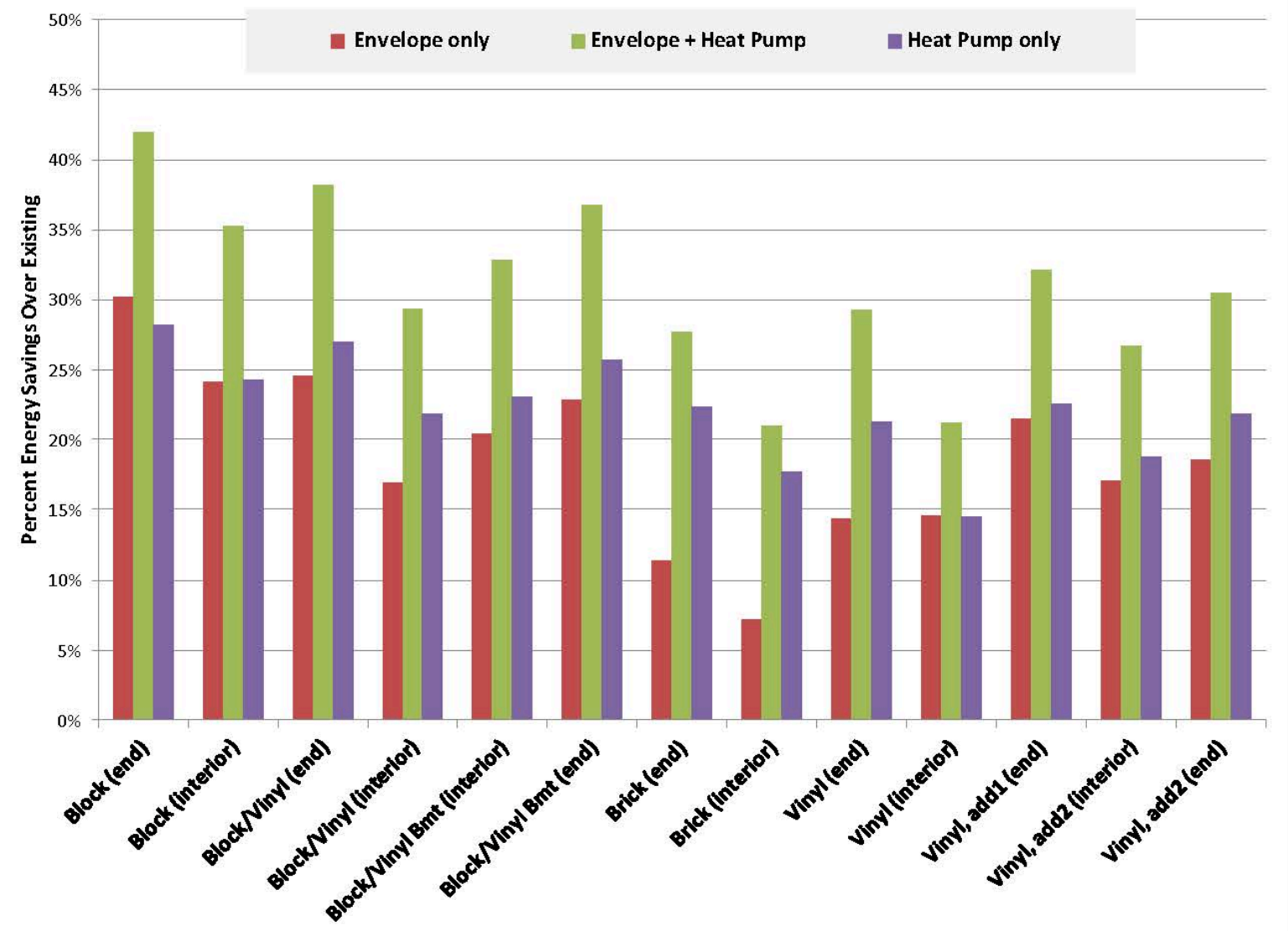

Figure 10. Percent Savings over Existing Conditions

Summary comparisons include:

- The largest percentage of energy savings is achieved by employing both a building envelope and an HVAC upgrade strategy in all houses, with a minimum $20 \%$ whole house energy savings to over $40 \%$ for the block homes.

- Block homes with envelope upgrades show the largest energy savings for all of the upgrade scenarios.

- The simulations indicate that the use of the efficient heat pump system alone results in nearly as much or more energy savings than the envelope upgrades alone for each of the building styles. Cooling energy was not analyzed.

- The heat pump technology provides the added feature of central cooling. 


\section{Cost Analysis for the Ductless Heat Pump System}

The energy savings estimates based on the simulations does provide a perspective of the potential for energy savings for the various building construction types. These energy savings are then analyzed in comparison with the cost investment using the same methodology developed for the envelope upgrades.

The cost for the heat pump systems was investigated through pricing estimates (some provided by GHI members) and through discussions with HVAC companies, and other resources. For most GHI homes, a configuration of ductless heat pump technology was used that includes one outdoor unit serving three indoor distribution fan coils (one in the living room, one in each bedroom, but none in the bathroom or storage room/bedroom 3 where applicable; existing electric baseboard and ceiling heaters would provide supplemental heat as needed in areas without a fan coil). This system was selected due to the highest performance for the least installed cost. This would provide the most favorable economic analysis. The estimated cost for a building of 4 homes is estimated at $\$ 48,000$, or $\$ 12,000$ average per home. While this estimated cost can range approximately $\$ 2,000$ in either direction, the average is in line with cost estimates from various sources.

The following tables provide a payback analysis based on energy savings attendant to each of the upgrade phases; envelope, HVAC (heat pump), and both. The original cost analysis was presented using both a net present value analysis and a simple payback analysis. The table format was retained for consistency. The analysis is performed for the heating system operation only so any cooling savings, which are highly member dependent, would accrue in addition to the savings identified here.

Table 2 shows the original cost analysis performed for the envelope upgrades alone. The table indicates that there is a positive cash flow for all but one of the upgrade configurations. For the positive cash flow configurations (all but column 8), simple paybacks range from 9 to 22 years and are much lower than the anticipated useful life of the upgrades.

When the heat pump technology is included in the analysis, the results shown in Table 3 demonstrate the significant change in the economics of the combination of the envelope and heat pump upgrades. These results show that there are few opportunities for positive cash flow and the payback range lengthens to 18 to 34 years.

The third analysis is performed to evaluate the use of the heat pump technology aside from and independent of the envelope upgrades (Table 4). The analysis is performed over a 15 year time frame in similar manner as the envelope upgrades that were performed over a 30 year time frame. Here the results demonstrate no positive cash flows on a net present value basis due to the shorter loan period. Payback analysis however, does indicate a reasonably good payback for the block homes but not so for the other house types. To reiterate however, the only benefit in this analysis is utility cost savings and ignores other benefits from upgraded heating systems.

Absent from the analysis is the inclusion of maintenance costs for the heat pump technology (the estimated cost for an annual service contract is $\$ 160-200$, not including potential repairs in later years). The reason for this exclusion is that it is not clear how the maintenance of the mechanical systems, 
should they fall under GHI maintenance procedures, would be included in the membership structure. A wide range of cost estimates for this maintenance service would be expected depending on the direction chosen, and this cost should be considered in the evaluation of the pilot program.

This economic analysis would lead to the conclusion that the upgrade to the heating system is not a viable option based on energy savings alone. Other details that are not taken into account in this type of economic analysis but influence the long-term costs/benefits are:

- The heat pump system does provide cooling which is often provided by wall or window units.

- The heat pump system may provide better distribution of conditioned air than baseboard electric heat that relies on natural convection which impacts physical comfort

- The heat pump system will require replacement in 15 to 20 years and some annual maintenance

- As with the existing electric baseboard heat, the heat pump will not operate when electrical power fails

- Implementation of the heat pump without envelope upgrades may result in a more costly system and continued use of some electric resistance heat

There are practical considerations for DSHP systems:

- Conventional air source heat pumps in this climate require electric resistance heaters installed in the fan coil to provide supplemental heat (as the outdoor temperature drops), heat during the defrost cycle, and backup heat if the heat pump stops working. DSHP systems with inverter technology can be sized to handle the entire heating load, and the fan in the fan coil normally does not operate during defrost cycles, so the DSHP systems generally do not have electric supplemental heat installed in the air handler.

- The existing electric baseboard and ceiling heaters should be left in place as supplemental heat, particularly in any room without an indoor fan coil (e.g., bath rooms), because the heat may not be adequately distributed to areas of the house away from the fan coils. These will also provide backup heat. The electric baseboard heater in the living room near the DSHP air handler could be disconnected as required to provide power for the DSHP system.

- The DSHP system may extend the life of the existing electric heaters (these will not operate as much or at all).

- The DSHP system may satisfy the thermostat and slow down (variable speed inverter compressors) or turn off before other areas of the house are comfortable. For example, an air handler installed in the living room near the back of the house may satisfy the thermostat before the kitchen is comfortable. Installing the thermostat in a different location or adjusting the thermostat set point may be necessary to improve comfort and minimize existing electric heater operation.

- Occupants may not be used to the air flow from heat pump systems. The DSHP fan coils should be located, or furniture may need to be relocated, to minimize uncomfortable drafts. 
Table 3. Envelope Plus Heat Pump Upgrade Economic Analysis

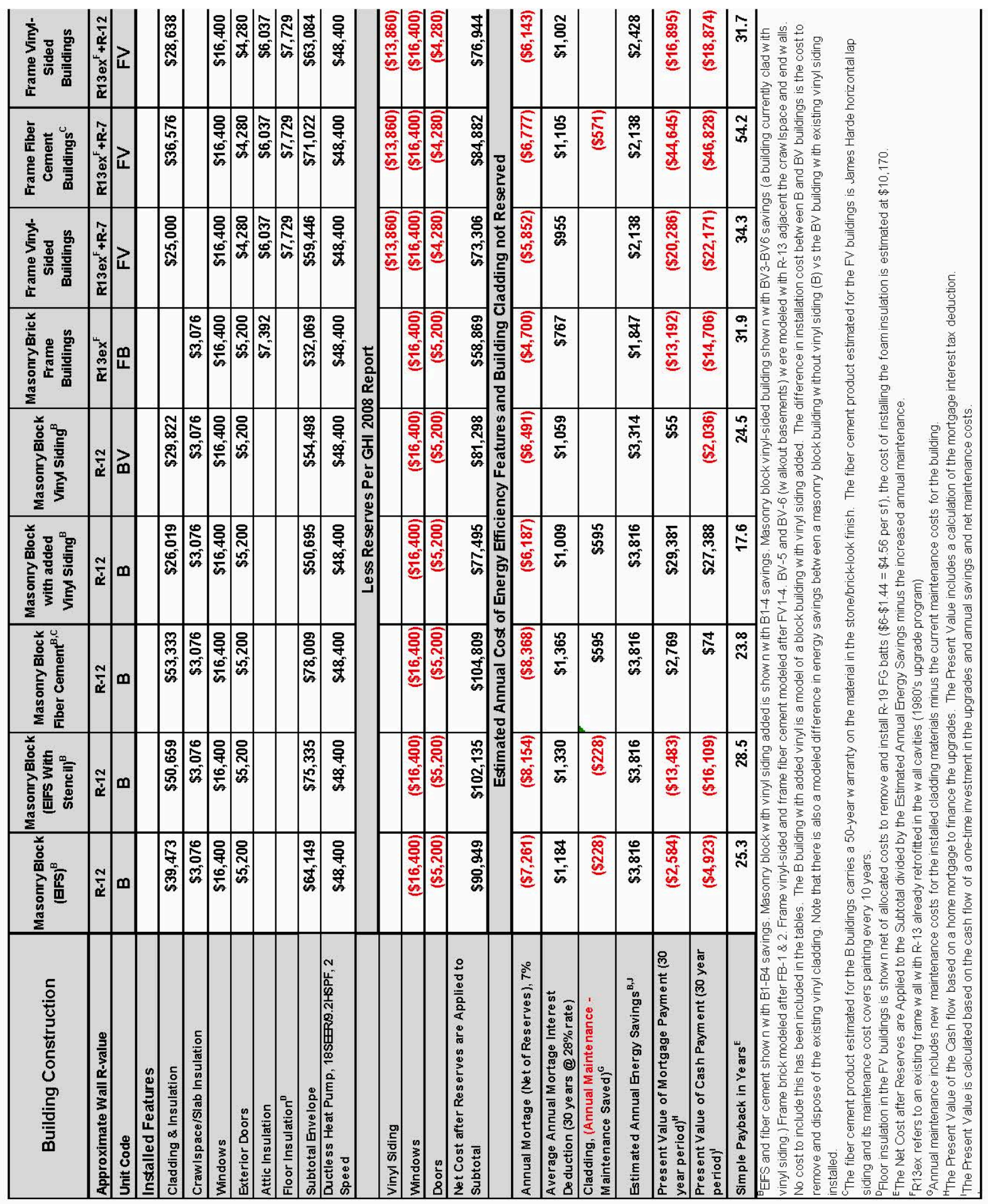


Table 4. Heat Pump Only Upgrade Economic Analysis

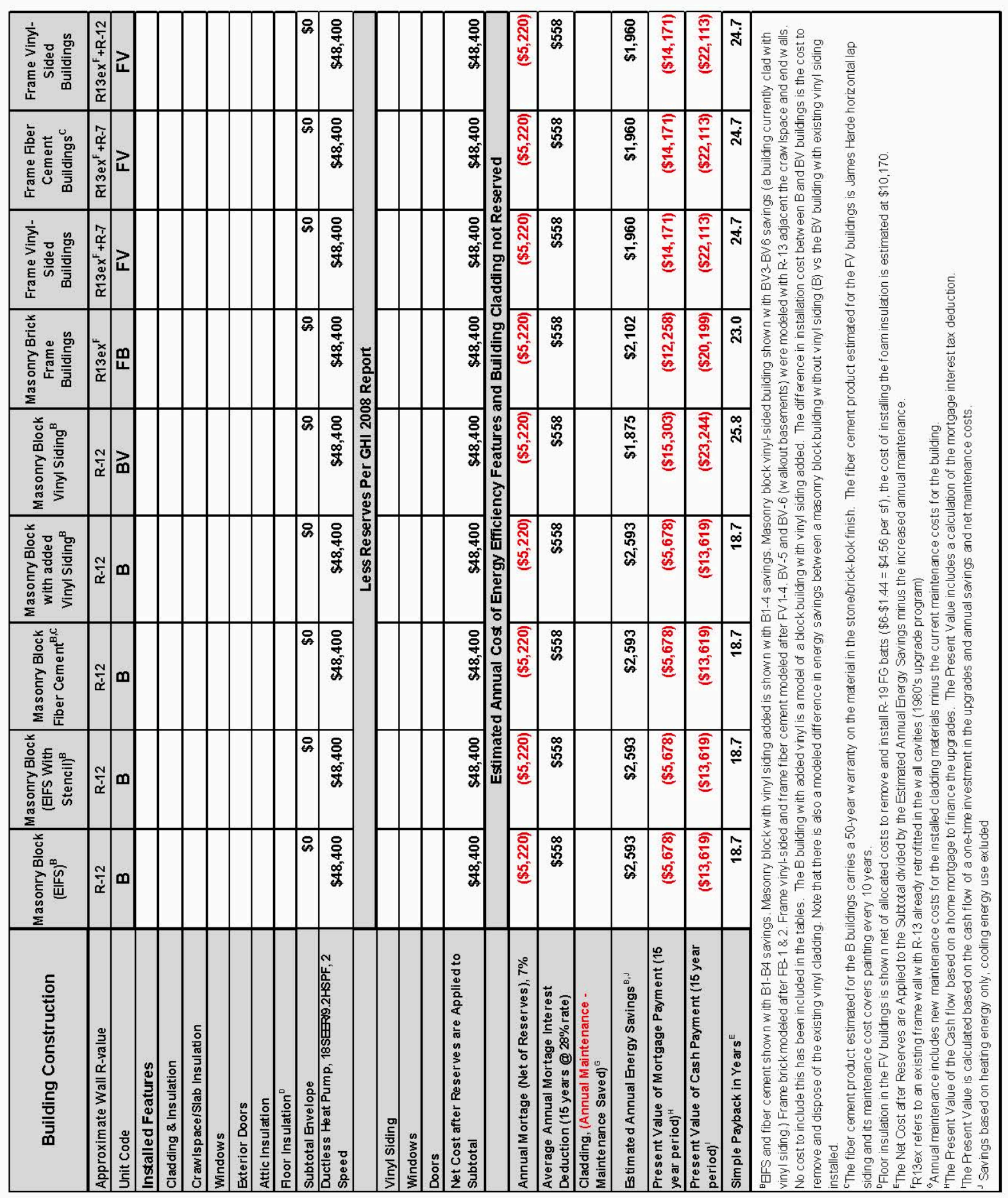




\section{Cost Comparison for Other Heating System Options}

Heating system options other than the ductless systems do not lend themselves to good estimates for costs, either for installation or operation. This is due to the increased complexity of the installation for all other technologies and a higher degree of uncertainty in the energy performance. However, based on experience with conventional systems, and incorporating known costs for hardware, a comparison of other heating systems can be compared to the ductless heat pump system used in the analysis above. Table 5 summarizes the relative costs associated each option.

Table 5. Summary of Heating System Options Compared with the Ductless HP Option

\begin{tabular}{llll}
\hline & \multicolumn{1}{c}{ Installation Cost } & \multicolumn{1}{c}{ Efficiency } & \multicolumn{1}{c}{ Supplemental Heat } \\
\hline Ducted Heat Pump & Slightly Higher & Slightly lower or Equal & Same as ductless \\
GSHP (hydronic fan coils) & Much Higher & Slightly Better & Less than ductless \\
\cline { 2 - 3 } Electric Fan Unit & Much lower & Much lower & none \\
Electric radiant panels & Somewhat lower & Much lower & none \\
\hline
\end{tabular}

The summary relative cost and efficiency estimates would lead to the following general conclusions:

- The overall lifecycle cost (including installation and energy savings) for the ducted heat pump system would be slightly lower than the ductless system but the comfort for the system is slightly higher since there are diffusers in each room. The cost of installation could be much higher if the construction of bulkheads is required.

- The GSHP system will require a further analysis when tax and other incentives are included. There are technical and installation issues that will also require resolution prior to any field test. Current residential incentives are $30 \%$ federal tax credit through $2016, \$ 3,000$ state rebate, and up to $\$ 5,000$ county property tax incentive. The availability of state and county incentives beyond 2013 is unknown. It is not clear how these incentives would apply at GHI.

- Electric wall fan units are expected to provide a higher level of comfort and be more easily controlled. Whether this translates into energy savings is unknown. Costs for the fan units are higher than the electric baseboard heaters and will require wiring modifications.

- Electric radiant panels are more expensive than the fan units and will require even more wiring modifications. The comfort and control aspects of the system operation will require further investigation. 


\section{Heating System Option Summary Matrix}

This report provides an overview of heating system options that could be used in GHI housing. Based on installed cost and energy savings estimates, a ductless heat pump system was selected as the least cost option to install and operate a higher efficiency heating system than the current electric baseboard heaters.

However, there are various attributes associated with different heating systems and in some cases different attributes associated with the various building types in $\mathrm{GHI}$. As a summary of these attributes and to highlight the comparison among the different systems and housing units, Table 6 through Table 8 are provided for each housing type (a scale of 1 to 5,5 indicates most positive for the attribute). The evaluation is performed based on heating season performance and does not include cooling season attributes. The community attribute was based on non-energy, non-cost considerations such as the visual or outdoor noise impact of numerous outdoor units and green/environmental considerations of equipment.

Table 6. Attribute Comparison - Block Units

\begin{tabular}{lcccccc}
\hline \multicolumn{1}{c}{ Block Units } & $\begin{array}{c}\text { Envelope } \\
\text { EBB Heat }\end{array}$ & $\begin{array}{c}\text { Ducted } \\
\text { Heat } \\
\text { Pump }\end{array}$ & $\begin{array}{c}\text { Ductless } \\
\text { Heat } \\
\text { Pump }\end{array}$ & GSHP & $\begin{array}{c}\text { Electric } \\
\text { Heat } \\
\text { Upgrades }\end{array}$ & $\begin{array}{c}\text { Envelope } \\
\text { \& Heat } \\
\text { Pump }\end{array}$ \\
\hline Energy Savings & 4 & 3 & 3 & 4 & 2 & 5 \\
\hline Interior Comfort & 5 & 4 & 3 & 3 & 4 & 5 \\
\hline Interior Noise & 5 & 3 & 4 & 3 & 5 & 4 \\
\hline Maintenance ${ }^{1}$ & 5 & 3 & 2 & 2 & 4 & 3 \\
Disruption During Install & 4 & 1 & 3 & 2 & 3 & 3 \\
Life Cycle Cost $^{2}$ & 5 & 4 & 4 & 3 & 5 & 2 \\
Community $^{1}$ Based on siding over furring, EIFS would score approximately 3 & & 5 & 2 \\
${ }^{2}$ Does not include any tax or financing incentives & & & & & \\
\hline
\end{tabular}

Table 7. Attribute Comparison - Brick Units

\begin{tabular}{|c|c|c|c|c|c|c|}
\hline Brick Units & $\begin{array}{l}\text { Envelope } \\
\text { EBB Heat }\end{array}$ & $\begin{array}{c}\text { Ducted } \\
\text { Heat } \\
\text { Pump }\end{array}$ & $\begin{array}{c}\text { Ductless } \\
\text { Heat } \\
\text { Pump }\end{array}$ & GSHP & $\begin{array}{c}\text { Electric } \\
\text { Heat } \\
\text { Upgrades }\end{array}$ & $\begin{array}{c}\text { Envelope } \\
\& \text { Heat } \\
\text { Pump }\end{array}$ \\
\hline Energy Savings & 2 & 3 & 3 & 4 & 2 & 4 \\
\hline Interior Comfort & 4 & 4 & 3 & 3 & 4 & 5 \\
\hline Interior Noise & 5 & 3 & 4 & 3 & 5 & 4 \\
\hline Maintenance & 5 & 3 & 2 & 2 & 4 & 3 \\
\hline Disruption During Install & 4 & 1 & 3 & 2 & 3 & 3 \\
\hline Life Cycle Cost ${ }^{1}$ & 5 & 2 & 2 & 2 & 4 & 2 \\
\hline Community & 5 & 2 & 3 & 5 & 5 & 4 \\
\hline \multicolumn{7}{|c|}{${ }^{1}$ Does not include any tax or financing incentives } \\
\hline
\end{tabular}


Table 8. Attribute Comparison - Vinyl Units

\begin{tabular}{lcccccc}
\hline \multicolumn{1}{c}{ Vinyl Units } & $\begin{array}{c}\text { Envelope } \\
\text { EBB Heat }\end{array}$ & $\begin{array}{c}\text { Ducted } \\
\text { Heat } \\
\text { Pump }\end{array}$ & $\begin{array}{c}\text { Ductless } \\
\text { Heat } \\
\text { Pump }\end{array}$ & GSHP & $\begin{array}{c}\text { Electric } \\
\text { Heat } \\
\text { Upgrades }\end{array}$ & $\begin{array}{c}\text { Envelope } \\
\text { \& Heat } \\
\text { Pump }\end{array}$ \\
\hline Energy Savings & 4 & 3 & 3 & 4 & 2 & 5 \\
Interior Comfort & 4 & 4 & 3 & 3 & 4 & 5 \\
\hline Interior Noise & 5 & 3 & 4 & 3 & 5 & 4 \\
Maintenance & 5 & 3 & 2 & 2 & 4 & 3 \\
Disruption During Install & 4 & 1 & 3 & 2 & 3 & 3 \\
Life Cycle Cost ${ }^{1}$ & 5 & 3 & 3 & 2 & 4 & 2 \\
Community $^{1}{ }^{1}$ Does not include any tax or financing incentives & & 3 & 5 & 5 & 4 \\
\hline
\end{tabular}

\section{Cooling}

The heat pump alternatives inherently provide central cooling if the occupant chooses to use this feature. Central cooling energy can be estimated using industry standards that include defined indoor and outdoor conditions, but this is difficult to compare to current energy use for cooling provided by window or through-the-wall air conditioners. Window and wall air conditioners are commonly operated as needed, and therefore may use a modest amount of energy even if they are relatively inefficient models. For example, a small capacity bedroom air conditioner may be operated only at night, or a larger capacity air conditioner (such as a through-the-wall unit frequently installed at the top of the stairs throughout the GHI community) may be turned off completely during the day when no one is home.

Current actual cooling energy use, estimated based on evaluating energy bills, appears to vary widely compared to the constant cooling approach used for the simulated central cooling energy, even after building envelope upgrades. This is likely due to occupant operation of the air conditioners, as described above, despite the much more efficient heat pumps selected for the energy simulations. For analysis purposes, the cooling energy use of the high efficiency heat pumps could be compared to two or three window or wall air conditioners controlled with integral thermostats, but the energy savings would be hypothetical based simply on the different efficiency ratings. Occupants may decide to run the central systems conventionally (set the thermostat and allow the system to run) to enjoy the comfort benefits of cooling and dehumidification, and this would not result in actual cooling energy cost savings for most.

\section{Summary Conclusions}

The information and analysis provided in this report are intended as an overview of the heating and cooling system options for the GHI homes. Based on the review of commercial technologies, installation requirements for existing homes without ducted systems, and performance estimates the following comments are offered:

- Fuel fired (natural gas or propane) systems are not recommended at this time due to the lack of infrastructure and cost of implementing the technology in homes without venting provisions. 
- Commercial type heating and cooling equipment (PTAC) do not provide the sufficient range of efficiencies and installation options needed for GHI homes.

- Traditional air source heat pump technology is a viable option but does require indoor space for the air handler and extensive construction to accommodate the duct system.

- Location of heating and cooling equipment in the attic or outdoors will lower the efficiency of the system and/or increase costs to insulate and air seal for higher performance. The energy penalty for locating the equipment in the attic is roughly $15 \%$.

- Based on extensive discussions with a Ground Source Heat Pump (GSHP) company, this technology would require both an indoor air handler and ducting (similar to the air source heat pump) or may be used in a water-based heating (and cooling) system. The water-based system would require retrofit of piping to each home from the GSHP equipment and installation of three to six fan coils in the home. GSHP systems also require access to an open field/yard in which to drill wells for the ground piping. GSHP systems often have higher air delivery temperatures than traditional air source heat pumps and can provide higher levels of comfort on cold days.

- Electric resistance heat options, in addition to the current passive convection system now used, are available in either fan convector wall units or ceiling radiant panels. Ceiling panels require less power than traditional electric heating units. Extensive electrical modifications would be necessary when relocating electric heating devices.

- Ductless split heat pump (DSHP) systems (ductless mini-splits)s can be designed with multiple indoor fan coils but refrigerant lines must be installed to each. Fan coils are most commonly installed high on the wall (ideally an exterior wall).

- Efficiency ratings are highest for the GSHP technology; however, field experience with GSHP systems has shown that the efficiency ratings may be decreased due to pump energy and variable ground loop temperatures.

- The cost of higher efficiency ratings appears to favor the ductless mini-split units. This higher efficiency rating also translates into better performance in terms of higher delivery air temperature as with the GSHP technology

- All of the heat pump technologies provide cooling (unless the GSHP technology selected is hydronic radiant only), an upgrade not typically included in $\mathrm{GHI}$ homes.

- Heat pump technologies require maintenance which must be considered when employing the technology (as with the existing electric baseboard heat for example). The maintenance will require refrigeration mechanic expertise.

- The most optimal simulations that use a high efficiency heat pump system with no duct losses does not show favorable paybacks when coupled with the envelope upgrades except for block homes using the least cost option for exterior insulation. 
- Initial simulations and cost analysis indicate that for the block buildings, installation of a heat pump system has favorable investment returns independent of the envelope upgrades; however, issues of comfort in all spaces may lead to unsatisfactory performance for some members if the envelope upgrades are not installed.

- Use of heat pump systems may for some homeowners, lead to an increase in cooling energy use, therefore offsetting energy savings. This offset may or may not be problematic for an individual homeowner when overall comfort and livability are considered.

- All of the heat pump technology options will require maintenance, and likely annual maintenance for the best long term performance of the units. The costs estimated here do not include this additional expense which may be incorporated within GHI's regular maintenance activities or may be contracted with an independent maintenance company.

The results offered in this report are provided as an interim analysis and to initiate further discussions on the feasibility of heating and cooling system upgrades in GHI homes.

\section{Heating (and Cooling) System Recommended Strategies for the Pilot Program}

Based on the analysis in this report, a mix of heating (and cooling) systems can be installed for the pilot project in order to evaluate and better understand actual design requirements, installation requirements, operation, maintenance, and performance. The selected systems can be focused on specific building types:

Block Homes - Due to the energy and cost benefit in insulating the block units, the envelope upgrades are recommended for B-1 through B-4 and BV-1, B-5, B-6, and BV-2. Regardless of the outcome of the decision to insulate the interior or exterior of the block units and the decision on the type of insulating system used, the envelope upgrades have been shown to provide a realistic payback period. In conjunction with the envelope upgrades:

1. Install a ductless split heat pump system (DSHP) in one end unit and one adjacent middle unit. (See equipment selection discussion at the end of this section). Recommended candidates: end unit B-1 (1 heat pump serving 3 indoor fan coils) and middle unit B-2 (1 heat pump serving 2 fan coils). Additionally, install a DSHP system in unit B-3 to evaluate a floor console fan coil on the first floor. Unit B-4 already has a DSHP system installed. Alternatively (or additionally), install DSHP systems in end unit BV-3 and adjacent unit BV-4 (same floor areas, different exterior wall areas)

2. Install new electric resistance heaters with integral fans in one end unit and one adjacent middle unit. These could be located on interior walls since the fans will distribute the air more reliably than the current passive baseboard heaters. Each heater could have a wall mounted thermostat. This option would not include cooling equipment. Candidates: end unit with addition BV-1 and adjacent unit B-5 
Install radiant ceiling panels in one unit. This option would require installation of thermostat controls and additional wiring to the ceiling where the panels are located. This option would not include cooling equipment. A candidate for this option has not been identified.

Brick Homes - The envelope upgrades for the brick homes involve only the windows, attics, slab edges, and crawlspaces. Simulation results and cost estimates demonstrate that these homes have the least amount of energy savings of all homes in the pilot program, though still show a positive net present value for the investment. However, the simulations indicate that the energy savings from the addition of a heat pump system in the brick units result in more energy savings. Unfortunately, the high cost of the heat pump system does not demonstrate a positive net present value based on energy savings alone.

The brick homes present a unique case for the pilot program: the opportunity to test the performance of a heating system less encumbered by extensive envelope upgrades. This allows for more direct homeowner response to the performance of the system, as well as energy and environmental measurements that correlate to the previous year's measurements. Strategies that may be considered include:

1. Contingent upon an acceptable ground source heat pump (GSHP) system design, component selection, ground loop layout, and cost estimates (including appropriate incentives), install GSHP systems in all units of one of the brick buildings. Multiple installations in one building would provide a more complete picture of the true cost of the installation including the feasibility of a common loop. Furthermore, the operation of the system should be analyzed using multiple homes to gain confidence in the data. The brick homes have a useable boiler room for equipment, if needed. Candidates: units FB-1 through FB-4 would provide good multiple tests in homes that are of the same size but with different exterior wall areas.

2. Also, due to the envelope upgrade set in the brick buildings, these homes provide an opportunity for a slightly more expanded test of the fan powered electric resistance heat. Since the wall systems are not being modified, use of the new electric resistance heaters located on interior or exterior walls can provide good information on comfort and heat distribution. This strategy would of course not include cooling. Candidates: end unit FB-5 and adjacent unit FB-6.

3. Similarly, a ductless heat pump system could be tested to evaluate the performance in one end and one middle unit. Candidates: end unit FB-8 and adjacent unit FB-7. Alternative candidates, if the GSHP systems are not practical: FB-1 through FB-4.

Frame Vinyl Homes - Envelope upgrades in the frame vinyl sided homes are more extensive than the brick homes. These upgrades were estimated to have a positive net present value for the investment. However, as for the brick buildings, the installation cost and energy savings for a heat pump system did not demonstrate a positive present value, either with or without the envelope upgrades. As with the brick buildings, the heat pump system would be installed for more than just the purpose of energy cost reduction. The frame vinyl buildings could be of interest for testing some other strategies for heating (and cooling) such as: 
1. Given the wood frame construction, it may be somewhat simpler to install a ducted forced air system in these homes. One option would be to develop a compact duct layout and air handler system that could be located in the house or since there is interest among GHI members, in the attic space. If placed in the attic, an analysis could be performed on the performance of the system and an installation methodology and procedures could be developed to reduce losses from an attic installation. Though less than ideal, this test would provide some relevant cost and performance data for comparison with other systems. The calculated heat loss and heat gain is anticipated to be somewhat less than the brick units due to the more extensive energy upgrades and smaller floor areas (see below for additional discussion on ducted equipment capacity and selection). Install ducted systems in one end unit and one inside unit. Candidates: end unit FV-1, and inside unit FV-7.

2. Again, given the wood frame construction, a test of a radiant ceiling panel heating system might be installed more easily than in the masonry homes using concealed wiring for the panels and thermostats. One or two homes would provide sufficient data, both empirical and anecdotal based on homeowner experience of comfort.

3. As with other building types, the use of the fan powered electric resistance heaters could be used to determine the performance and homeowner comfort in the frame homes with envelope upgrades. This test could be arranged to generally compare homes that have the existing resistance heaters left in place with those with the fan powered units. This system would not include cooling.

Discussion (all homes) - Each of the building types lends itself to test installations of various heating systems, some of which include cooling. These test installations should be useful to evaluate the design, installation, and performance of the heating systems prior to recommendation for a specific building type.

It is important to reiterate that given the cost estimates at this time, the addition of a heat pump system of any technology, is not likely to demonstrate a positive present value except for block homes that are insulated with foam board and siding. Furthermore, even the installation of a heat pump system as the only upgrade measure is not demonstrating a positive cash flow in the brick and frame vinyl buildings. In the block buildings there is an estimated positive cash flow if the heat pump were the only upgrade; however, based on load calculations, it is fully expected that the system will underperform in the colder winter periods and would require continued use of the resistance heaters for supplemental heat.

For DSHP systems, equipment selection should be based on load calculations after envelope upgrades. High efficiency DSHP systems rely on inverter technology (variable speed) compressors for best low outdoor temperature heating performance, dehumidification control during cooling, and design and equipment selection flexibility. The primary types of indoor fan coils are high wall, floor console, and ducted. One outdoor heat pump may serve multiple and different types of indoor fan coils, but the number of fan coils is limited by the capacity of the heat pump (varies by manufacturer). For example, 4 fan coils may require a 3-ton or larger heat pump, 3 fan coils may be available for 2 and 2.5-ton heat 
pumps, and a 1.5 ton heat pump may be limited to a maximum of 2 fan coils. A very low heating and cooling load unit may call for two 0.5 -ton systems (two heat pumps, each serving one fan coil).

The heating and cooling capacity of conventional ducted heat pump systems may be too large for the majority of units after thermal enclosure updates. The smallest capacity available is 1.5-tons (nominal 18,000 Btuh), and the smallest capacity for high efficiency models is generally 2-tons (nominal 24,000 Btuh). Installing systems that are too large can result in excessive air flow noise and inadequate dehumidification (the system cools the house so quickly and satisfies the thermostat that it does not run long enough to dehumidify). Where a ducted system is being considered, a solution could be a DSHP with a ducted fan coil. These ducted fan coils are available in smaller capacities (commonly 9,000 , 12,000 , and 18,000 Btuh); one DSHP can serve one or more of these, or a combination of ducted and ductless fan coils could be installed.

After installation, monitor the energy use of the installed system and continue to monitor the existing electric heaters and the total energy use of the unit. This data will be compared with previous energy use. Also continue to monitor temperatures and relative humidity to compare heating distribution and operation and normalize the data as needed for different conditions. Homeowners could be solicited to provide anecdotal performance and comfort information. The pilot program heating systems will be evaluated before final recommendations for a specific building type for the rest of the community.

For each building type and strategy, a specific design for each unit and a detailed installation scope of work will need to be developed. This will help to ensure a fair bidding process and a successful installation. The selected strategies will be a good test of the enclosure and space conditioning alternatives. Evaluating the design, implementation, operation, and energy results in the pilot homes will lead to an optimum plan for the balance of GHI homes. 

